Aus der Klinik für Neurologie

(Prof. Dr. med. M. Bähr)

im Zentrum Neurologische Medizin

der Medizinischen Fakultät der Universität Göttingen

\title{
Magnetresonanztomographie bei Patienten mit der E200K- und V210I-Mutation
}

\author{
INAUGURAL-DISSERTATION \\ zur Erlangung des Doktorgrades \\ der Medizinischen Fakultät der \\ Georg-August-Universität zu Göttingen
}

vorgelegt von

Maren Breithaupt

aus

Kappeln

Göttingen 2014 
Dekan:

\section{Berichterstatterin:}

II. Berichterstatter/in:

III. Berichterstatter/in:

Tag der mündlichen Prüfung: 15. Oktober 2014
Prof. Dr. rer. nat. H. K. Kroemer

Prof. Dr. med. I. Zerr

Prof. Dr. med. M. Knauth 


\section{Inhaltsverzeichnis}

1 EINLEITUNG $\quad 8$

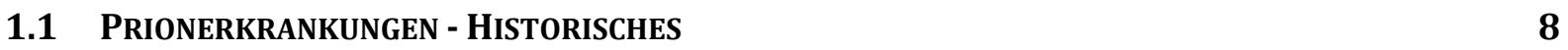

1.2 Pathogenese 9

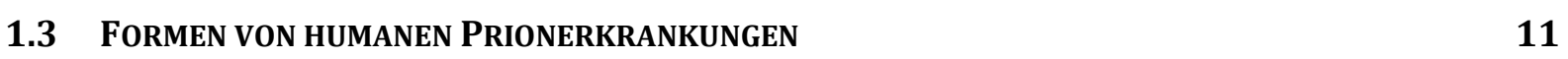

1.3.1 SPORADISCHE PRIONERKRANKUNGEN 12

1.3.2 Genetische PRIONERKRANKUNGEN 13

1.3.3 IATROGENE CJK 16

1.3.4 NeUE VARIANTE CJK (VCJK) 17

$\begin{array}{lll}1.4 & \text { KLINISCHE PräSENTATION } & 18\end{array}$

$\begin{array}{lll}1.5 & \text { SUBTYPEN DER CJK } & 18\end{array}$

1.5.1 POLYMORPHISMUS AM CODON $129 \quad 18$

$\begin{array}{llr}1.5 .2 & \text { PRIONPROTEINTYP } & 19\end{array}$

1.5.3 CHARAKTERISIERUNG DER SUBTYPEN 20

$\begin{array}{lll}1.6 & \text { DiagnOSTIK } & 22\end{array}$

1.6.1 LIQUORUNTERSUCHUNG 22

1.6.2 ELEKTROENZEPHALOGRAMM (EEG) 23

1.6.3 MAGNETRESONANZTOMOGRAPHIE (MRT) 24

1.6.4 NeURoPathologische UNTERSUCHUNG 28

1.6.5 GENETISCHE UNTERSUCHUNG 29

1.7 DIAGNOSEKRITERIEN

1.8 Fragestellung 30

$\underline{2}$ MATERIAL UND METHODEN

$\begin{array}{lll}2.1 & \text { Patientenkollektiv } & 31\end{array}$

\begin{tabular}{lll}
2.2 & KontrollKolLEKTIV \\
\hline 2
\end{tabular}

2.3 Genetische TESTUNG $\quad 33$

2.4 DiagnOSTISCHE UNTERSUCHUNGEN 23

$\begin{array}{lll}2.4 .1 & \text { LIQUORDIAGNOSTIK } & 33\end{array}$

$\begin{array}{lll}2.4 .2 & \text { EEG } & 34\end{array}$

2.4.3 NEUROPATHOLOGISCHE DiAgNOSTIK 34

$\begin{array}{llr}2.4 .4 & 35 T\end{array}$ 


\section{ERGEBNISSE}

3.1 Patientenkollektiv $\quad 39$

3.2 MAGNETRESONANZTOMOGRAPHIE $\quad 40$

$\begin{array}{lll}3.2 .1 & \text { MRT-DATENSATZ } & 40\end{array}$

3.2.2 SignalaLterationEN IN DER FLAIR-WiCHTUNG 42

3.2.3 SignalalterationEN IN DER DWI-WichtUNG 44

3.2.4 Signalalterationen NACH MUtATiON 46

3.2.5 SignALALTERATIONEN NACH POLYMORPHISMUS AM CODON 129

3.3 ERGEBNISSE DER ZUSATZDIAGNOSTIK

3.3.1 LIQUORUNTERSUCHUNG 56

3.3.2 ELEKTROENZEPHALOGRAPHIE (EEG) 57

$\begin{array}{lll}3.4 & \text { MRT-KRITERIEN } & 58\end{array}$

3.4.1 MRT-KRITERIEN NACH PATIENTENKOLLEKTIV 58

3.4.2 MRT-KRITERIEN NACH MUTATION

3.4.3 MRT-KRITERIEN NACH POLYMORPHISMUS AM CODON $129 \quad 60$

3.4.4 SENSITIVITÄT UND SPEZIFITÄT $\quad 62$

3.5 VERGLEICH DER E200K-PATIENTEN AUS ARGENTINIEN UND DEUTSCHLAND 62

3.6 VERGLEICH DER BEIDEN RATER UND INTER-RATER-ÜBEREINSTIMMUNG 64

4 DISKUSSION $\quad 65$

4.1 Die UnTERSuchten Patientenkollektive $\quad 65$

$\begin{array}{llr}4.2 & \text { MAGNETRESONANZTOMOGRAPHIE (MRT) } & 69\end{array}$

$\begin{array}{lll}4.2 .1 & \text { MRT-DATENSATZ } & 69\end{array}$

$\begin{array}{lll}\text { 4.2.2 } & \text { EINFLUSS DER MRT-WICHTUNG } & 70\end{array}$

$\begin{array}{lll}4.2 .3 & \text { EINFLUSS DER MUTATION } & 72\end{array}$

4.2.4 MRT-VERÄNDERUNGEN BEI DER E200K-MUTATION $\quad 72$

4.2.5 MRT-VERÄNDERUNGEN BEI DER V210I-MUTATION 73

4.2.6 EINFLUSS DES SUBTYPS ANHAND DES POLYMORPHISMUS AM CODON 129

$\begin{array}{lll}4.2 .7 & \text { EINFLUSS DES URSPRUNGSLANDES } & 77\end{array}$

$\begin{array}{lll}4.3 & \text { Diagnostische ZuSATZUNTERSUCHUNGEN } & \mathbf{7 8}\end{array}$

$\begin{array}{lll}4.3 .1 & \text { LIQUORUNTERSUCHUNG } & 78\end{array}$

4.3.2 ElektroenZePhaLOGRAPHiE (EEG) 80

$\begin{array}{lll}4.4 & \text { ANWENDBARKEIT DER MRT-KRITERIEN } & 81\end{array}$ 
4.4.1 SEnSitivitäT

82

4.4.2 SPEZIFITÄT

83

4.5 INTER-RATER-BEWERTUNG

83

5 ZUSAMMENFASSUNG

85

6 LITERATURVERZEICHNIS 88 


\section{Abkürzungsverzeichnis}

$\mathrm{AL} \quad$ antero-lateral

BSE bovine spongiforme Enzephalopathie

CJK Creutzfeldt-Jakob-Krankheit

cMRT cranielle Magnetresonanztomographie

CWD chronic wasting disease

DM dorso-medial

DNA Desoxyribonukleinsäure

DWI diffusion weighted imaging, Diffusionswichtung

EEG Elektroenzephalogramm/-graphie

ELISA enzyme-linked immunosorbent assay

fCJK familiäre Creutzfeldt-Jakob-Krankheit

FFI familiäre fatale Insomnie

FLAIR fluid-attenuated-inversion recovery

gCJK genetische Creutzfeldt-Jakob-Krankheit

GSS Gerstmann-Sträussler-Scheinker-Syndrom

iCJK iatrogene Creutzfeldt-Jakob-Krankheit

J. Jahre

K Kollektiv

kDa Kilodalton

m männlich

M Methionin

M. Monate

MM Methionin-homozygot am Codon 129

MRT Magnetresonanztomographie

ms Millisekunde

MV Methionin-/Valin-heterozygot am Codon 129

NSE neuronenspezifische Enolase

NRZ Nationales Referenzzentrum

PCR polymerase chain reaction, Polymerasekettenreaktion

PD proton density, protonengewichtet 


$\begin{array}{ll}\text { PET } & \text { paraffin-embedded tissue } \\ \text { PRNP } & \text { Prion-Protein-Gen } \\ \text { PrP } & \text { Prionprotein } \\ \text { PrPc } & \text { celluläres Prionprotein } \\ \text { PrPsc } & \text { pathologisches Prionprotein (sc für Scrapie) } \\ \text { PSWC } & \text { periodic sharp/wave-complex, periodische Sharp-Wave-Komplexe } \\ \text { RFLP } & \text { Restriktionsfragmentlängenpolymorphismus } \\ \text { sCJK } & \text { sporadische Creutzfeldt-Jakob-Krankheit } \\ \text { sec } & \text { Sekunde } \\ \text { SFI } & \text { sporadische fatale Insomnie } \\ \text { TSE } & \text { transmissible spongiforme Enzephalopathie } \\ \text { vCJK } & \text { neue Variante der Creutzfeldt-Jakob-Krankheit } \\ \text { V } & \text { Valin } \\ \text { VV } & \text { homozygot am Codon 129 } \\ \text { w } & \text { weiblich } \\ \text { ZNS } & \text { Zentrales Nervensystem }\end{array}$




\section{Einleitung}

\subsection{Prionerkrankungen - Historisches}

Prionerkrankungen sind eine Gruppe von übertragbaren, neurodegenerativen Erkrankungen, die durch den schwammartigen Untergang von Hirngewebe gekennzeichnet sind und daher auch unter dem Begriff transmissible spongiforme Enzephalopathien (TSE) bekannt sind. Die Erkrankungen kommen sowohl im Tierreich als auch beim Menschen vor und enden stets tödlich.

Bereits seit mehr als 250 Jahren ist die bei Schafen und seltener auch Ziegen vorkommende, Scrapie genannte Prionerkrankung beschrieben. Der Name leitet sich vom Verhalten der erkrankten Tiere ab, die sich aufgrund eines massiven Juckreizes ständig Kratzen ([engl.] scrape = kratzen). Die Infektiosität dieser endemisch auftretenden Erkrankung konnte bereits 1936 experimentell nachgewiesen werden (Cuillé und Chelle 1939). Die wohl bekannteste TSE im Tierreich ist jedoch die bovine spongiforme Enzephalopathie (BSE), umgangssprachlich auch „Rinderwahnsinn“ genannt, die erstmals 1986 beschrieben wurde und Mitte der 90er Jahre für großes Medienaufsehen und Unsicherheit in der Bevölkerung sorgte. Zurückgeführt wurde die Erkrankung auf die Verwendung von Tiermehl Scrapie-infizierter Schafe als Futterersatzmittel für Rinder. Darüber hinaus findet man die chronic wasting disease (CWD, [engl. $]=$ „chronische Auszehrungskrankheit") bei Hirschen, die transmissible mink encephalopathy bei Nerzen, die feline spongiforme Enzephalopathie bei der Hauskatze sowie den Befall von exotischen Antilopenarten.

Anfang der 50er Jahre gab eine Erkrankung Forschern Rätsel auf, die sich wie eine Epidemie unter den Menschen des Fore-Volksstammes auf Papua-Neuguinea ausbreitete. Die Krankheit wurde unter dem Namen Kuru bekannt, welcher sich von dem eingeborenen Wort für „Zittern“ ableitete. Das klinische Erscheinungsbild der Erkrankung war gekennzeichnet durch komplexe Bewegungsstörungen sowie eine zerebelläre Ataxie und führte innerhalb weniger Monate unweigerlich zum Tod der erkrankten Stammesmitglieder. Der amerikanische Virologe D. C. Gajdusek und der neuguineische Arzt Vincent Zigas führten die Erkrankung auf den vom Fore-Volksstamm praktizierten rituellen 
Kannibalismus zurück und postulierten eine Übertragung durch infiziertes Hirngewebe von Verstorbenen (Gajdusek und Zigas 1957). 1959 machte William Hadlow erstmals auf neuropathologische Ähnlichkeiten zwischen der Scrapie-Erkrankung bei Schafen und Kuru beim Menschen aufmerksam. Als Mitte der 60er Jahre dann Gajdusek und Joseph Gibbs nach jahrelanger Inkubationszeit die Übertragung von Kuru auf Primaten gelang, war der Grundstein für die nachfolgende Erforschung der transmissiblen spongiformen Enzephalopathien gelegt (Gajdusek et al. 1966). Aufgrund der langen Inkubationszeit wurde bereits damals der Begriff einer slow-virus-Erkrankung ([engl.] = langsames Virus) benutzt.

Den wesentlichsten Beitrag zum näheren Verständnis der Erkrankung lieferte der amerikanische Arzt Stanley Prusiner 1982 mit der Formulierung der „Prion-Hypothese“, für die er 1997 mit dem Nobelpreis für Medizin und Physiologie ausgezeichnet wurde. Bereits Jahre zuvor hatte die Strahlenbiologin Tikvah Alper zeigen können, dass ionisierende und ultraviolette Strahlung die Infektiosität des Erregers kaum beeinflussen konnten. Dies legte den Verdacht nahe, dass es sich bei dem Erreger keineswegs um ein herkömmliches Virus handeln könne, da die enthaltene Nukleinsäure durch Bestrahlung im Normalfall zerstört wird. Anknüpfend an diese Erkenntnis, etablierte Prusiner die Hypothese, dass es sich um proteinartige infektiöse Partikel ([engl.] „proteinaceous infectious particles“ = prion) handeln könne, die ohne Nukleinsäure auskämen und prägte somit den Begriff der Prionerkrankungen (Prusiner 1982).

Beim Menschen unterscheidet man sporadische, genetische und erworbene Prionerkrankungen. Die häufigste Form ist die sporadische Creutzfeldt-Jakob-Erkrankung (sCJK), die ihren Namen den beiden Erstbeschreibern zu verdanken hat. Anfang des 20. Jahrhunderts veröffentlichten der Neurologe Hans Gerhard Creutzfeldt und kurze Zeit später der Neurologe Alfons Jakob Berichte „über eigenartige Erkrankungen des Zentralnervensystems“, die als „spastische Pseudosklerose“ beschrieben wurden (Creutzfeldt 1920; Jakob 1921).

\subsection{Pathogenese}

Die genaue Pathophysiologie der Prionerkrankungen ist auch heute noch Gegenstand der Forschung. Es wird angenommen, dass die Aggregation des fehlgefalteten Prionpro- 
teins $\operatorname{PrPsc}^{\text {sc }}$ (sc für Scrapie) hauptverantwortlich für den folgenden Zelltod ist. Das Prionprotein ist ein Membranprotein, welches in physiologischer Form ( $\mathrm{PrP}^{\mathrm{c}}$ ) im menschlichen Körper, insbesondere in Neuronen und dem lymphoretikulären Gewebe, exprimiert wird. Es besteht aus 209 Aminosäuren mit einem Molekulargewicht von 35-36 kDa und wird im Prionprotein-Gen (PRNP) auf dem kurzen Arm von Chromosom 20 kodiert. Die Funktion des zellulären Prionproteins ist noch nicht abschließend geklärt. Es gibt jedoch Hinweise, dass $\mathrm{PrP}^{c}$ die Zelle durch Bindung von Kupferionen vor oxidativem Stress schützt (Brown et al. 1997; Kramer et al. 2001). Andere Autoren beschreiben eine Rolle des $\mathrm{PrP}^{\mathrm{c}}$ bei der Signaltransduktion in Synapsen (Hu et al. 2007; Mouillet-Richard et al. 2007).

Die beiden Isoformen des $\mathrm{PrP}^{\mathrm{c}}$ und $\mathrm{PrP}^{\mathrm{Ps}}$ gleichen sich in ihrer Primärstruktur. Betrachtet man jedoch die Konformation ihrer Tertiärstruktur, dominieren alpha-helikale Anteile im $\mathrm{PrP}^{\mathrm{c}}$, während das $\mathrm{PrPsc}^{\mathrm{sc}}$ vorwiegend beta-Faltblatt Strukturen aufweist (Pan et al. 1993).

\section{Abbildung 1.1 Schematische Darstellung des PrPc und PrPsc, modifiziert nach} (Prusiner 2001)

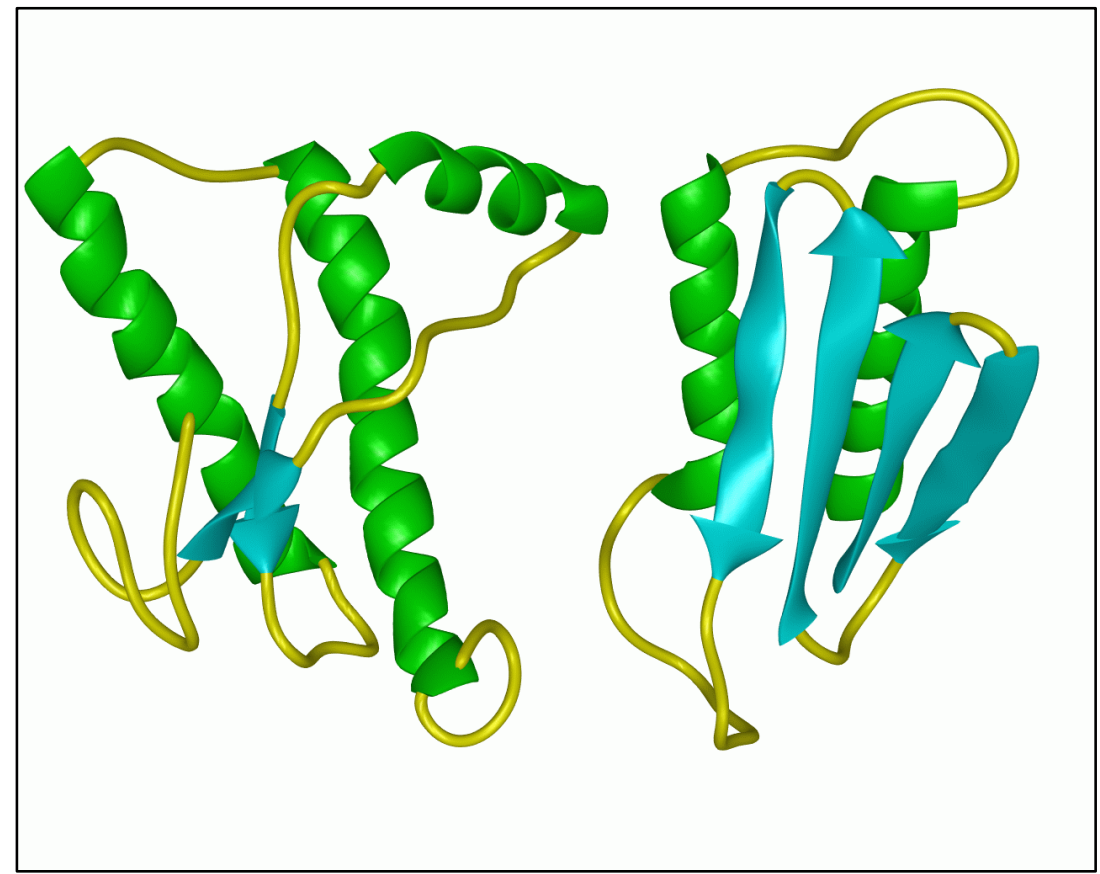


Dies resultiert in stark unterschiedlichen biophysikalischen Eigenschaften. Während $\mathrm{PrP}^{\mathrm{c}}$ hydrophil und gut löslich in Detergenzien ist und durch das Enzym Proteinkinase $\mathrm{K}$ abgebaut werden kann, ist PrPsc schlecht löslich, partiell gegen Proteinkinase K resistent und neigt zur Aggregation. Darüber hinaus ist es in der Lage, eine Konformationsänderung des $\mathrm{PrP}^{\mathrm{c}}$ in die pathologische Form zu bewirken. Im Zuge dessen kommt es zu einer Art Kettenreaktion und immer mehr pathologisches PrPsc entsteht. Es lassen sich zwei Typen des pathogenen Prionproteins (Typ 1 und Typ2) aufgrund unterschiedlich stark glykolisierter Isoformen (un-, mono- oder diglykolisiert) anhand ihrer elektrophoretischen Mobilität unterscheiden (Parchi et al. 1997). Der Proteinkinase K resistente Rest des PrPsc Typ 1 hat ein Molekulargewicht von 21kDa, Typ 2 von 19 kDa.

Durch massive Ablagerung des $\mathrm{PrP}^{\mathrm{sc}}$ und die dadurch bedingte Neurotoxizität, kommt es schließlich zum Zelltod und dem typischen neuropathologischen Bild der schwammartigen Auflockerung.

\subsection{Formen von humanen Prionerkrankungen}

Die humanen Prionerkrankungen lassen sich anhand der Ätiologie in drei Gruppen einteilen (siehe Tabelle 1.1). Unabhängig von der Ätiologie handelt es sich jedoch bei allen Formen um potentiell übertragbare Erkrankungen.

\section{Tabelle 1.1 Formen humaner Prionerkrankungen}

\begin{tabular}{|l|l|}
\hline Ätiologie & Prionerkrankungen \\
\hline idiopathisch & $\begin{array}{l}\text { sporadische CJK } \\
\text { sporadische letale ([engl.] fatal) Insomnie (SFI) }\end{array}$ \\
\hline hereditär & $\begin{array}{l}\text { Gerstmann-Sträussler-Scheinker-Syndrom (GSS) } \\
\text { letale familiäre Insomnie ([engl.] fatal familial insomnia = FFI) } \\
\text { familiäre/genetische CJK (fCJK/gCJK) }\end{array}$ \\
\hline infektiös & $\begin{array}{l}\text { iatrogene CJK (iCJK) } \\
\text { neue Variante der CJK (vCJK) } \\
\text { Kuru }\end{array}$ \\
\hline
\end{tabular}


Neben der Ätiologie unterscheiden sich die unterschiedlichen Formen von Prionerkrankungen insbesondere im Hinblick auf ihr klinisches Erscheinungsbild. Man findet ein breites Spektrum an neurologischen und neuropsychologischen Symptomen, eine sehr variable Dauer der Erkrankung von Symptombeginn bis zum Tod sowie heterogene Befunde in den diagnostischen Zusatzuntersuchungen.

\subsubsection{Sporadische Prionerkrankungen}

Die sporadische CJK stellt mit über 85-90\% den größten Teil der humanen Prionerkrankungen dar. Während bei den genetischen und infektiösen Formen der zur Erkrankung führende Pathomechanismus hinlänglich bekannt ist, konnte für die sCJK bisher der eigentliche Auslöser nicht identifiziert werden. Postuliert werden eine mögliche spontane Umfaltung des $\mathrm{PrP}^{\mathrm{c}}$ in PrPsc oder eine mögliche somatische Mutation im PRNP. Die sCJK tritt mit einer weltweiten Inzidenz von ca. 1,5 auf eine Million Einwohner pro Jahr auf (Ladogana et al. 2005). Das mittlere Erkrankungsalter liegt bei 68 Jahren, Männer und Frauen sind in etwa gleich häufig betroffen (Collins et al. 2006). Der typische Verlauf präsentiert sich mit einer rasch fortschreitenden dementiellen Entwicklung und weiteren neurologischen Ausfallerscheinungen wie Sehstörungen, Koordinationsstörungen, Myoklonien und extrapyramidalen oder pyramidalen Zeichen. Das Endstadium der Erkrankung ist mit dem Eintreten des akinetischen Mutismus erreicht. Die Erkrankung führt in der Regel innerhalb von 5-6 Monaten zum Tod. Atypische Krankheitsverläufe mit einem früheren Erkrankungsbeginn und einer prolongierten Krankheitsdauer sind in ca. $10 \%$ der Fälle beschrieben.

Das klinische Erscheinungsbild der sporadischen CJK wird im Wesentlichen vom Polymorphismus am Codon 129 des Prion-Protein-Gens (Homozygotie für Methionin (MM) oder Valin (VV), Heterozygotie MV) und den PrPsc -Typ beeinflusst (Parchi et al. 1996) (siehe Kapitel 1.5).

Die erstmals 1999 beschriebene sporadische letale Insomnie ist die seltenste Form der Prionerkrankungen und ähnelt klinisch der familiären letalen Insomnie. Eine Mutation im Prion-Protein-Gen lässt sich jedoch bei der SFI nicht nachweisen. Namensgebend für die Erkrankung ist das klinische Symptom der Schlaflosigkeit (Insomnie). Neuropathologisch stehen insbesondere Veränderungen des Thalamus im Vordergrund. Das Er- 
krankungsalter liegt im Durschnitt bei 46 Jahren, die Erkrankungsdauer beträgt in der Regel 24 Monate (Parchi et al. 1999a; Krasnianski et al. 2008a).

\subsubsection{Genetische Prionerkrankungen}

Den genetischen Formen der Prionerkrankungen liegen Mutationen in dem für das Prionprotein kodierende Gen (PRNP) zu Grunde. Mittlerweile konnten mehr als 30 verschiedene Insertions- und Punktmutationen identifiziert werden, die zu einer Prionerkrankung führen.

\section{Abbildung 1.2 Schematische Darstellung des Prion-Protein-Gens mit den häufigs- ten Mutationen und Polymorphismen}

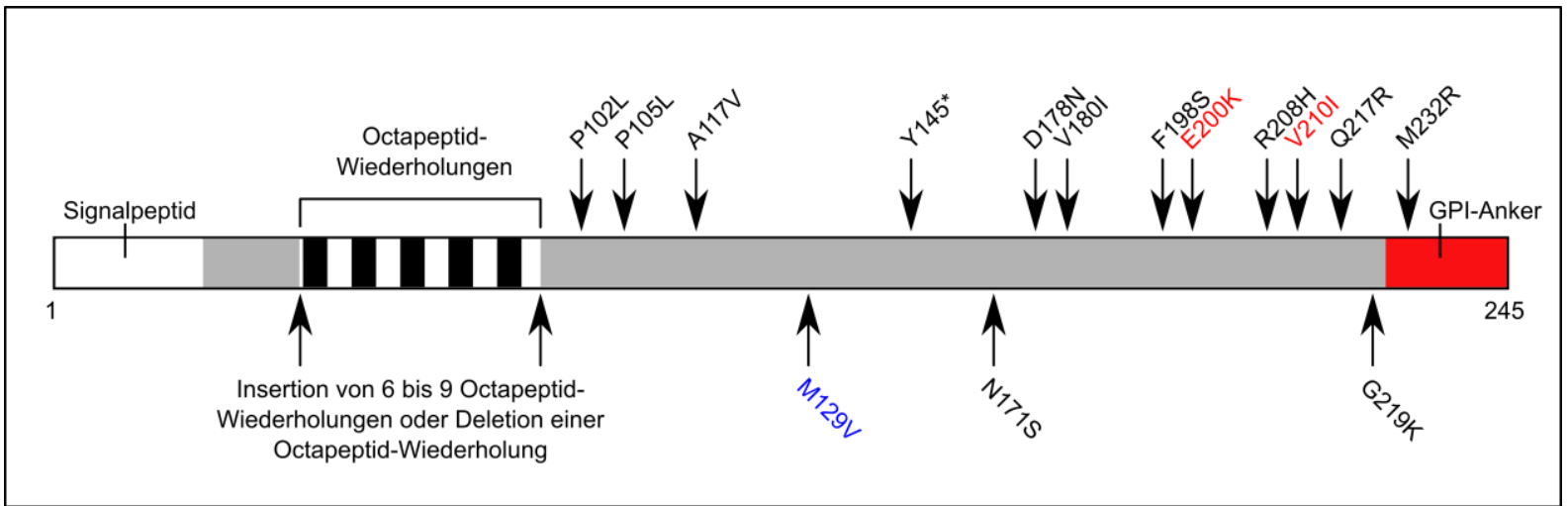

Man geht davon aus, dass durch die Mutation im PRNP ein instabileres $\mathrm{PrP}^{c}$ gebildet wird, welches eine höhere Bereitschaft zur Umfaltung in die pathologische PrPsc-Form zeigt. $\mathrm{Zu}$ den genetischen Prionerkrankungen werden das Gerstmann-SträusslerScheinker-Syndrom (GSS), die letale familiäre Insomnie (FFI aus dem Englischen fatal familial insomnia) sowie die familiäre CJK gezählt. Da die Familienanamnese in mehr als 40\% aller Fälle negativ ist, trifft der Begriff genetische CJK (gCJK) besser zu als familiäre CJK. Alle Formen genetischer Prionerkrankungen zeigen einen autosomal-dominanten Erbgang. Das bedeutet, dass die Kinder eines Erkrankten ein Risiko von 50\% haben die Mutation zu erben und im Laufe des Lebens ebenfalls an der Erkrankung zu sterben. Das Erkrankungsalter genetischer Prionerkrankungen ist typischerweise früher als bei der 
sCJK. Dennoch ist in den meisten Fällen die Familienplanung bei Ausbruch der Erkrankung bereits abgeschlossen, so dass eine genetische Beratung oftmals nicht möglich ist. In Deutschland stellt die D178N-129M-Mutation, welche mit dem Phänotyp der FFI assoziiert ist, die häufigste Mutation dar. Das GSS wird am häufigsten durch die P201LMutation verursacht. Während beim GSS und der FFI deutlich längere Überlebenszeiten und ein abweichendes klinisches Erscheinungsbild imponieren, ähneln andere Mutationen im PRNP dem Phänotyp der sporadischen CJK. Die häufigsten dieser Mutationen sind die E200K-Mutation und die V210I-Mutation. Aufgrund der häufig negativen Familienanamnese und dem klassischen klinischen Krankheitsverlauf, der der sCJK ähnelt, werden diese Fälle oftmals nur zufällig im Rahmen der durchgeführten genetischen Untersuchung entdeckt. Die Diagnosekriterien der genetischen Prionerkrankungen sind in Tabelle 1.2 aufgeführt.

Tabelle 1.2 Diagnosekriterien der genetischen Prionerkrankungen

\begin{tabular}{|l|l|}
\hline sicher & $\begin{array}{l}\text { neuropathologische Diagnose einer TSE plus } \\
1 . \text { sichere oder wahrscheinliche TSE bei einem Verwandten } 1 . \\
\text { Grades } \\
\text { ODER } \\
2 . \text { Vorliegen einer pathogenen PRNP-Mutation }\end{array}$ \\
\hline wahrscheinlich & $\begin{array}{l}\text { fortschreitende neuropsychiatrische Erkrankung plus } \\
1 . \text { sichere oder wahrscheinliche TSE bei einem Verwandten } 1 . \\
\text { Grades } \\
\text { ODER } \\
2 . \text { Vorliegen einer pathogenen PRNP-Mutation }\end{array}$ \\
\hline
\end{tabular}




\subsubsection{E200K-Mutation}

Die meisten Fälle von genetischer CJK werden durch die E200K-Mutation bedingt. Am Codon 200 kommt es zu einem Austausch der Base Adenin durch Guanin, was wiederum zu einer Substitution der Aminosäure Glutamat (E) durch Lysin (K) führt. Die Mutation kommt in großen Clustern, insbesondere unter lybischen Juden in Israel, in Chile und der Slowakei vor. Darüber hinaus ist sie jedoch auch in Deutschland, Frankreich, Italien, anderen europäischen Ländern und den USA häufig zu finden. Wie alle anderen genetischen Prionerkrankungen folgt die Mutation einem autosomal-dominanten Erbgang. Die Familienanamnese ist jedoch in vielen Fällen negativ, was unter anderem auch dadurch erklärt werden kann, dass die Penetranz der Mutation sehr variabel scheint und mit 5489\% angegeben wird (Goldfarb et al. 1990; Chapman et al. 1994; D'Alessandro et al. 1998; Mitrova und Belay 2002). Nicht alle Mutationsträger erkranken also auch klinisch an einer gCJK, entweder weil die Krankheit nicht zum Ausbruch kommt oder die Betroffenen vorher an einer anderen Ursache versterben. Die Wahrscheinlichkeit einer Manifestation der Erkrankung steigt mit zunehmendem Alter (Meiner et al. 1997). Das durchschnittliche Alter bei Erkrankung liegt bei 60-63 Jahren und somit etwas früher als bei der sCJK (Kovács et al. 2005; Heinemann et al. 2007; Meiner et al. 2011). Der Phänotyp ähnelt dem der sporadischen CJK und wird dabei ebenfalls maßgeblich vom Polymorphismus am Codon 129 sowie dem PrP-Typ beeinflusst. So ist die Erkrankungsdauer bei homozygoten MM-Patienten signifikant kürzer als bei MV-Patienten (Mitrova und Belay 2002). Klinisch im Vordergrund stehen wie bei der sCJK insbesondere eine rasch progrediente Demenz, eine zerebelläre Ataxie sowie Bewegungsstörungen. In der apparativen Diagnostik mittels cMRT, EEG und Liquoruntersuchung lassen sich wie bei der sCJK häufig typische Befunde erheben. Eine Unterscheidung zwischen E200K-Patienten und Patienten mit sporadischer CJK ist bei negativer Familienanamnese daher erst nach einer Sequenzierung des PRNP möglich.

\subsubsection{V210I-Mutation}

Die zweithäufigste Punktmutation V210I resultiert aus einem Austausch der Aminosäure Valin (V) durch Isoleucin (I) am Codon 210 des PRNP. In Italien stellt sie unter den genetischen Creutzfeldt-Jakob-Erkrankungen sogar die häufigste Mutation dar (Ladogana et al. 2005). Bei 90\% der Patienten ist die Familienanamnese für CJK leer. Das 
klinische Erscheinungsbild der V210I-Mutation ähnelt dem häufigsten Subtyp der sporadischen CJK. Das mittlere Alter bei Erkrankung wird mit 60 bis 63 Jahren angegeben, die Erkrankungsdauer liegt im Mittel bei vier Monaten (Kovács et al. 2005; Heinemann et al. 2007; Schelzke et al. 2012). Eine rasch progrediente dementielle Entwicklung und die zerebelläre Ataxie sind die häufigsten klinischen Symptome. Darüber hinaus finden sich oftmals auch typische Befunde in der apparativen Diagnostik (EEG, Liquordiagnostik und cMRT), so dass die meisten Patienten anhand der klinischen Diagnosekriterien als „wahrscheinliche“ CJK klassifiziert werden. Auch hier deckt in der Regel erst die zufällig genetische Testung das Vorliegen der Mutation auf.

\subsection{3 latrogene CJK}

Die iatrogene CJK gehört zur den übertragenen Prionerkrankungen und macht 1\% aller TSE-Fälle aus. Bereits 1974 wurde über einen Patienten berichtet, der nach einer Korneatransplantation an CJK erkrankte (Duffy et al. 1974). Die meisten Fälle von iCJK wurden durch die intramuskuläre Injektion kontaminierter Wachstumshormone aus Leichenhypophysen und die Verwendung von Dura-mater-Transplantaten von an CJK verstorbenen Spendern ausgelöst. Das klinische Erscheinungsbild und die Krankheitsdauer entsprechen der sCJK. Auch die Verwendung von kontaminiertem Operationsbesteck nach neurochirurgischen Eingriffen an CJK-erkrankten Patienten führte zur Übertragung der Erkrankung auf Gesunde. Aufgrund der ungewöhnlichen Resistenz des PrPsc kann dieses durch konventionelle Sterilisationsmaßnahmen nicht unschädlich gemacht werden.

Im Zusammenhang mit der vCJK wurde darüber hinaus vor einiger Zeit die Möglichkeit der Übertragung der Erkrankung durch Blutspender bekannt (Llewelyn et al. 2004; Hewitt et al. 2006). Die Inkubationszeit der iatrogenen CJK ist sehr unterschiedlich und liegt zwischen 1,5 und 12 Jahren und ist abhängig von der Menge des übertragenen infektiösen Gewebes, genetischer Suszeptibilität und dem Infektionsweg (intrazerebral oder peripher) (Brown et al. 2000). Eine genaue Rückverfolgung des Infektionsweges ist daher erschwert. 


\subsubsection{Neue Variante CJK (VCJK)}

Nach dem Auftreten der BSE-Epidemie in Großbritannien wurden in Europa und vielen Ländern Zentren gegründet, die Veränderungen im Vorkommen der CJK beobachten und erforschen sollten, um mögliche Zusammenhänge mit der BSE-Erkrankung bei Rindern nicht zu übersehen. 1995 und 1996 wurden erste Fälle von jungen Erwachsenen publik, die eine klinische und neuropathologische Form von Prionerkrankung aufwiesen, die bis dato in der Literatur nicht beschrieben waren (Will et al. 1996). Auffällig war, dass die erkrankten Patienten wesentlich jünger waren als die der sporadischen CJK und insbesondere Verhaltensauffälligkeiten aufwiesen. Der Verdacht einer Assoziation dieser „neuen Variante“ mit der BSE-Erkrankung beim Rind wurde durch Laborversuche an Mäusen 1997 erhärtet (Bruce et al. 1997). Es wird angenommen, dass einer Übertragung des pathogenen Agens durch den Konsum von BSE-verseuchtem Rind-fleisch erfolgt (Will 2003).

Das mittlere Alter bei Erkrankung liegt bei 29 Jahren und somit deutlich früher als bei anderen Formen von Prionerkrankungen. Der Beginn der Erkrankung wird geprägt von psychiatrischen Symptomen wie Depression, Angststörungen und Wesensänderung (Brandel et al. 2009; Heath et al. 2010). Dies hat häufig zur Folge, dass Patientin irrtümlicherweise im Hinblick auf eine psychiatrische Grunderkrankung untersucht und behandelt werden. Erst mit dem Auftreten neurologischer Symptome wie Dysästhesien, Demenz und extrapyramidale Bewegungsstörungen, häufig in Form von Dyskinesien und Hyperkinesien im Verlauf der Erkrankung, wird das Vorliegen einer neurologischen Ursache demaskiert. Die Erkrankungsdauer liegt im Mittel bei 13 Monaten und ist somit länger als die der sporadischen CJK (Mackay et al. 2011). Die EEG- und Liquoruntersuchung von vCJK-Patienten weist nur sehr selten die typischen Befunde einer CJK auf (PSWC und positiver 14-3-3-Nachweis). In der cMRT hingegen findet sich bei mehr als 90\% der Patienten das sogenannte pulvinar sign ([engl.] pulvinares Zeichen), welches gekennzeichnet ist durch symmetrische Hyperintensitäten im Bereich des Pulvinar des Thalamus.

Mittlerweile ist die Zahl der an vCJK Erkrankten auf 228 weltweit angewachsen (EUROCJD-Stand November 2013). Die meisten Fälle finden sich in England, gefolgt von Frankreich. Interessanterweise waren bisher alle neuropathologisch bestätigten vCJKFälle homozygot für Methionin am Codon 129. 


\subsection{Klinische Präsentation}

Nicht zuletzt die heterogene klinische Präsentation der Prionerkrankungen macht die Diagnosestellung zu einer Herausforderung. Die Erkrankung umfasst ein breites Spektrum an neurologischen und psychiatrischen Symptomen, die in allen Fällen unaufhaltbar fortschreiten und schlussendlich zum Tod führen. Prodromalsymptome beinhalten häufig unspezifische Schwindelsymptomatik, Schlafstörungen, Persönlichkeitsveränderungen und Depression. Eine neurologische oder psychiatrische Vorstellung erfolgt jedoch oft erst bei Auftreten von Symptomen wie einer rasch progrediente dementielle Entwicklung, einer zerebelläre Ataxie, extrapyramidalen oder pyramidale Bewegungsstörungen, Sehstörungen und Myoklonien. Die Symptome schreiten innerhalb kürzester Zeit rasch fort bis zum Endstadium des akinetischen Mutismus. Die Patienten zeigen dann eine schwerste Antriebsstörung und fehlende Sprachproduktion. Der Tod wird oft durch sekundäre Komplikationen der Bettlägerig-keit, wie z.B. Infektionen oder vegetative Dysregulation hervorgerufen.

\subsection{Subtypen der CJK}

Bereits früh wurden deutliche Unterschiede im Krankheitsverlauf von Patienten mit CJK beschrieben. Der PrPsc Typ (1 oder 2) sowie der Polymorphismus am Codon 129 des PRNP konnten diesbezüglich als wesentliche Einflussfaktoren identifiziert werden (Parchi et al. 1999b). Resultierend aus der Kombinationsmöglichkeit der zwei PrPsc_ Typen und dem Polymorphismus am Codon 129 (MM, MV und VV), werden in der gängigen Praxis sechs verschiedene Subtypen der CJK unterschieden (MM1, MV1, VV1, MM2, MV2, VV2) (Parchi et al. 1999b).

\subsubsection{Polymorphismus am Codon 129}

Am Codon 129 des für das Prionprotein kodierenden Gens können aufgrund eines Polymorphismus die Aminosäuren Valin (V) und Methionin (M) in hetero- oder homozygoter Form vorliegen (MV, MM oder VV). Es konnte gezeigt werden, dass sich die Normalverteilung in der Bevölkerung deutlich von der Verteilung unter sCJK-Patienten unter- 
scheidet (siehe Abbildung 1.1). Während in der Normalbevölkerung am häufigsten die Heterozygotie gefunden wird, weisen sCJK-Patienten am häufigsten den MM-Typ auf. Dieser scheint mit einem erhöhtem Risiko für die Entwicklung einer CJK assoziiert zur sein (Palmer und Collinge 1993). Darüber hinaus werden jedoch auch das Erkrankungsalter, die Dauer der Erkrankung, das klinische Erscheinungsbild, die Konstellation verschiedener Untersuchungsergebnisse und die Neuropathologie maßgeblich beeinflusst.

Abbildung 1.3 Verteilung des Polymorphismus am Codon 129 bei sCJK-Patienten und in der Normalbevölkerung. (Modifiziert nach (Alperovitch et al. 1999))

sCJK-Patienten

$\square \mathrm{MM} \square \mathrm{MV} \square \mathrm{VV}$

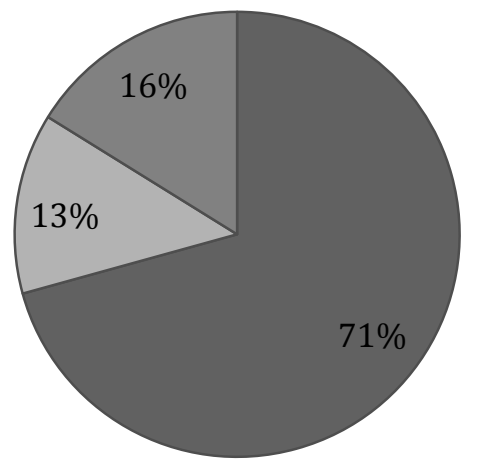

Normalbevölkerung

$\square \mathrm{MM} \square \mathrm{MV} \square \mathrm{VV}$

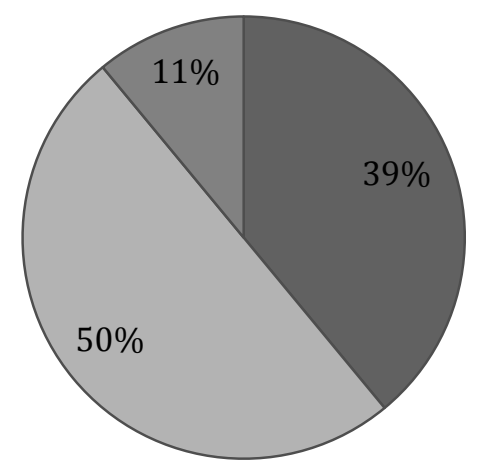

\subsubsection{Prionproteintyp}

Das Prionprotein verfügt über zwei Stellen, an denen eine Glykosylierung stattfinden kann. Daraus resultiert, dass es in di-, mono- oder unglykosylierter Form vorliegen kann. Es werden zwei verschiedene PrPsc-Typen (Typ 1 und Typ2) unterschieden, die sich im Ausmaß der Glykosylierung und durch die Schnittstelle nach partieller Verdauung durch Proteinase K unterscheiden (Parchi et al. 1996). Die Differenzierung erfolgt mittels GelElektrophorese anhand des Migrationsverhaltens und des molekularen Gewichts. Der PrPsc-Typ 1 kommt deutlich häufiger vor als der Prionproteintyp 2 und ist mit einem klassischen Krankheitsverlauf assoziiert. Bei einigen Patienten lassen sich beide Prion- 
proteintypen finden, so dass die Klassifikation der CJK in verschiedene Subtypen noch nicht abschließend geklärt zu sein scheint (Puoti et al. 2012).

\subsubsection{Charakterisierung der Subtypen}

Wie bereits erwähnt, weisen die sechs molekularen Subtypen der sCJK sehr unterschiedliche Phänotypen auf. Die Tabelle 1.3 gibt einen Überblick über die verschiedenen Charakteristika der jeweiligen Subtypen. Da die molekularen Subtypen MM1 und MV1 in ihrem Phänotyp nicht zu unterscheiden waren, wurden sie als MM1-/MV1-Subtyp zusammengefasst (Parchi et al. 1996). Im Kollektiv der MM2-Patienten finden sich zwei unterschiedliche Phänotypen im Hinblick auf die neuropathologischen Veränderungen, welche, entweder überwiegend kortikal (kortikaler Subtyp) oder im Thalamus (thalamischer Subtyp) zu finden sind (Parchi et al. 1999b). 
Tabelle 1.3 Charakterisierung der verschiedenen Subtypen der sporadischen CJK

\begin{tabular}{|c|c|c|c|c|c|c|}
\hline & MM1/MV1 & VV2 & MV2 & MM2-t & MM2-k & VV1 \\
\hline Häufigkeit & $70 \%$ & $16 \%$ & $9 \%$ & $2 \%$ & $2 \%$ & $1 \%$ \\
\hline Alter (Jahre) & $65,5 / 62,1$ & 61,3 & 59,4 & 52,3 & 64,3 & 39,3 \\
\hline $\begin{array}{l}\text { Dauer } \\
\text { (Monate) }\end{array}$ & $3,9 / 4,9$ & 6,5 & 17,1 & 15,6 & 15,7 & 15,3 \\
\hline Klinik & $\begin{array}{l}\text { frühe Demenz, My- } \\
\text { oklonien }\end{array}$ & $\begin{array}{l}\text { Ataxie, später De- } \\
\text { menz }\end{array}$ & Ataxie und Demenz & $\begin{array}{l}\text { Insomnie, Hyperki- } \\
\text { nesien, Ataxie und } \\
\text { Demenz }\end{array}$ & Demenz & Demenz \\
\hline Pathologie & $\begin{array}{c}\text { occipitaler Kortex, } \\
\text { PrP-Ablagerung } \\
\text { vom synaptischen } \\
\text { Typ }\end{array}$ & $\begin{array}{l}\text { Schädigung insbe- } \\
\text { sondere der sub- } \\
\text { kortikalen Struktu- } \\
\text { ren, perineuronales } \\
\text { PrP }\end{array}$ & $\begin{array}{l}\text { Amyloid-Plaques } \\
\text { („Kuru“-Plaques), } \\
\text { Spongiose kann } \\
\text { fehlen }\end{array}$ & $\begin{array}{c}\text { Atrophie des Tha- } \\
\text { lamus und Nucleus } \\
\text { olivaris }\end{array}$ & $\begin{array}{l}\text { große Vakuolen } \\
\text { und perivakuoläre } \\
\text { PrP-Ablagerungen }\end{array}$ & $\begin{array}{c}\text { ausgeprägte Ver- } \\
\text { änderungen korti- } \\
\text { kal, Aussparung } \\
\text { des Hirnstamms, } \\
\text { Spongiose, Gliose, } \\
\text { Neuronenverlust }\end{array}$ \\
\hline EEG & + & - & - & - & - & - \\
\hline $14-3-3$ & + & + & $(+)$ & $(+)$ & $(+)$ & + \\
\hline MRT & $\begin{array}{c}\text { Basalganglien, } \\
\text { Kortex }\end{array}$ & $\begin{array}{l}\text { Basalganglien, Tha- } \\
\text { lamus }\end{array}$ & $\begin{array}{c}\text { Kortex, Basalgang- } \\
\text { lien, Thalamus }\end{array}$ & Basalganglien & Kortex & Kortex \\
\hline
\end{tabular}




\subsection{Diagnostik}

Die definitive Diagnose der CJK erfordert nach wie vor eine neuropathologische Untersuchung von Hirngewebe durch eine Biopsie oder Autopsie nach dem Tod. Verschiedene apparative Untersuchungen zusammen mit einer eingehenden Untersuchung der klinischen Symptome und Erhebung einer ausführlichen Anamnese erlauben jedoch eine Einschätzung wie wahrscheinlich das Vorliegen einer Prionerkrankung ist. Genetische Prionerkrankungen können durch den Nachweis einer Mutation im PRNP gesichert werden.

\subsubsection{Liquoruntersuchung}

Die Nervenwasseruntersuchung dient neben dem Nachweis CJK-typischer Veränderungen insbesondere dem Ausschluss anderer, behandelbarer Erkrankungen des zentralen Nervensystems. Die Routineparameter für Zellzahl, Eiweiß und Lactat sollten normwertig sein. Gelegentlich liegt eine leichte, unspezifische Eiweißerhöhung vor. Durch den raschen und massiven Untergang von Nervenzellen, lassen sich im Liquor von Patienten mit CJK verschiedene neuronale Destruktionsmarker nachweisen. Hierzu gehören die Proteine 14-3-3, das Tau-Protein die neuronenspezifische Enolase (NSE) sowie das astrozytäre S100b. Der Nachweis der 14-3-3-Proteine mittels Western Blot ist Bestandteil der klinischen Diagnosekriterien (Zerr et al. 2000). Die Sensitivität für 14-3-3 wird zwischen $86 \%$ und 94\% angegeben und ist somit die höchste aller apparativen Untersuchungsmethoden (Collins et al. 2006). Die Sensitivität ist jedoch abhängig vom Subtyp der CJK. Die Homozygotie am Codon 129 (MM, VV) sowie der PrP-Typ 1 gehen mit einer höheren Sensitivität einher als die anderen Subtypen (Castellani et al. 2004). In atypischen Fällen mit langem Krankheitsverlauf, bei genetischen Prionerkrankungen und der vCJK lassen sich die Proteine 14-3-3 häufig nicht nachweisen. Da die 14-3-3-Proteine auch bei anderen Erkrankungen nachweisbar sind, die mit einem Nervenzelluntergang einhergehen (z.B. Status epilepticus, zerebrale Ischämien oder anderen Enzephalopathien), kann eine Spezifität von nur 68-72\% erreicht werden (Zerr et al. 2009; Coulthart et al. 2011). 
Das Tau-Protein kommt in Gliazellen und Astrozyten vor und ist mit Mikrotubuli assoziiert. Bei der CJK ist es häufig in sehr hoher Konzentration im Nervenwasser von Patienten messbar und erlaubt eine Abgrenzung der CJK gegenüber anderen neurodegenerativen Prozessen (Otto et al. 1997). Bei einem Cut-off von ca. 1000pg/ml wird die Sensitivität und Spezifität des Tau-Proteins mit 91\% und 88\% respektive angegeben und ist somit der Bestimmung der Proteine 14-3-3 überlegen (Coulthart et al. 2011). Die Bestimmung aller Marker scheint die diagnostische Aussagekraft zu erhöhen.

\subsubsection{Elektroenzephalogramm (EEG)}

Das EEG stellte lange Zeit die wichtigste apparative Diagnostik der CJK dar und fand zuerst Einzug in die klinischen Diagnosekriterien. Als typische Veränderungen der Hirnstromkurve bei CJK-Patienten lassen sich sogenannte periodische Sharp-WaveKomplexe (PSWC) nachweisen. Die Kriterien zur objektiven Beurteilung dieser PSWC definierte Steinhoff wie folgt (Steinhoff et al. 1996; Steinhoff et al. 2004):

- Strikt periodische Potentiale mit einer Dauer von 100 bis $600 \mathrm{~ms}$ und einer Frequenz von 0,5 bis 2/sec

- Generalisierte oder lateralisierte Komplexe

- Mindestens fünf repetitive Intervalle, die sich in ihrer Dauer um nicht mehr als 500ms unterscheiden

Die PSCW können eine mono-, bi- oder triphasische Konfiguration aufweisen. Die Sensitivität dieser Untersuchung wird mit 44\% bis 64\% angegeben, die Spezifität liegt bei 9192\% (Steinhoff et al. 2004; Zerr et al. 2009). Einfluss auf die Aussagekraft der Untersuchung haben insbesondere der Polymorphismus am Codon 129, das Alter bei Erkrankung, die Krankheitsdauer, sowie der Zeitpunkt der Untersuchung im Krankheitsverlauf (Collins et al. 2006). Bei Patienten mit dem Subtyp MM, einem Alter > 70 Jahre bei Erkrankungsbeginn und einer Dauer < 6 Monate finden sich am häufigsten typische EEGBefunde. Zu Beginn der Erkrankung oder bei atypischen Verläufen finden sich hingegen häufig nur unspezifische Veränderungen wie ein verlangsamter Grundrhythmus oder diffuse Theta- und Deltaaktivität. 


\subsubsection{Magnetresonanztomographie (MRT)}

Die kraniale Kernspintomographie liefert hochauflösende Bilder des Gehirns und hat sich in der Diagnostik der CJK als eine der wichtigsten Zusatzuntersuchungen etabliert. Neben dem Nachweis CJK-typischer Veränderungen, dient die MRT insbesondere auch dem Ausschluss bzw. der Abgrenzung gegenüber anderen, ggf. auch behandelbaren rasch progredienten Demenzerkrankungen (Vitali et al. 2011). Während die kraniale Computertomographie häufig nur eine unspezifische Atrophie erkennen lässt, finden sich in der cMRT oftmals charakteristische Veränderungen im Hinblick auf eine CJK.

\subsubsection{MRT bei sporadischer CJK}

1988 beschrieben Gertz und Kollegen erstmals Auffälligkeiten im MRT eines sCJKPatienten in Form von Signalhyperintensitäten des Striatums, des Thalamus und des Kortex, die mit den post mortem erhobenen neuropathologischen Befunden korrelierten (Gertz et al. 1988). Es folgten weitere Falldarstellungen die ähnliche, oft bilateral im Striatum lokalisierte Veränderungen in verschiedenen Sequenzen des MRTs nachweisen konnten (Milton et al. 1991; Rother et al. 1992). In einer ersten größeren Studie an insgesamt 29 Patienten fanden sich Hyperintensitäten des Putamens und Nucleus caudatus in den T2- und protonengewichteten Sequenzen bei 79\% der Patienten (Finkenstaedt et al. 1996). In folgenden größeren Studien wurden für die CJK-typischen MRTVeränderung eine Sensitivität von 63-67\% und eine Spezifität von 88-93\% nachgewiesen (Schroter et al. 2000; Meissner et al. 2004).

Mit Entwicklung neuerer und sensitiverer Sequenzen wie der FLAIR (fluid attenuated inversion recovery) und insbesondere der Diffusionswichtung (DWI), ließen sich die Veränderungen noch besser darstellen. Die DWI konnte in mehreren Studien als sensitivste Sequenz identifiziert werden (Shiga et al. 2004; Tschampa et al. 2005; Kallenberg et al. 2006). Durch ihren Einsatz lässt sich die Sensitivität und Spezifität auf 83-92\% beziehungsweise 83-95\% verbessern (Shiga et al. 2004; Young et al. 2005; Zerr et al. 2009). Neben den zunächst beschriebenen Hyperintensitäten der Basalganglien, lassen sich bei der Mehrzahl der Patienten zusätzliche Signalalterationen des Neocortex nachweisen. 
Das Verteilungsmuster der MRT-Veränderungen weist große Unterschiede zwischen den verschiedenen molekularen Subtypen auf (Meissner et al. 2009). Während sich bei den Subtypen MV2, VV2 und MM1 häufig Hyperintensitäten der Basalganglien nachweisen lassen, finden sich bei VV1-, MV1- und MM2-Patienten vermehrt kortikale Signalalterationen. Insgesamt finden sich bei etwas mehr als zwei Drittel der Patienten Veränderungen der Basalganglien und des Kortex, bei knapp einem Drittel rein kortikale Veränderungen und bei sehr wenigen Patienten eine reine Beteiligung der Basalganglien (Young et al. 2005; Meissner et al. 2008).

Der genaue Grund für die sichtbaren MRT-Alterationen ist bisher nicht geklärt. Es gibt jedoch eine enge Korrelation zwischen den sichtbaren Hyperintensitäten und neuropathologischen Veränderungen in diesen Gebieten. Insbesondere scheinen hier die spongiformen Veränderungen mit Vakuolenbildung eine Rolle zu spielen (Geschwind et al. 2009; Manners et al. 2009).

Die MRT-Untersuchung ist im Hinblick auf Sensitivität und Spezifität der EEGUntersuchung überlegen, im Vergleich zur Bestimmung der 14-3-3-Proteine im Liquor finden sich unterschiedliche Angaben (Shiga et al. 2004; Zerr et al. 2009). Nicht nur sind die MRT-Veränderungen sehr spezifisch, sie weisen auch eine hohe Übereinstimmung zwischen verschiedenen Befundern auf (Shiga et al. 2004; Vitali et al. 2011). Im Gegensatz zur vCJK, wo das dort zu findende typische pulvinar sign bereits seit 2000 Bestandteil der Diagnosekriterien ist, findet die MRT bei sCJK jedoch trotz der bereits langjährig beschriebenen sensitiven Veränderungen erst seit 2009 Berücksichtigung in den etablierten klinischen Diagnosekriterien. Durch die Ergänzung der MRT konnte die Sensitivität der bisherigen Diagnosekriterien von 92\% auf 98\% erhöht werden. Die Kriterien für typische MRT-Veränderungen bei CJK-Patienten werden dabei wie folgt definiert (Zerr et al. 2009):

- Signalsteigerung im Nucleus caudatus und Putamen UND / ODER

- In mindestens zwei kortikalen Regionen (temporal-parietal-occipital) In DWI- und/oder FLAIR-gewichteten MRT-Aufnahmen 


\subsubsection{MRT bei genetischen Prionerkrankungen}

Die für die sporadische CJK beschriebenen MRT-Veränderungen im Sinne von Hyperintensitäten des Kortex und/oder der Basalganglien lassen sich in vielen Fällen von genetischen Prionerkrankungen nicht nachweisen. Insbesondere bei der FFI und dem GSS ist oftmals nur eine allgemeine Hirnatrophie zu verzeichnen. In nur 8-18\% der FFI-Fälle und 30\% der GSS-Fälle lassen sich Hyperintensitäten detektieren (Kovács et al. 2005; Heinemann et al. 2007). Für die häufigen Mutationen E200K und V210I der genetischen CJK trifft dies nicht zu. In vielen Fallberichten und kleineren Studien werden Signalalterationen beschrieben, die MRT-Veränderungen der sporadischen CJK imitieren.

Interessant ist die Tatsache, dass in einer Studie bei asymptomatischen Trägern der E200K-Mutation bereits vor Ausbruch der Erkrankung MRT-Veränderungen nachgewiesen werden konnten (Lee et al. 2009). Sowohl bei den bereits erkrankten Patienten als auch bei den gesunden Trägern der E200K-Mutation im untersuchten Kollektiv wurden gegenüber einer gesunden Kontrollgruppe ohne Nachweis einer Mutation im PNRP Diffusionseinschränkungen im thalamo-striatalen Netzwerk nachgewiesen. Dies unterstreicht einmal mehr, dass die pathologischen Veränderungen im zentralen Nervensystem lange vor klinischer Manifestation der Erkrankung stattzufinden scheinen.

Insbesondere im Hinblick auf zukünftige Therapien ist die frühe Erkennung pathologischer Veränderungen für einen zeitnahen Therapiebeginn wichtig. Eine Literaturübersicht über MRT-Veränderungen bei der E200K- und V210I-Mutation gibt Tabelle 1.4.

Die Abbildungen 1.4 und 1.5 zeigen CJK-typische Veränderungen der MRT in der FLAIR und DWI am Beispiel eines Patienten aus dem vorliegenden Kollektiv der genetischen CJK-Patienten. 
Abbildung 1.4 Typische MRT-Veränderungen am Beispiel eines Patienten mit der E200K-Mutationen in der FLAIR-Wichtung mit Nachweis von Hyperintensitäten im Bereich der Basalganglien (Nucleus caudatus und Putamen) sowie des insulären und frontalen Kortex

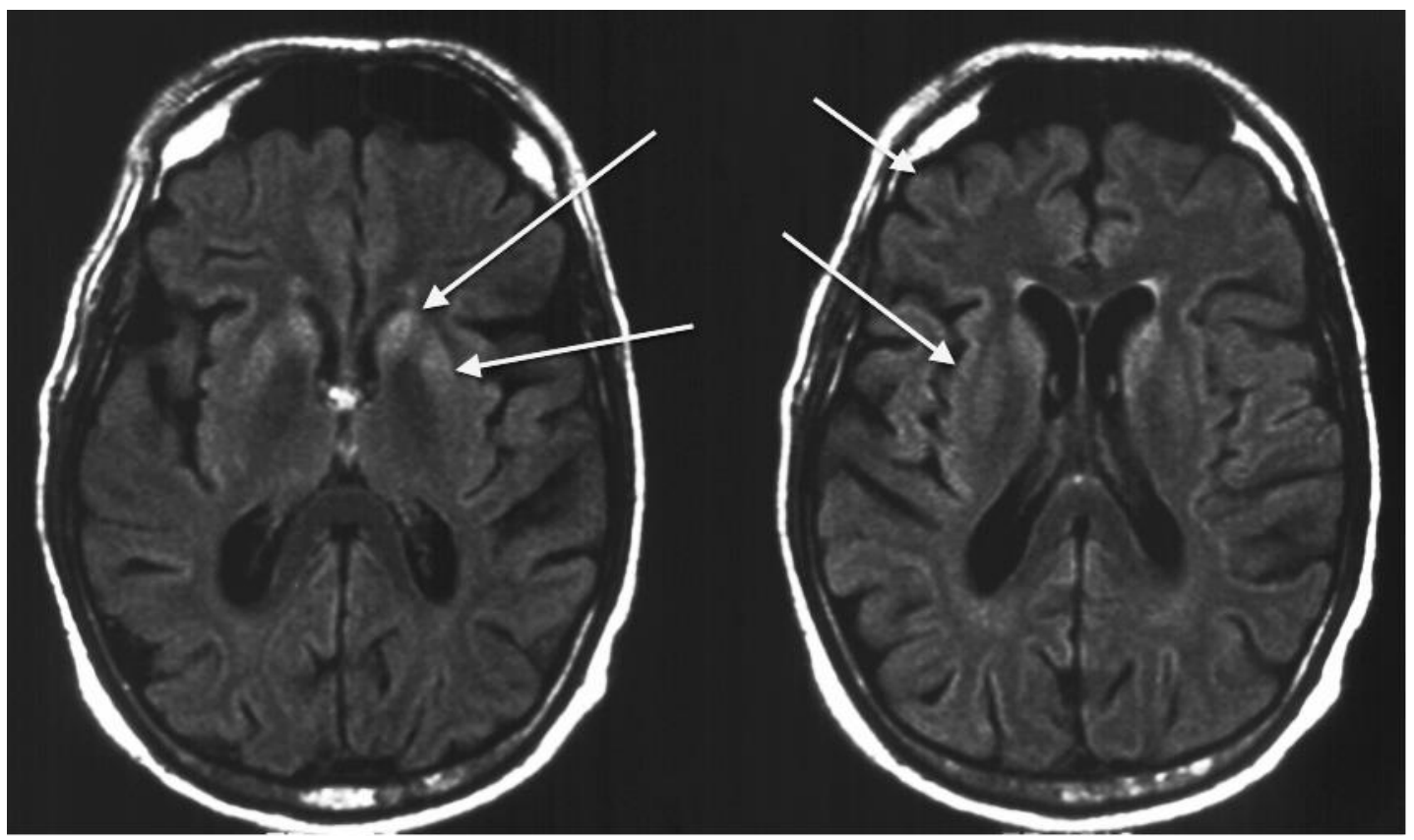

Abbildung 1.5 Typische MRT-Veränderungen am Beispiel eines Patienten mit der E200K-Mutation in der DWI mit Nachweis deutlicher Hyperintensitäten in den Basalganglien, im Thalamus und Kortex

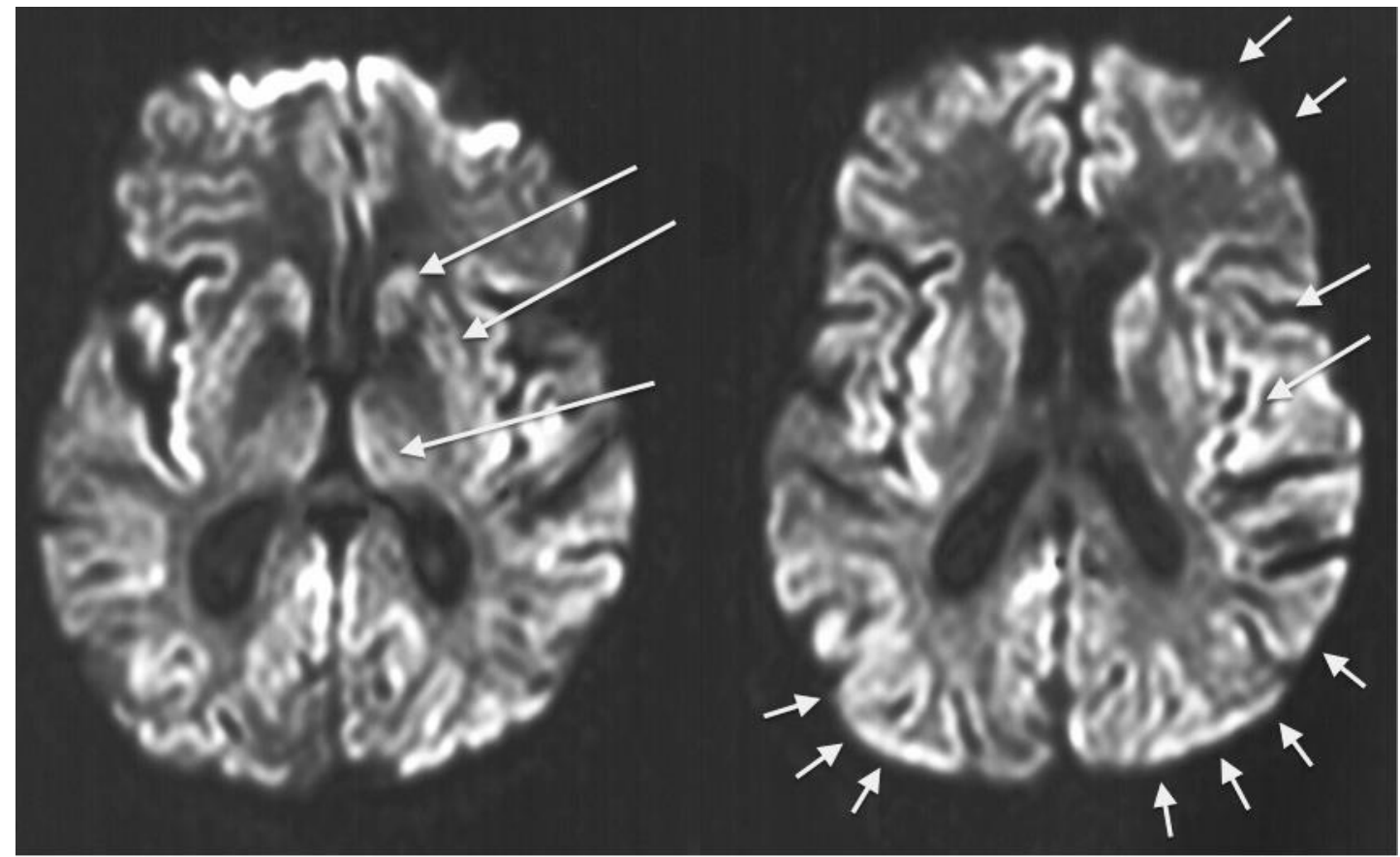




\subsubsection{Neuropathologische Untersuchung}

Eine neuropathologische Untersuchung ist zur Stellung der „gesicherten“ Diagnose einer Prionerkrankung nach wie vor unerlässlich. Gewebe kann entweder durch eine Hirnbiopsie oder im Rahmen einer Autopsie nach dem Tod gewonnen werden. Im Gehirn von betroffenen Patienten finden sich charakteristische Veränderungen. Hierzu gehören die typischen spongiformen Veränderungen durch Vakuolenbildung im Neuropil (dem zwischen Nerven- und Gliazellen liegenden „Neurofilz“), der neuronale Verlust sowie die astrozytäre Gliose (Budka et al. 1995). Typische entzündliche zelluläre Reaktionen sucht man vergeblich. Die mikroskopischen Veränderungen können in vielen Bereichen des Gehirns auftreten, finden sich jedoch am häufigsten im Neokortex, im Thalamus, in den Basalganglien und dem Kleinhirn (Kretzschmar et al. 1996). Die höchste Spezifität der lichtmikroskopisch erkennbaren morphologischen Veränderungen wird für die spongiformen Veränderungen beschrieben. Bei Prionerkrankungen finden sich meist kleine intrazelluläre Vakuolen in den Nervenfortsätzen, die gruppiert oder einzeln liegen können. Darüber hinaus gibt es bei bestimmten Subtypen der CJK auch konfluierende Vakuolenbildungen (Kretzschmar und Feiden 2002). Keine der lichtmikroskopisch erkennbaren neuropathologischen Veränderungen weist eine hohe Spezifität auf, da auch andere Erkrankungen des Gehirns mit Nervenzellverlust, astrozytärer Gliose und spongiformen Veränderungen einhergehen können. Der direkte Nachweis des pathologischen Prionproteins ist die verlässlichste Untersuchung im Hinblick auf eine sichere neuropathologische Diagnose (Kretzschmar et al. 1996). Pathologische PrPscAblagerungen lassen sich bei wenigen Patienten in Form von Kuru-Plaques bereits lichtmikroskopisch nachweisen. Kleinere Ablagerungen sind jedoch erst durch Untersuchungsverfahren wie z.B. der Westernblot, PET-Blot ([engl.] paraffin-embedded tissue = in Paraffin eingebettetes Gewebe) oder Immunhistochemie nachzuweisen. Letztere sind aufgrund der Durchführbarkeit an formalin-fixiertem Gewebe in der Praxis die am häufigsten verwendeten Methoden. Mit Antikörpern gegen das Prionprotein können PrionProtein-Ablagerungen und - nach Vorbehandlung des Gewebes mit denaturierenden Substanzen - immunhistochemisch sichtbar gemacht werden. 


\subsubsection{Genetische Untersuchung}

Anhand einer Blut- oder Gewebeuntersuchung kann durch Gewinnung von DNA eine Sequenzierung des PRNP und so eine mögliche Mutation nachgewiesen werden. Abbildung 1.4 zeigt eine schematische Abbildung des PRNP und die Lokalisation der häufigsten Mutationsformen.

\subsection{Diagnosekriterien}

Die Klassifikation der sCJK erfolgt basierend auf der klinischen Symptomatik und Befunden der apparativen Diagnostik in sichere, wahrscheinliche und mögliche Fälle. Für die Diagnosestellung einer sicheren CJK ist nach wie vor eine neuropathologische Untersuchung post-mortem oder durch eine Biopsie notwendig. Um eine Einschätzung der Diagnosewahrscheinlichkeit vor dem Tod zu ermöglichen, wurden folgende klinische Diagnosekriterien nach Ausschluss aller behandelbaren Differentialdiagnosen etabliert:

Tabelle 1.4 Diagnosekriterien der sCJK (World Health Organisation 1998; Zerr et al. 2000; Zerr et al. 2009)

\begin{tabular}{|l|l|}
\hline \multicolumn{2}{|l|}{ I Rapid progressive Demenz } \\
\hline II Klinische Symptome & $\begin{array}{l}\text { 1. Myoklonien } \\
\text { 2. visuelle/zerebelläre Symptome } \\
\text { 3. extrapyramidale/pyramidale Symptome } \\
\text { 4. akinetischer Mutismus }\end{array}$ \\
\hline III Apparative Diagnostik & $\begin{array}{l}\text { EEG mit typischen PSWC } \\
\text { 14-3-3-Nachweis im Liquor } \\
\text { MRT mit typischen Hyperintensitäten* }\end{array}$ \\
\hline \hline Wahrscheinliche CJK & $\begin{array}{l}\text { I und } \geq 2 \text { aus II und } \geq 1 \text { aus III } \\
\text { I und } \geq 2 \text { aus II bei einer Erkrankungsdauer }<2 \text { Jahre }\end{array}$ \\
\hline
\end{tabular}

* Signalalterationen im Nucleus caudatus und Putamen ODER mindestens zwei kortikalen Regionen (temporal, parietal, occipital) in der FLAIR oder DWI 
Nachdem typische MRT-Veränderungen bei CJK-Patienten im Sinne von hyperintensen Signalalterationen des Cortex und der Basalganglien bereits seit einiger Zeit beschrieben wurden, erhielten sie schließlich 2009 aufgrund der hohen Sensitivität Einzug in die Diagnosekriterien. Die Kombination aller drei apparativen Untersuchungen hat die Sensitivität und Spezifität der Diagnosestellung der sCJK deutlich erhöht (Zerr et al. 2009).

\subsection{Fragestellung}

Viele Patienten mit der E200K- und V210I-Mutation werden als sporadische CJK klassifiziert und insbesondere bei negativer Familienanamnese nur zufällig im Rahmen einer genetischen Untersuchung als genetische Krankheitsfälle identifiziert. Auch die Ergebnisse der gängigen apparativen Diagnostik wie EEG sowie der Nachweis der Proteine 14-3-3 im Liquor scheinen sich nicht von denen der SCJK zu unterscheiden. Mehrere Falldarstellungen sowie wenige kleinere Studien haben zudem Signalalterationen in Basalganglien und Kortex beschrieben. Die Fallzahlen sind jedoch klein und eine genaue Charakterisierung der MRT-Veränderungen bei Patienten mit der E200K- und V210IMutation gibt es bisher nicht.

Ziel dieser Arbeit ist, die Häufigkeit von MRT-Veränderungen bei gCJK-Patienten mit der E200K- oder V210I-Mutation zu untersuchen und das Verteilungsmuster der Signalalterationen zu charakterisieren. Insbesondere soll dabei auch die Anwendbarkeit der neu formulierten SCJK-MRT-Kriterien für die gCJK evaluiert werden. Darüber hinaus sollte die Sensitivität der MRT-Diagnostik bei gCJK im Vergleich mit anderen apparativen Untersuchungen wie dem Nachweis der Proteine 14-3-3 und dem EEG analysiert werden. 


\section{Material und Methoden}

Seit 1993 werden in Deutschland alle Verdachtsfälle einer Prionerkrankung dem Nationalen Referenzzentrum (NRZ) für TSE in Göttingen gemeldet. Dabei werden klinische Daten der Patienten gesammelt, um epidemiologische Auswertungen durchzuführen, mögliche neue Formen der Erkrankung, insbesondere die vCJK, zu erkennen, Verbesserungen der diagnostischen Möglichkeiten zu erarbeiten und Ringversuche mit anderen Studienzentren zu ermöglichen. Die Mitarbeiter des Referenzzentrums beraten zudem Ärzte, Krankenhäuser und Gesundheitsämter in allen Aspekten der Prionerkrankungen. In diesem Rahmen werden auch fast alle Patienten mit dem Verdacht auf eine Prionerkrankung von den Ärzten des Referenzzentrums vor Ort in den zuweisenden Kliniken untersucht und mit Hilfe eines standardisierten Erfassungsbogen Daten zur Krankengeschichte und möglichen Risikofaktoren erhoben. Die Befunde aller durchgeführten apparativen Zusatzuntersuchungen, insbesondere des EEGs, der cMRT und der Liquoruntersuchung werden durch einen Arzt des NRZ auf das Vorliegen CJK-typischer Veränderungen geprüft. Die Bestimmung der Proteine 14-3-3 erfolgt im Labor des NRZ in Göttingen. Diese epidemiologische Arbeit wird auf ähnliche Art und Weise in fast allen europäischen und vielen außereuropäischen Ländern durchgeführt. Aufgrund der Seltenheit von Prionerkrankungen erfolgt eine enge Zusammenarbeit der Referenzzentren, unter anderem dem Centro de Referencia de Encefalopatías Espongiformes Transmisibles in Buenos Aires, Argentinien.

\subsection{Patientenkollektiv}

Das Kollektiv der vorliegenden Arbeit setzt sich aus Patienten zusammen, die im Zeitraum von 1996 bis 2008 den Nationalen Referenzzentren für transmissible spongiforme Enzephalopathien in Deutschland und Argentinien zugewiesen wurden. Alle Patienten hatten die Diagnose einer „sicheren“ oder „wahrscheinlichen“ CJK erhalten. Im Rahmen der genetischen Untersuchung wurde bei allen in das Patientenkollektiv eingeschlossenen Fällen eine Mutation des PRNP nachgewiesen. Die beiden häufigsten Mutationen stellten hierbei die E200K- und die V210I-Mutation dar. Andere Mutationen des PRNP waren zu selten und wurden dementsprechend nicht in das Patientenkollektiv der Studie eingeschlossen. Im Rahmen der epidemiologischen Arbeit des jeweiligen Landes 
wurden die Ergebnisse der verschiedenen Untersuchungen aller Patienten gesammelt und entsprechende Daten erhoben.

Die genauen Einschlusskriterien für die vorliegende Arbeit lauteten:

- Klinische Diagnose einer Creutzfeldt-Jakob-Erkrankung

- Nachweis der E200K- oder V210I-Mutation im PRNP

- Vorliegen einer kraniellen MRT mit FLAIR und/oder DWI

- Bekannter PRNP-Codon129-Genotyp

\subsection{Kontrollkollektiv}

Für die Bildung des Kontrollkollektivs wurden Patienten mit der „sicheren“ oder „wahrscheinlichen“ Diagnose einer sporadischen CJK ausgewählt, bei denen eine Mutation des PRNP ausgeschlossen werden konnte. Um ein möglichst ähnliches Kollektiv zu erstellen, wurden die Kontrollen hinsichtlich der wichtigsten Einflussfaktoren angepasst. Zusätzlich musste von allen Patienten des Kontrollkollektivs ein kraniales MRT mit den sensitiven Wichtungen FLAIR und/oder DWI zur Evaluation vorliegen. Da sich die MRTBefunde bei CJK im Verlauf der Erkrankung ändern können wurde darauf geachtet, dass die Kontrollen dem Patientenkollektiv bezüglich des Durchführungszeitpunktes der MRT im Verhältnis zur gesamten Krankheitsdauer (erstes, zweites oder drittes Krankheitsdrittel) angeglichen wurden. Jedem gCJK-Patienten wurde hinsichtlich Polymorphismus am Codon 129 des PRNP, des Zeitpunktes der MRT-Untersuchung, des Geschlechts und des Alters eine passende Kontrolle zugeordnet. Dementsprechend unterschieden sich die beiden Kollektive bezüglich der verschiedenen Merkmale nach Analyse mittels Student's t-Test nicht signifikant voneinander.

Die genauen Einschlusskriterien für die Einbeziehung in das Kontrollkollektiv lauteten:

- „Definitive“ oder „wahrscheinliche“ Diagnose einer sporadischen CJK

- Ausschluss einer Mutation im PRNP

- Vorliegen einer cMRT mit FLAIR und/oder DWI

- Bekannter PRNP-Codon129-Genotyp 
Insgesamt wurde also jedem Patienten ein Kontrollpatient zugewiesen, so dass das Kontrollkollektiv ebenfalls aus 35 Patienten bestand.

Zur Bestimmung der Spezifität der MRT-Kriterien wurde ein Kollektiv von 141 Patienten verwendet, die dem Referenzzentrum zunächst mit der Verdachtsdiagnose einer CJK gemeldet worden waren, bei denen aber schließlich eine andere Diagnose gestellt werden konnte (Zerr et al. 2009).

\subsection{Genetische Testung}

Eine genetische Untersuchung erfolgte nur nach ausführlicher Aufklärung und schriftlicher Einwilligung des Patienten oder des gesetzlichen Betreuers. Die Proben der deutschen Patienten wurden am Institut für Neuropathologie der LMU München untersucht. Die genetische Testung der argentinischen Patienten wurde am dortigen Referenzzentrum, namentlich der Abteilung für Neuropathologie durchgeführt. Von allen Patienten wurde Vollblut verwendet, um DNA zu extrahieren. Anschließend wurde das PRNP durch Polymerase-Kettenreaktion (PCR) amplifiziert und anschließend durch die Restriktionsnuklease Nspl auf vorliegende Mutationen untersucht (Windl et al. 1999). Die E200K-Mutation konnte bei 23 Patienten nachgewiesen werden, die anderen 12 Patienten wiesen die V210I-Mutation auf.

Der Polymorphismus am Codon 129 wurde entweder im Rahmen der Totalsequenzierung durch direkte Sequenzierung oder durch Restriktionsfragmentlängenpolymorphismus (RFLP) bestimmt.

\subsection{Diagnostische Untersuchungen}

\subsubsection{Liquordiagnostik}

Die Lumbalpunktion erfolgte zum Ausschluss anderer pathologischer Vorgänge wie z.B. entzündlichen ZNS-Erkrankungen. Die Routineparameter wie Zellzahl, Gesamteiweiß, Laktat und spezifische Antikörper-Indices wurden in der jeweiligen Klinik bestimmt. Bei begründetem Verdacht auf das Vorliegen einer Prionerkrankung, erfolgte die Zusendung 
der Proben an das jeweilige Nationale Referenzzentrum zur Bestimmung der Proteine 14-3-3 mittels Western-Blot. Das Verfahren wird für jede Liquorprobe zweimal wiederholt um mögliche Fehlerquellen zu reduzieren (Zerr et al. 2000). Darüber hinaus erfolgte die Bestimmung der weiteren Zelldestruktionsmarker TAU, S100b und NSE mittels standardisierter ELISA. Der Cut-off Wert für erhöhtes TAU-Protein wurde mit $1200 \mathrm{pg} / \mathrm{ml}$ festgesetzt.

\subsubsection{EEG}

Die Anfertigung der EEG-Kurve fand im Rahmen der Routinediagnostik in verschiedenen Kliniken und an verschiedenen Geräten statt. Auszüge der Untersuchung oder die gesamte Untersuchung wurden in Papierformat oder digital auf CD an das Nationale Referenzzentrum des jeweiligen Landes geschickt und von dort tätigen Neurologen hinsichtlich des Vorliegens typischer PSWC untersucht. Dabei wurden die von Steinhoff definierten Kriterien angewandt, welche unter 1.6.2 aufgeführt sind (Steinhoff et al. 1996).

\subsubsection{Neuropathologische Diagnostik}

Im Falle einer erfolgten Hirnbiopsie oder Autopsie nach dem Tod, wurde eine neuropathologische Untersuchung des Hirngewebes am jeweiligen neuropathologischen Referenzzentrum durchgeführt. Neben der lichtmikroskopischen Untersuchung zum Nachweis der typischen pathologischen Veränderungen (spongiforme Degeneration, Nervenzellverlust und astrozytärer Gliose), erfolgte der spezifische Nachweis des Prionproteins. Darüber hinaus wurde mittels Western-Blot-Verfahren der Prionprotein-Typ (Typ 1 oder Typ 2) bestimmt. 


\subsubsection{MRT}

\subsubsection{Akquirierung}

Die MRT-Aufnahmen wurden im Rahmen der normalen Routinediagnostik veranlasst und in verschiedenen Krankenhäusern und radiologischen Praxen an unterschiedlichen Geräten angefertigt. Insbesondere kamen dabei Geräte von Siemens, Philips, Marconi und General Electric zum Einsatz. Die Feldstärke lag zwischen 0,5 und 3 Tesla, wobei die meisten Untersuchungen bei 1,5 Tesla durchgeführt wurden. Da die MRTUntersuchungen an verschiedenen Orten durchgeführt wurden, gab es kein einheitliches Studienprotokoll. Die Auswahl der durchgeführten Wichtungen und der b-Werte für die Diffusionswichtung (0,333, 666, 1000 (am häufigsten) und $1500 \mathrm{~s} / \mathrm{mm}^{2}$ ) waren abhängig von den Standards der jeweiligen Klinik.

Im Rahmen der epidemiologischen Arbeit der Referenzzentren wurden die MRT-Bilder entweder als Hardcopy oder digital auf CD-ROM gesammelt. Die meisten Bilder standen als Hardcopy zur Verfügung. Bei einigen wenigen Patienten lagen mehrere MRTVerlaufsuntersuchungen vor. In der vorliegenden Arbeit wurde daher nur die erste Untersuchung berücksichtigt.

\subsubsection{Auswertung}

Zur Auswertung der MRT-Bilder wurde ein standardisiertes Protokoll verwendet, welches bereits in früheren Studien zum Einsatz kam (Abbildung 2.1). Sieben kortikale Regionen (namentlich der Gyrus cinguli, die Inselregion, der Hippocampus, der frontale, parietale, temporale und occipitale Gyrus) sowie die Basalganglien (Nucleus caudatus, Putamen und Globus pallidus), der Thalamus und der zerebelläre Kortex wurden auf das Vorkommen von hyperintensen Signalsteigerungen hin untersucht. Zudem erfolgte eine genauere Untergliederung des Thalamus in die Regionen antero-lateraler Nucleus, dorso-medialer Nucleus und Pulvinar und die Evaluation auf das Vorliegen oder Fehlen des von der vCJK bekannten pulvinar sign (Meissner et al. 2009; Zerr et al. 2009). Die Bewertung der verschiedenen Hirnregionen hinsichtlich des Vorliegens von Hyperintensitäten erfolgte im Vergleich zu isointensen, nicht involvierten Hirnregionen. Die Methode ist somit semiquantitativ; weitere quantitative Untersuchungen erfolgten nicht. Jede Sequenz wurde einzeln bewertet, angefangen mit der am wenigsten sensitiven T2Wichtung, gefolgt von FLAIR und zuletzt, sofern vorhanden, der DWI. Für die weitere 
Beurteilung und Statistik wurden nur die beiden sensitivsten Wichtungen FLAIR und DWI berücksichtigt.

Die Qualität der Bilder wurde in Schulnoten von 1 bis 6 bewertet $(1=$ exzellent, $6=$ schlecht) und alle MRT-Aufnahmen mit einer Note schlechter als 4 aus der Studie ausgeschlossen.

Die Auswertungen wurden von zwei erfahrenen Neuroradiologen aus Deutschland und Argentinien vorgenommen. Diese hatten zum Zeitpunkt der MRT-Bewertung keinerlei klinische oder genetische Informationen über die Patienten, wussten aber sehr wohl, dass das Vorliegen einer Creutzfeldt-Jakob-Erkrankung eine mögliche Differentialdiagnose war. Am Ende der Bewertung folgte die Prüfung, ob die definierten MRT-Kriterien der sCJK für ein „typisches“ MRT zutrafen oder nicht (Zerr et al. 2009). 
Abbildung 2.1 Standardisiertes Protokoll zur Auswertung der MRT-Aufnahmen

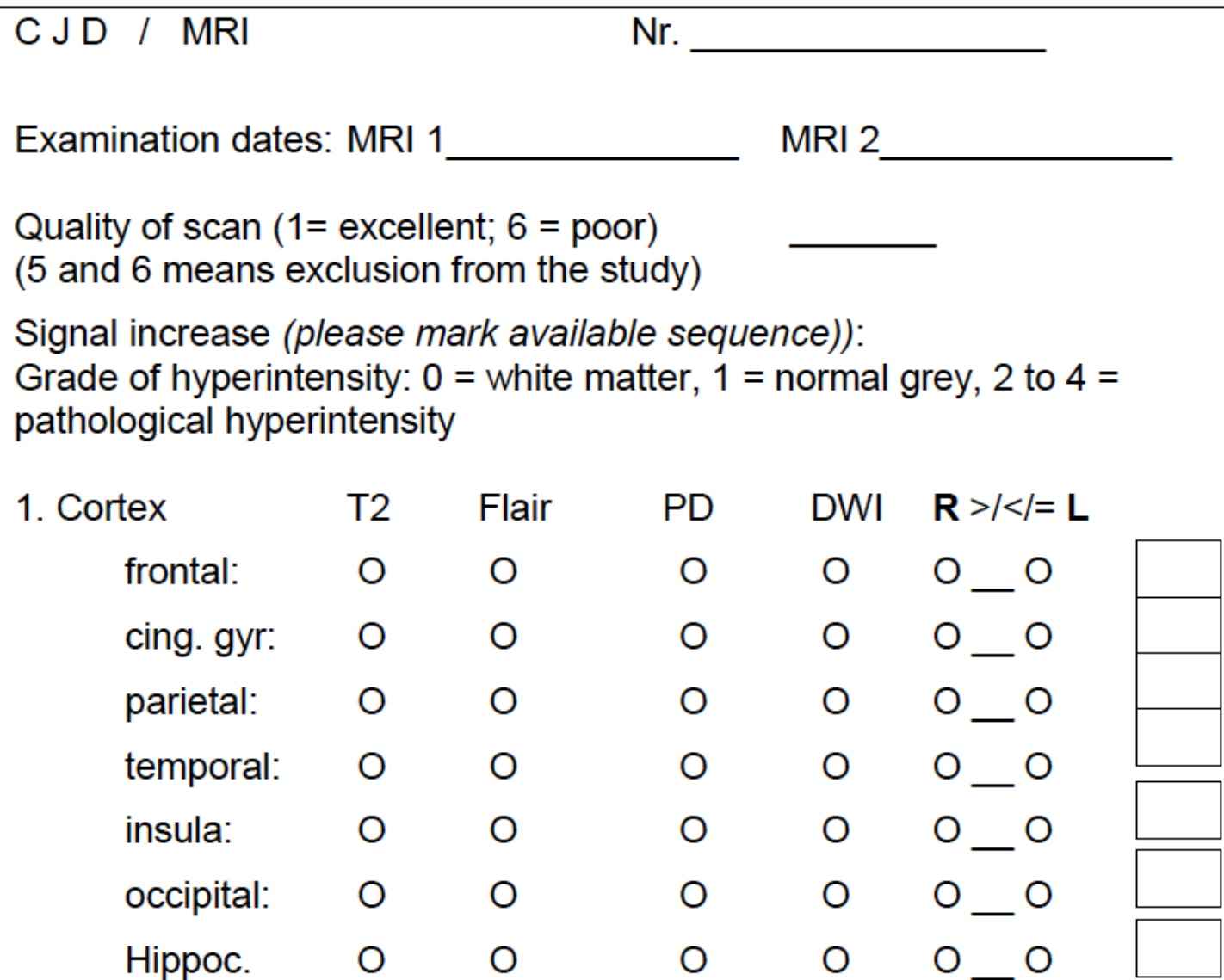

2. Basal ganglia

$\begin{array}{llllll}\text { Pallidum: } & 0 & 0 & 0 & 0 & 0 \\ \text { Putamen: } & 0 & 0 & 0 & 0 & 0 \\ \text { Caudate } & 0 & 0 & 0 & 0 & 0\end{array}$

3. Thalamus

$\begin{array}{llllll}\text { AL nuclei: } & 0 & 0 & 0 & 0 & 0 \ldots 0 \\ \text { DM nuclei: } & 0 & 0 & 0 & 0 & 0 \ldots 0 \\ \text { Pulvinar: } & 0 & 0 & 0 & 0 & 0 \ldots 0\end{array}$

Pulvinar sign: $\quad \mathrm{O} \quad \mathrm{O} \quad \mathrm{O} \quad \mathrm{O} \quad \mathrm{O}$
4. Cerebellum:
$0 \quad 0$
O
$\mathrm{O} \quad \mathrm{O}_{-} \mathrm{O}$

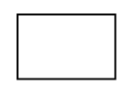

Remarks: 


\subsection{Statistische Analyse}

Die statistische Auswertung der Daten erfolgt mit Hilfe des Statistikprogramms SPSS 20.0 für Mac. Die deskriptive Statistik wurde im Betriebssystem Excel erstellt. Zur Berechnung von Unterschieden der kategorischen und kontinuierlichen Variablen wurden der $\chi 2$-Test, der exakte Test nach Fisher sowie der Mann-Whitney-Test/Student's t-Test verwendet. Die Bestimmung der Interrater-Reliabilität erfolgte mit Hilfe des KappaTests. P-Werte von $<0,05$ wurden als statistisch signifikant betrachtet. 


\section{Ergebnisse}

\subsection{Patientenkollektiv}

Insgesamt 35 Patienten entsprachen den Einschlusskriterien. Von diesen Patienten wiesen 23 die E200K-Mutation auf, bei den restlichen zwölf Patienten konnte die V210IMutation identifiziert werden. Da bei sechs Patienten die Qualität der MRT-Bilder mit der Note "4“ oder schlechter bewertet wurde, erfolgte der Ausschluss dieser Patienten aus der vorliegenden Studie. Vier dieser Patienten hatten die E200K-Mutation, die anderen zwei die V210I-Mutation.

Insgesamt blieben also 29 Patienten in der Studie eingeschlossen, deren MRT-Bilder und Daten von entsprechender Qualität waren und somit weiter ausgewertet werden konnten. 19 Patienten mit der E200K-Mutation und zehn Patienten mit der V210I-Mutation bildeten das Patientenkollektiv. Alle V210I-Patienten und elf der 19 E200K-Patienten kamen aus Deutschland, während die restlichen acht E200K-Patienten aus Argentinien stammten. Die Altersverteilung zu Erkrankungsbeginn lag zwischen 44 und 80 Jahren, bei einem medianen Alter bei Erkrankung von 61 Jahren. Die Geschlechterverteilung im gCJK-Kollektiv zeigte ein Verhältnis von 13 Männern zu 16 Frauen. Wie zu erwarten, lag bei der Mehrzahl der Patienten der MM-Genotyp am Codon 129 vor ( $\mathrm{n}=16)$. Zwölf Patienten wiesen den heterozygoten MV-Genotyp und nur ein Patient aus der Gruppe der V210I-Mutationsträger war homozygot für Valin (VV). Fünf Patienten hatten eine positive Familienanamnese für CJK. Bei weiteren fünf Patienten gab es Verwandte ersten Grades, welche an einer rasch fortschreitenden neurologischen Erkrankung verstorben waren, ohne dass die Diagnose einer CJK gestellt worden war.

Da das SCJK-Kontrollkollektiv anhand definierter Kriterien dem gCJK-Kollektiv angepasst wurde, gab es keinen signifikanten Unterschied in der Geschlechterverteilung oder der Verteilung des Genotyps am Codon 129. Das mediane Alter bei Erkrankung im sCJKKontrollkollektiv lag bei 61 Jahren und unterschied sich somit nicht signifikant von dem der gCJK-Patienten.

Die Krankheitsdauer betrug bei den E200K-Patienten im Median sechs Monate, bei den V210I-Patienten 5 Monate. Im Vergleich zum Patientenkollektiv war die mediane Dauer der Erkrankung im Kontrollkollektiv mit neun Monaten etwas länger.

Die Patientencharakteristika - auch aufgeschlüsselt nach Mutationen - sind nochmals in Tabelle 3.1 zusammengefasst. 
Tabelle 3.1 Übersichtstabelle der Charakteristika der untersuchten Kollektive

\begin{tabular}{|lc|c|c|c|c|}
\hline & & E200K & V210I & $\mathrm{K}_{\mathrm{gCJK}}$ & $\mathrm{K}_{\text {sCJK }}$ \\
\hline \hline \multicolumn{2}{|l|}{ Anzahl der Patienten } & 19 & 10 & 29 & 29 \\
\hline Geschlecht & männlich & 8 & 5 & 13 & 13 \\
& weiblich & 11 & 5 & 16 & 16 \\
\hline Alter (Jahre) & Median & 61 & 60 & 61 & 61 \\
\hline Codon 129 & MM & 10 & 6 & 16 & 16 \\
& MV & 9 & 3 & 12 & 12 \\
\hline DV & 0 & 1 & 1 & 9 \\
\hline
\end{tabular}

\subsection{Magnetresonanztomographie}

\subsubsection{MRT-Datensatz}

Von den 35 Patienten, die entweder die E200K- oder V210I-Mutation im PRNP aufwiesen, erfüllten 29 Patienten die Einschlusskriterien, so dass eine weitere Analyse der Daten erfolgte. Die sechs übrigen Patienten wurden entweder aufgrund der schlechten Qualität der MRT-Bilder ausgeschlossen (Note schlechter als 4) oder weil keine der sensitiven Wichtungen FLAIR oder DWI durchgeführt worden war.

Insgesamt wurde die Qualität der MRT-Bilder im sCJK-Kollektiv wie folgt bewertet: vier Patienten (14\%) „exzellent“ (Note1), acht Patienten (28\%) „gut“ (Note 2), 15 Patienten (52\%) „befriedigend“ (Note 3), zwei Patienten (7\%) „ausreichend“ (Note 4). Die Qualität der MRT-Aufnahme in der sCJK-Kontrollgruppe war vergleichbar. Acht Patienten (28\%) erhielten die Note 1, sechs Patienten (21\%) die Note 2, acht Patienten (28\%) die Note 3 und sieben Patienten (24\%) die Note 4.

Bei allen 29 eingeschlossenen gCJK-Patienten waren MRT-Aufnahmen mit FLAIRSequenzen vorhanden. Die DWI-Wichtung wurde bei insgesamt 15 Patienten des gCJK- 
Kollektivs durchgeführt, davon bei zwölf Patienten mit der E200K-Mutation und drei Patienten mit der V210I-Mutation. T2-Aufnahmen waren bei 26 Patienten durchgeführt worden (18 E200K und acht V210I), während PD-Aufnahmen nur bei insgesamt drei Patienten Teil des Untersuchungsprotokolls waren.

Da FLAIR und DWI nachweislich die sensitivsten Untersuchungssequenzen der MRT in der Diagnostik der CJK sind und auch nur diese beiden Sequenzen in die etablierten diagnostischen Kriterien der sporadischen CJK eingehen, wurden die T2- und PDWichtungen nicht in die weiteren Analysen einbezogen.

Die Mehrzahl der Patienten erhielt früh nach dem Auftreten erster Symptome die MRTUntersuchung. Der Zeitpunkt der MRT-Untersuchung lag im Median bei 2,7 Monaten nach Krankheitsbeginn mit einer Spannbreite von 0,5 bis 14 Monaten. Betrachtete man den Zeitpunkt der MRT im Verhältnis zur gesamten Krankheitsdauer des einzelnen Patienten, so fand bei 14 Patienten die MRT im ersten Drittel der Erkrankung statt, bei vier Patienten im zweiten Drittel und acht Patienten wurden im letzten Drittel der Erkrankungsdauer untersucht. Bei drei Patienten lag keine Information über das Sterbedatum vor, so dass eine Bestimmung der Krankheitsdauer nicht möglich war.

Nur bei zwei Patienten wurde eine MRT-Verlaufsuntersuchung durchgeführt, daher erfolgte keine weitere Auswertung dieser Bilder.

Auch im sCJK-Kontrollkollektiv waren bei allen 29 Patienten MRT-Untersuchungen inklusive der FLAIR-Wichtung durchgeführt worden. Die sensitivere DWI lag bei 13 Patienten des Kontrollkollektivs vor. Die übrigen Sequenzen T2 und PD wurden bei 26 und vier von 29 Patienten durchgeführt und wie auch die Aufnahmen des Kollektivs der gCJK-Patienten keiner weiteren Analyse zugeführt. Vom Krankheitsbeginn bis zur Durchführung der MRT vergingen im Mittel 4,8 Monate bei einer Spannbreite von 0,4 bis 28 Monaten und einem Median von 3,1 Monaten. Einen wichtigen Aspekt in der Auswahl der sCJK-Patienten für das Kontrollkollektiv stellte der Zeitpunkt der MRTUntersuchung im Verhältnis zur Gesamtkrankheitsdauer dar. Die sCJK-Patienten wurden den gCJK-Patienten diesbezüglich gematched. Bei neun Patienten erfolgte die MRTBildgebung im ersten Drittel der Erkrankung, bei zwölf Patienten im zweiten Drittel und acht Patienten wurden im letzten Drittel untersucht.

Tabelle 3.3 gibt einen Überblick über die vorhandenen MRT-Datensätze. 
Tabelle 3.2 Übersichtstabelle der MRT-Untersuchungen der untersuchten Kollektive

\begin{tabular}{|l|c|c|c|c|}
\hline & E200K & V210I & $\mathrm{K}_{\mathrm{gCJK}}$ & $\mathrm{K}_{\text {sCJK }}$ \\
\hline FLAIR (Anzahl n, \%) & $19(100 \%)$ & $10(100 \%)$ & $29(100 \%)$ & $29(100 \%)$ \\
\hline DWI (Anzahl n, \%) & $12(63 \%)$ & $3(30 \%)$ & $15(52 \%)$ & $13(45 \%)$ \\
\hline $\begin{array}{l}\text { Zeitpunkt MRT nach } \\
\text { Krankheitsbeginn } \\
\text { (Median in Monaten) }\end{array}$ & 3,1 & 2,0 & 2,7 & 3,1 \\
\hline
\end{tabular}

\subsubsection{Signalalterationen in der FLAIR-Wichtung}

In beiden Kollektiven lagen für alle 29 Patienten FLAIR-Aufnahmen vor und wurden auf das Vorkommen von Hyperintensitäten in den definierten kortikalen und subkortikalen Regionen untersucht.

Sowohl im gCJK-Kollektiv als auch im sCJK-Kollektiv waren Signalalterationen häufig. Es ließen sich keine signifikanten Unterschiede bezüglich der Häufigkeit von pathologischen Hyperintensitäten oder deren Verteilungsmuster zwischen den untersuchten Kollektiven feststellen. Am häufigsten fanden sich Auffälligkeiten im Bereich der Basalganglien. 52\% der sporadischen CJK Fälle und 55\% der genetischen CJK-Patienten zeigten Hyperintensitäten im Putamen. Der Nucleus caudatus war mit 66\% im gCJK-Kollektiv und mit 55\% im sCJK-Kontrollkollektiv tendenziell noch häufiger betroffen. Kortikale Hyperintensitäten ließen sich insbesondere im Gyrus frontalis (gCJK 59\%, sCJK 45\%) und Gyrus cinguli (gCJK 45\%, sCJK 38\%) darstellen, gefolgt von der Parietal- und Temporalregion.

Weder im sCJK-Kollektiv noch im gCJK-Kollektiv konnten Hyperintensitäten im Pallidum oder antero-lateralen Nucleus des Thalamus nachgewiesen werden. Annähernd statistische Signifikanz erreichte der Vergleich von Hyperintensitäten im Cerebellum. Während im Patientenkollektiv keine Hyperintensitäten in dieser Hirnregion gefunden werden konnten, zeigten $17 \%$ des Kontrollkollektivs Signalalterationen in diesem Bereich $(p=0,052)$. 
Tabelle 3.3 fasst die Ergebnisse für die einzelnen Regionen nochmals zusammen.

Tabelle 3.3 Überblick über die Signalalterationen in den verschiedenen Hirnregionen in der FLAIR-Wichtung

\begin{tabular}{|c|c|c|}
\hline Hirnregion & $\begin{array}{l}\mathrm{gCJK} \\
\mathrm{n}=29\end{array}$ & $\begin{array}{l}\mathrm{sCJK} \\
\mathrm{n}=29\end{array}$ \\
\hline \multicolumn{3}{|l|}{ Kortex } \\
\hline frontal & $59 \%(17)$ & $45 \%(13)$ \\
\hline Gyrus cinguli & $45 \%(13)$ & $38 \%(11)$ \\
\hline parietal & $31 \%(9)$ & $34 \%(10)$ \\
\hline pemporal & $34 \%(10)$ & $31 \%(9)$ \\
\hline Insula & $31 \%(9)$ & $17 \%(5)$ \\
\hline occipital & $14 \%(4)$ & $17 \%(5)$ \\
\hline Hippocampus & $28 \%(8)$ & $17 \%(5)$ \\
\hline \multicolumn{3}{|l|}{ Basalganglien } \\
\hline Pallidum & $0 \%(0)$ & $0 \%(0)$ \\
\hline Putamen & $55 \%(16)$ & $52 \%(15)$ \\
\hline Nucleus caudatus & $66 \%(19)$ & $55 \%(16)$ \\
\hline Thalamus & $7 \%(2)$ & $0 \%(0)$ \\
\hline Nucleus AL & $0 \%(0)$ & $0 \%(0)$ \\
\hline Nucleus DM & $4 \%(1)$ & $10 \%(3)$ \\
\hline Pulvinar & $4 \%(1)$ & $10 \%(3)$ \\
\hline Hockeystick & $0 \%(0)$ & $4 \%(1)$ \\
\hline Cerebellum & $0 \%(0)$ & $17 \%(5)$ \\
\hline
\end{tabular}




\subsubsection{Signalalterationen in der DWI-Wichtung}

Bei 15 der gCJK-Patienten (52\%) und 13 der sCJK-Patienten (45\%) lagen DWIAufnahmen zur Auswertung vor. Insgesamt konnten in dieser Wichtung bei beiden Kollektiven häufiger Hyperintensitäten dokumentiert werden als in der FLAIR-Wichtung. Der Unterschied im Vergleich zur FLAIR machte sich insbesondere bei Betrachtung der verschiedenen kortikalen Regionen bemerkbar. Zwar waren der frontale und parietale Kortex sowie der Gyrus cinguli weiterhin häufig betroffen, es ließen sich jedoch ebenso häufig nun auch Hyperintensitäten im Bereich des temporalen, insulären und occipitalen Kortex feststellen. Wie bereits in der FLAIR-Wichtung fanden sich weder im sCJKKollektiv, noch im sCJK-Kollektiv Auffälligkeiten im Pallidum.

Der Vergleich der beiden Kollektive in der DWI hinsichtlich der Frequenz und des Verteilungsmusters der Signalalterationen erbrachte keinen statistisch signifikanten Unterschied. Es fiel jedoch auf, dass in der sCJK-Kontrollgruppe tendenziell häufiger Hyperintensitäten in der Parietalregion zu finden waren $(\mathrm{p}=0,055)$.

Tabelle 3.4 gibt fasst die Ergebnisse zusammen. 
Tabelle 3.4 Überblick über die Signalalterationen in den verschiedenen Hirnregionen in der DWI

\begin{tabular}{|c|c|c|}
\hline Region & $\begin{array}{l}\text { gCJK } \\
n=15\end{array}$ & $\begin{array}{l}\text { sCJK } \\
n=13\end{array}$ \\
\hline \multicolumn{3}{|l|}{ Kortex } \\
\hline frontal & $73 \%(11)$ & $69 \%(9)$ \\
\hline Gyrus cinguli & $47 \%(7)$ & $54 \%(7)$ \\
\hline parietal & $47 \%(7)$ & $85 \%(11)$ \\
\hline temporal & $60 \%(9)$ & $62 \%(8)$ \\
\hline Insula & $73 \%(11)$ & $54 \%(7)$ \\
\hline occipital & $40 \%(6)$ & $46 \%(6)$ \\
\hline Hippocampus & $13 \%(2)$ & $8 \%(1)$ \\
\hline \multicolumn{3}{|l|}{ Basalganglien } \\
\hline Pallidum & $0 \%(0)$ & $0 \%(0)$ \\
\hline Putamen & $40 \%(6)$ & $62 \%(8)$ \\
\hline Nucleus caudatus & $67 \%(10)$ & $62 \%(8)$ \\
\hline Thalamus & $20 \%(3)$ & $15 \%(2)$ \\
\hline Nucleus AL & $7 \%(1)$ & $0 \%(0)$ \\
\hline Nucleus DM & $20 \%(3)$ & $8 \%(1)$ \\
\hline Pulvinar & $20 \%(3)$ & $8 \%(1)$ \\
\hline Hockeystick & $7 \%(1)$ & $0 \%(0)$ \\
\hline Cerebellum & $0 \%(0)$ & $8 \%(1)$ \\
\hline
\end{tabular}




\subsubsection{Signalalterationen nach Mutation}

Die E200K-Mutation und die V210I-Mutation zeigen einen sehr ähnlichen Phänotyp sowohl im direkten Vergleich als auch im Vergleich zum häufigsten Subtyp der sporadischen CJK. Um mögliche Unterschiede zwischen den jeweiligen Mutationen bezüglich der Veränderungen in der MRT-Bildgebung aufzudecken, wurde das Patientenkollektiv mit genetischer CJK anhand der zwei verschiedenen Mutationen analysiert. Diese wurden sowohl direkt untereinander als auch unabhängig voneinander mit dem Kontrollkollektiv, bestehend aus SCJK-Patienten, verglichen.

\subsubsection{E200K im Vergleich mit V210I}

Betrachtete man die beiden Gruppen des Patientenkollektivs der gCJK anhand der Mutationen (E200K und V210I) getrennt voneinander, so ließen sich in der FLAIR-Wichtung keine signifikanten Unterschiede bezüglich der Häufigkeit oder des Verteilungsmusters der hyperintensen Läsionen zwischen den beiden Gruppen nachweisen. Bei beiden $\mathrm{Mu}-$ tationen fanden sich am häufigsten Signalalterationen im Nucleus caudatus, im Putamen, im frontalen Kortex sowie im Gyrus cinguli. Der Thalamus wies hingegen nur sehr selten Hyperintensitäten auf.

Ein statistischer Vergleich anhand der DWI-Wichtung war aufgrund der niedrigen Fallzahlen in der V210I-Gruppe nicht möglich. Es fiel jedoch auf, dass keiner der V210IPatienten in der DWI-Wichtung Hyperintensitäten in der Frontalregion aufwies.

In den Abbildungen 3.1 und 3.2 sind die Verteilung und Häufigkeit der Hyperintensitäten in der FLAIR und DWI jeweils für beide Mutationen aufgeführt. 
Abbildung 3.1 Frequenz und Verteilung von Hyperintensitäten in der FLAIRWichtung für die E200K- und V210I-Mutation

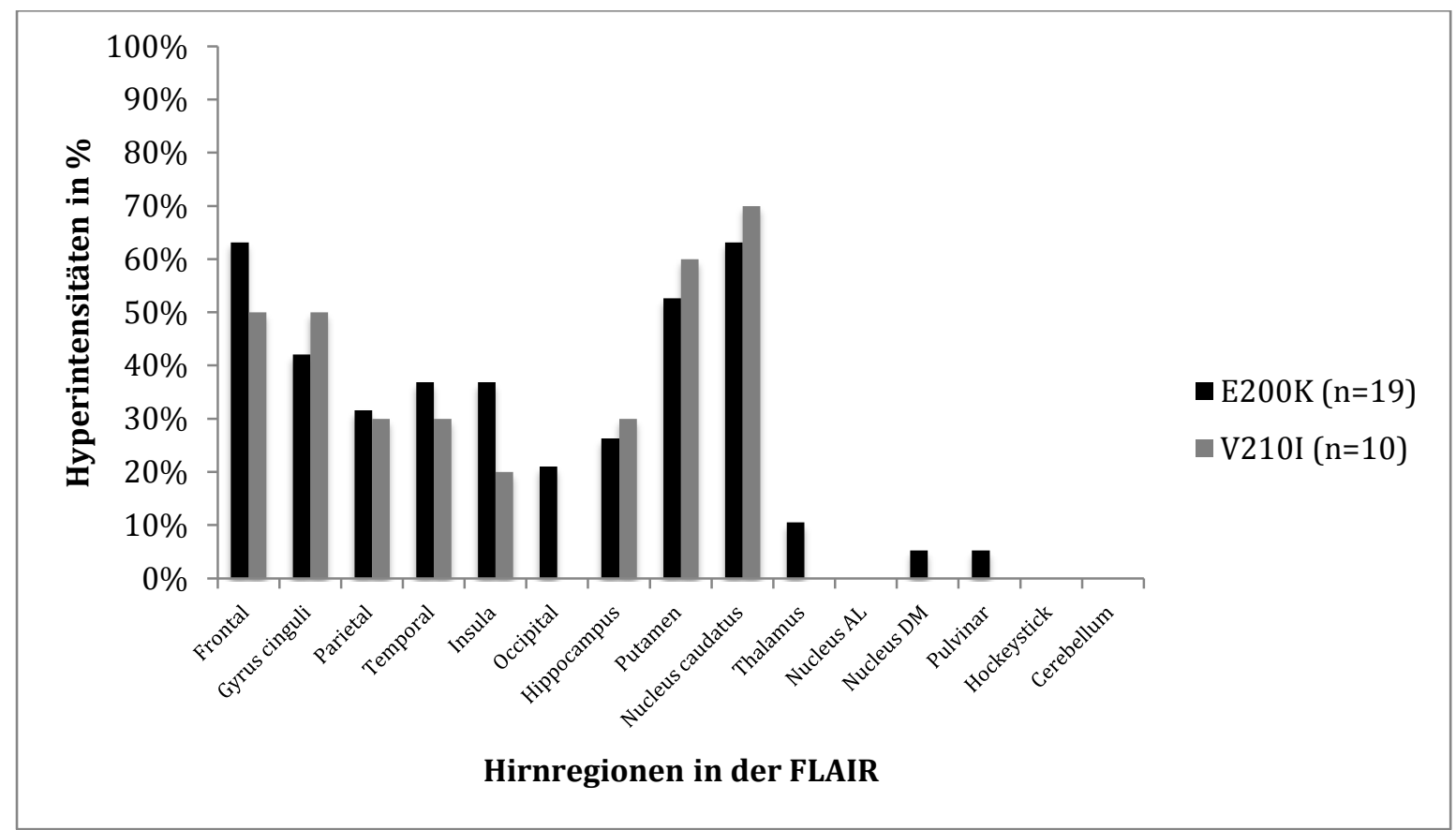

Abbildung 3.2 Frequenz und Verteilung von Hyperintensitäten in der DWI für die E200K- und V210I-Mutation

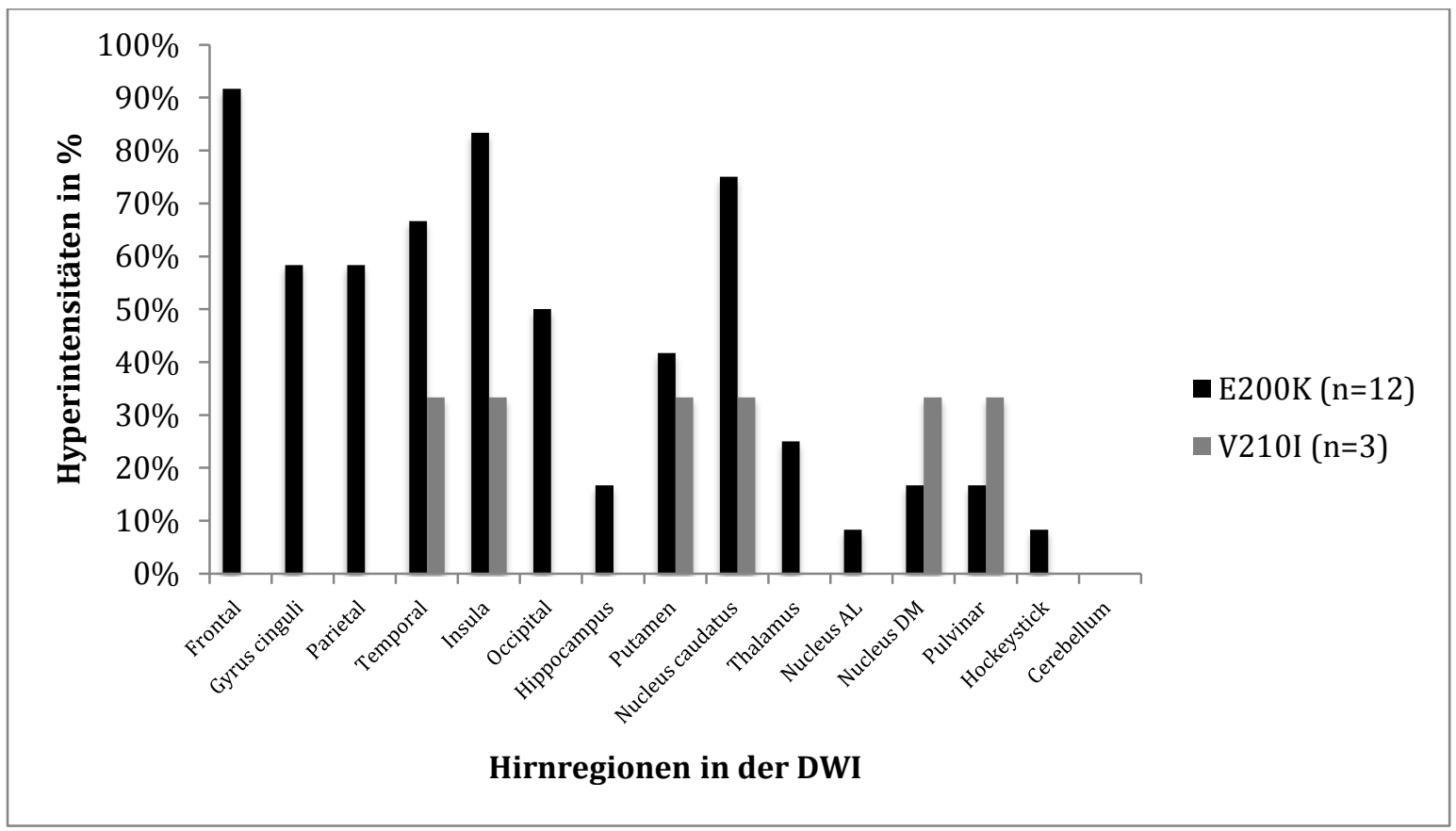




\subsubsection{E200K im Vergleich mit sCJK}

Im direkten Vergleich fanden sich keine signifikanten Unterschiede zwischen der E200K-Gruppe und dem Kontrollkollektiv hinsichtlich des Vorkommens von Hyperintensitäten in den verschiedenen Hirnregionen. In beiden Gruppen waren die Frontalregion sowie die Basalganglien am häufigsten betroffen. Wie bereits zuvor erwähnt, ließen sich kortikale Signalalterationen deutlich häufiger in der DWI-Wichtung feststellen. Insbesondere in den Hirnregionen, welche für die MRT-Kriterien relevant sind (parietal, temporal und occipital) konnten in beiden Kollektiven bei rund der Hälfte der Patienten Hyperintensitäten beobachtet werden.

Abbildungen 3.3 und 3.4 zeigen den Anteil an Hyperintensitäten für die verschiedenen Hirnregionen jeweils in der FLAIR und DWI.

Abbildung 3.3 Frequenz und Verteilung von Hyperintensitäten in der FLAIRWichtung bei der E200K-Mutation und im Kontrollkollektiv

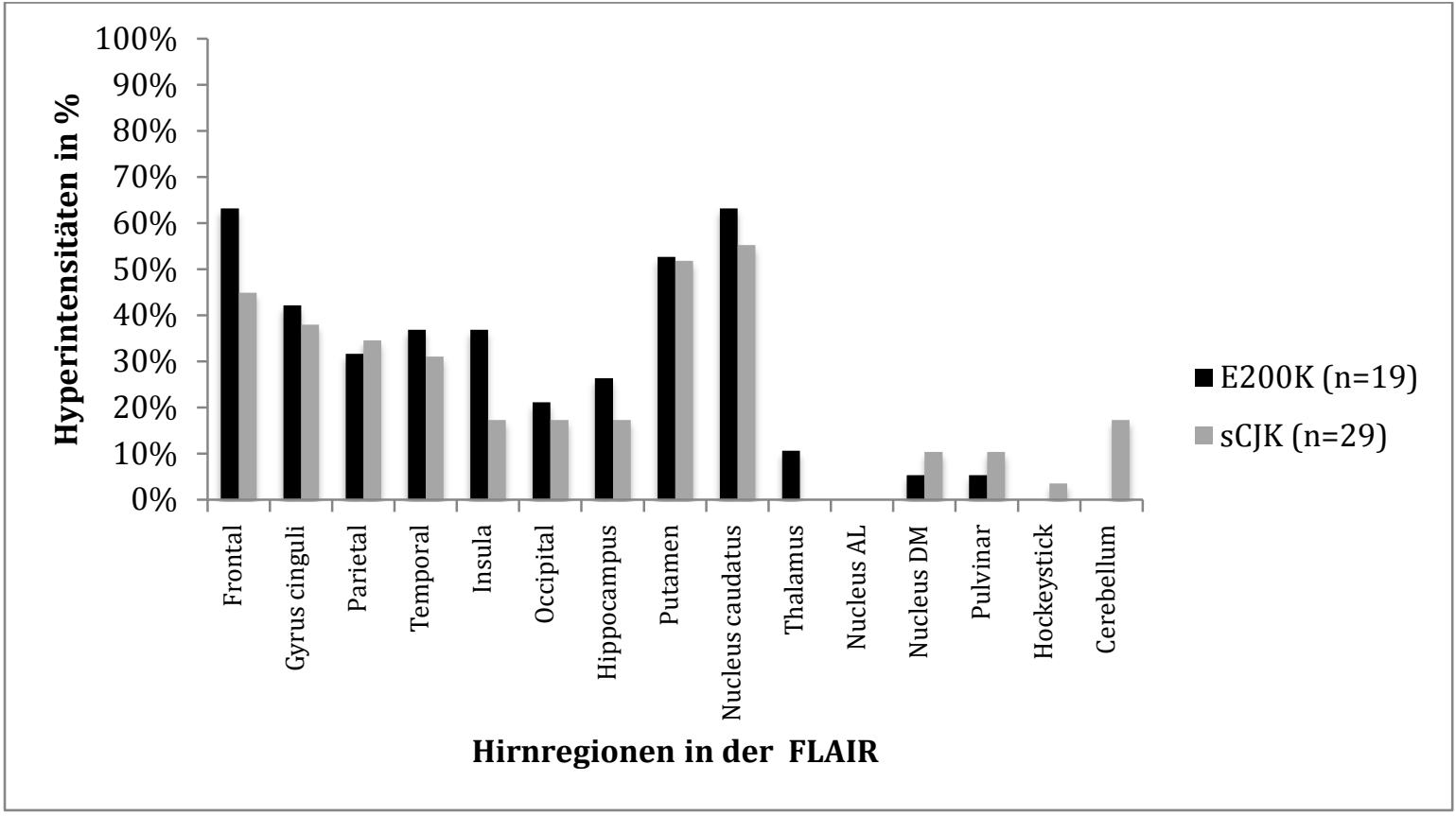


Abbildung 3.4 Frequenz und Verteilung von Hyperintensitäten in der DWIWichtung bei der E200K-Mutation und im Kontrollkollektiv

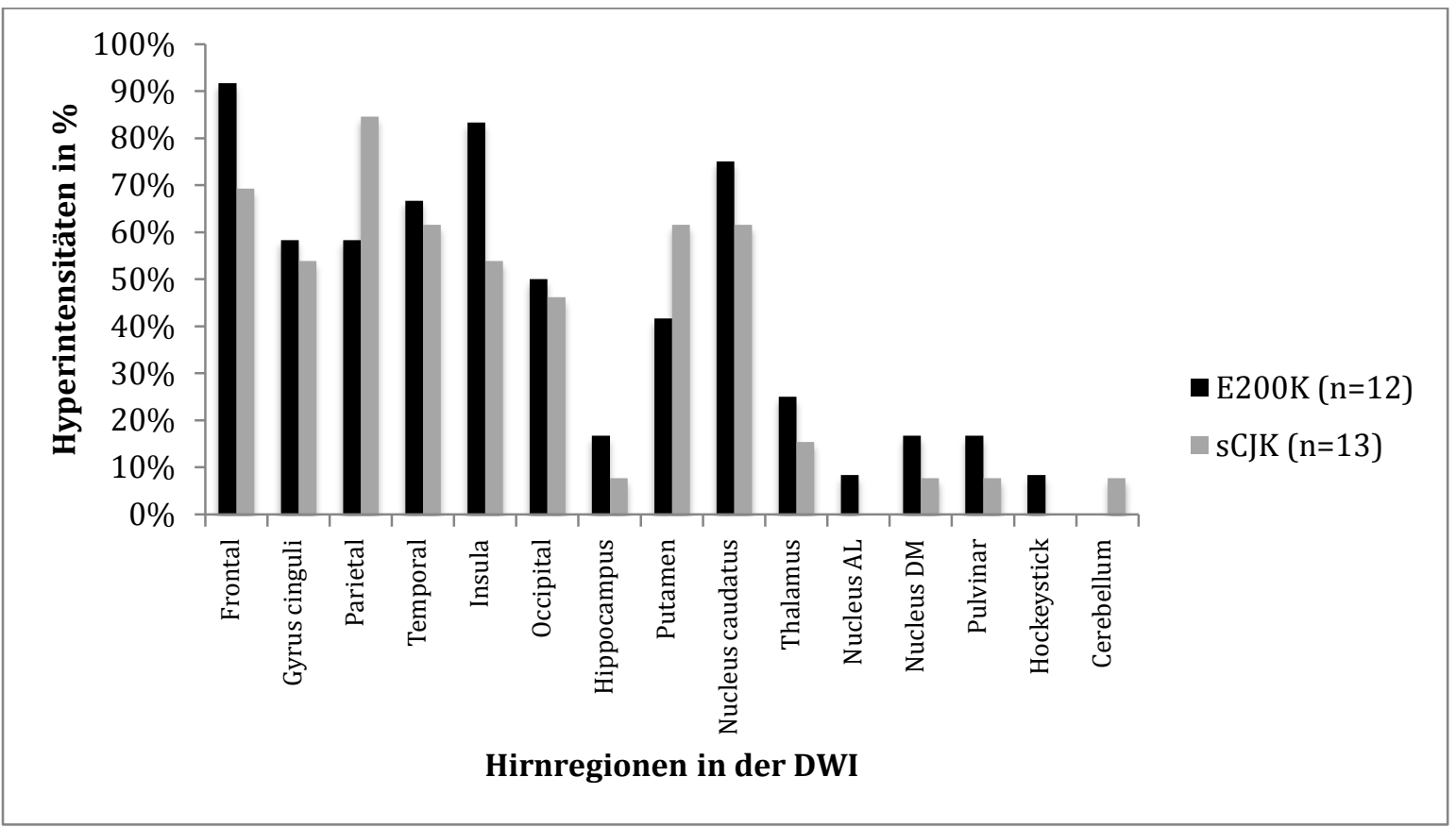




\subsubsection{V210I im Vergleich mit SCJK}

Wie auch für die E200K-Gruppe fanden sich keine signifikanten Unterschiede hinsichtlich des MRT-Läsionsmusters zwischen V210I-Patienten und dem Kontrollkollektiv der sCJK-Patienten. Tendenziell waren in der FLAIR-Wichtung im Patientenkollektiv etwas häufiger Signalalterationen im Bereich der Basalganglien zu finden.

In der DWI fiel auf, dass Signalalterationen in der V210I-Gruppe nur im parietalen und insulären Kortex zu finden waren. Die statistische Auswertung der MRT-Veränderungen in der DWI-Wichtung war jedoch aufgrund der niedrigen Fallzahl in der V210I Gruppe nicht möglich.

Abbildungen 3.5 und 3.6 zeigen die Hyperintensitäten der verschiedenen Hirnregionen beiden Wichtungen.

Abbildung 3.5 Frequenz und Verteilung von Hyperintensitäten in der FLAIRWichtung bei der V210I-Mutation und im Kontrollkollektiv

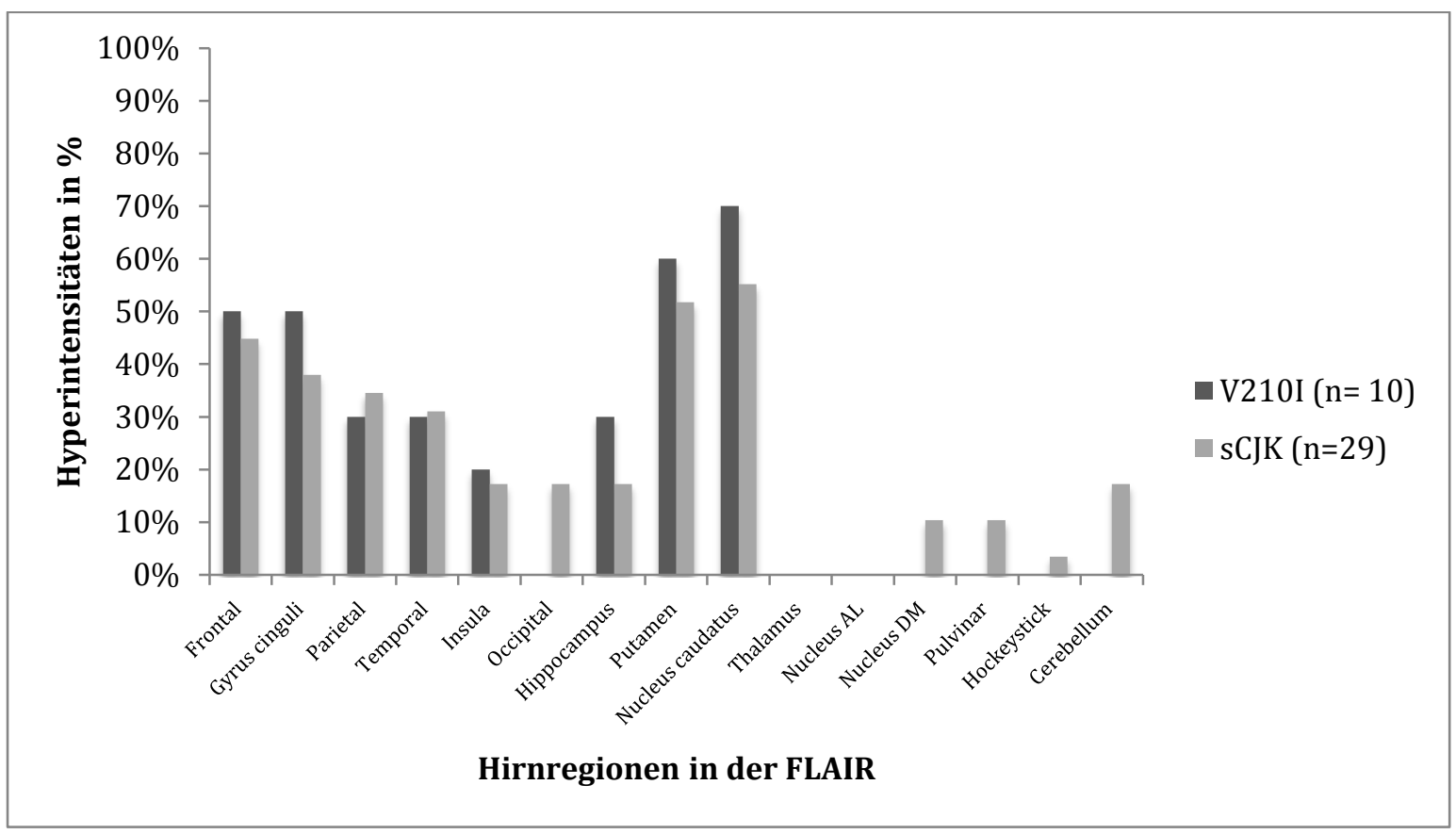




\section{Abbildung 3.6 Hyperintensitäten in der DWI-Wichtung bei der V210I-Mutation und SCJK}

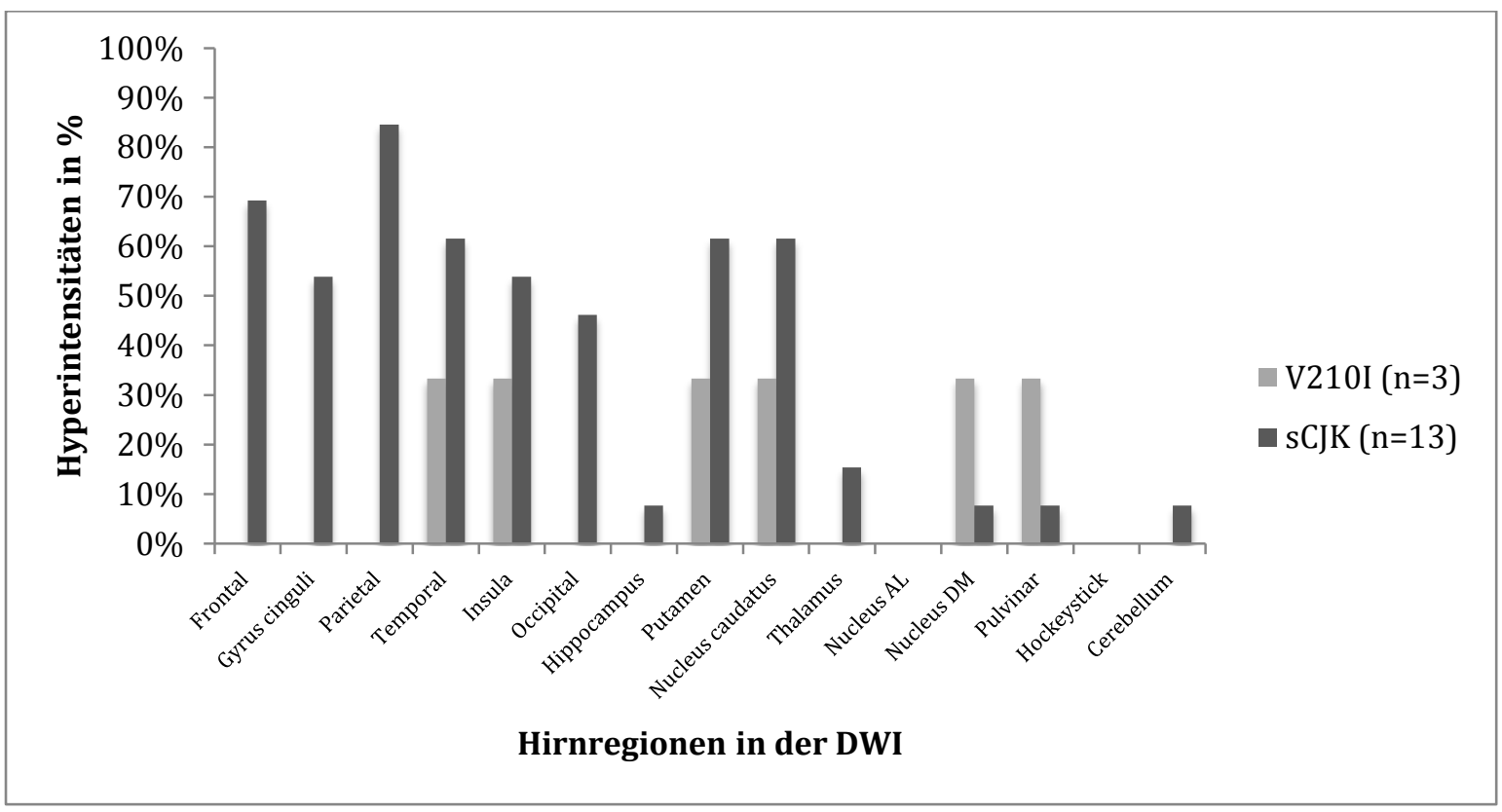

\subsubsection{Signalalterationen nach Polymorphismus am Codon $\mathbf{1 2 9}$}

Um den Einfluss des Genotyps am Codon 129 des PRNP auf die Veränderungen im MRT zu untersuchen, erfolgte eine Aufteilung der Kollektive anhand des Polymorphismus am Codon129 in die Gruppen MM, MV und VV. Lediglich ein einziger Patient mit dem Genotyp VV konnte im Patientenkollektiv identifiziert werden. Die MRT-Veränderungen dieses Patienten werden einzeln beschrieben, da eine statistische Analyse im Vergleich zu den restlichen Patienten nicht möglich ist (siehe 3.3.5.5).

\subsubsection{Hyperintensitäten in der FLAIR-Wichtung: MM-Subtyp}

Die Patienten aus dem gCJK-Kollektiv mit dem MM-Subtyp zeigten am häufigsten Hyperintensitäten im Nucleus caudatus (E200K 70\%, V210I 67\%), gefolgt von Hyperintensitäten im Putamen (E200K 60\%, V210I 50\%), frontalen Kortex (E200K 60\%, V210I 56\%) und Gyrus cinguli (E200K 50\%, V210I 67\%). Im sCJK-Kontrollkollektiv fanden sich etwas seltener Hyperintensitäten im Bereich der Basalganglien (44\% und 38\% im NC und Putamen respektive), ohne dass das Ergebnis statistische Signifikanz erreichte ( $\mathrm{p}=$ 
0,285 und $\mathrm{p}=0,479$ ). Die Verteilung der Hyperintensitäten in den kortikalen Regionen glich ebenfalls dem des genetischen Patientenkollektivs. Während keiner der Patienten mit einer Mutation im PRNP in der FLAIR-Wichtung Hyperintensitäten im Bereich des Thalamus oder Kleinhirn bot, fanden sich bei drei Patienten des sCJK-Kontrollkollektivs Signalalterationen im Kleinhirn. Dieser Unterschied war jedoch nicht statistisch signifikant $(\mathrm{p}=0,226)$.

In Abbildung 3.7 sind die Ergebnisse für die einzelnen Patientenuntergruppen getrennt aufgeführt.

Abbildung 3.7 Frequenz und Verteilung der Hyperintensitäten in den verschiedenen Kollektiven bei Patienten mit dem MM-Genotyp in der FLAIR-Wichtung

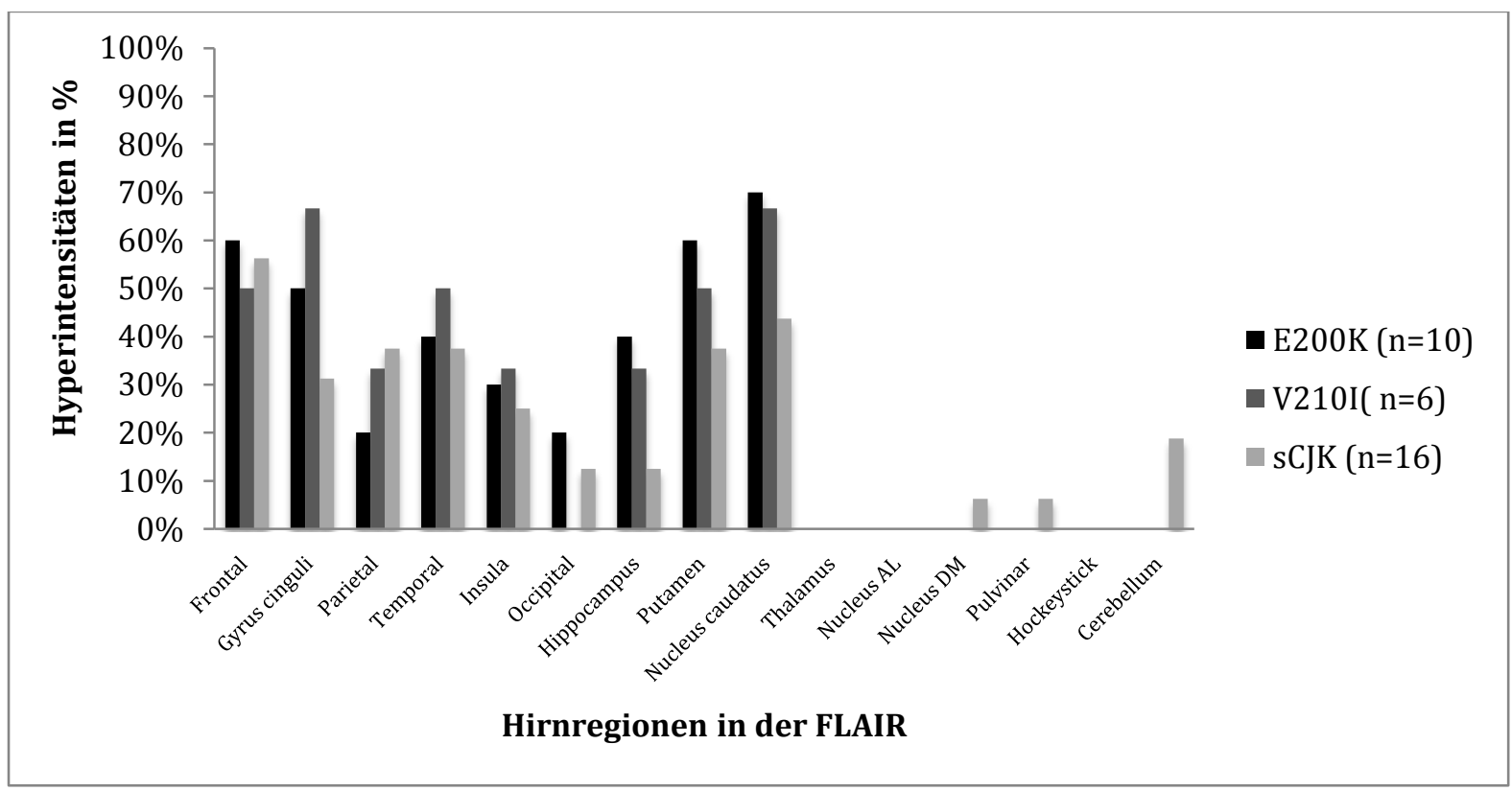




\subsubsection{Hyperintensitäten in der FLAIR-Wichtung: MV-Subtyp}

Im Vergleich zum MM-Subtyp fanden sich bei Patienten, die heterozygot am Codon 129 waren häufiger Hyperintensitäten in den Basalganglien. Alle drei Patienten aus der Gruppe der V210I-Mutation und 75\% der Patienten aus dem sCJK-Kontrollkollektiv zeigten Signalalterationen im Bereich des Nucleus caudatus und Putamens. In der Gruppe der E200K-Patienten konnten hingegen nur in 56\% der Fälle im Bereich des Nucleus caudatus und nur in 44\% der Fälle im Putamen Hyperintensitäten dokumentiert werden. Der Unterschied hinsichtlich der Beteiligung der Basalganglien zwischen den Gruppen war jedoch nicht statistisch signifikant. In der Gruppe der E200K-Patienten fanden sich darüber hinaus häufige Veränderungen im Bereich des frontalen Kortex (67\%), welche in den anderen Gruppen etwas seltener zu finden waren. Der Unterschied erreichte jedoch keine statistische Signifikanz.

Abbildung 3.8 fasst die Ergebnisse zusammen.

Abbildung 3.8 Frequenz und Verteilung von Hyperintensitäten in den verschiedenen Kollektiven bei Patienten mit dem MV-Genotyp in der FLAIR-Wichtung

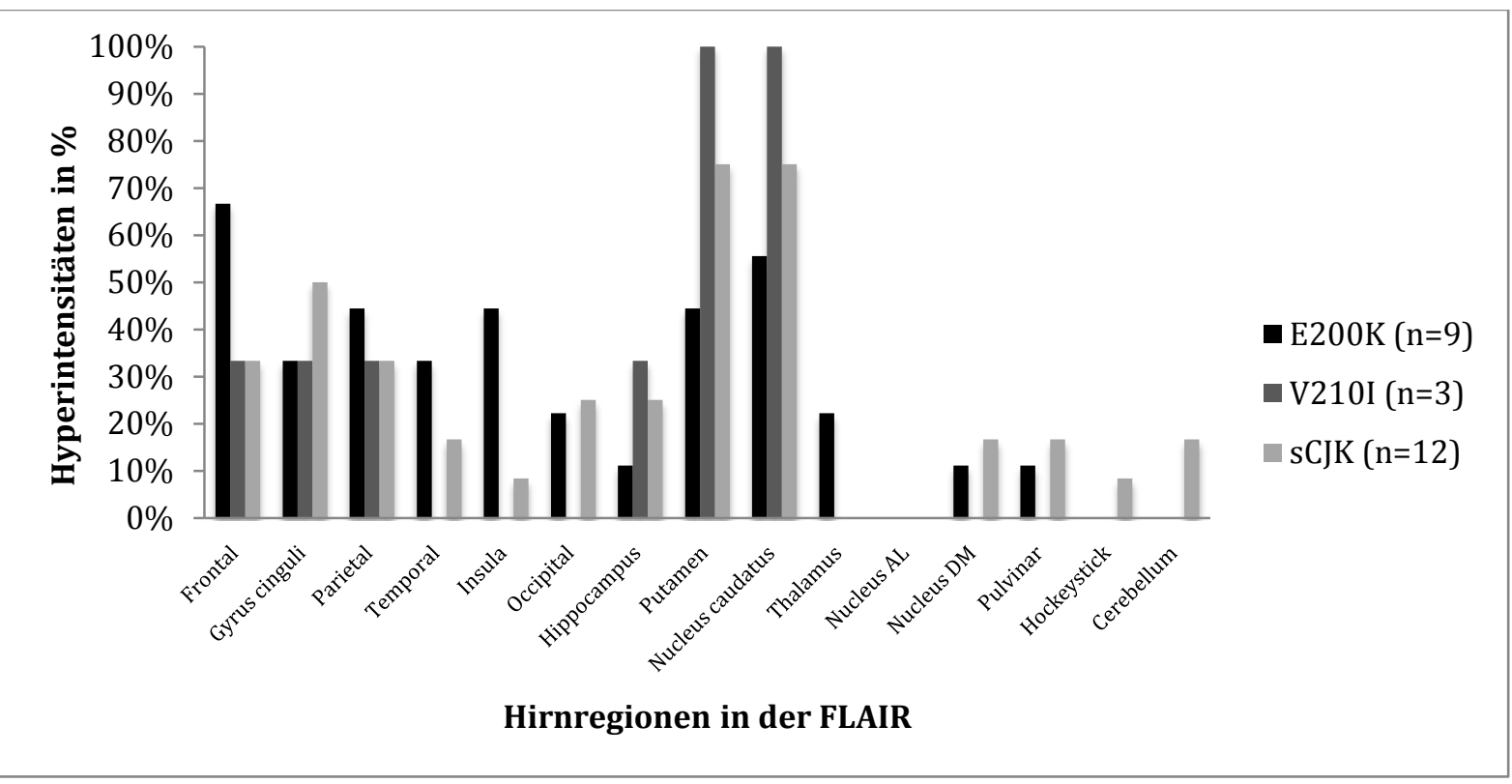




\subsubsection{Hyperintensitäten in der DWI-Wichtung: MM-Subtyp}

Wie bereits erwähnt, waren in der DWI häufiger Hyperintensitäten in kortikalen Arealen zu finden als in der FLAIR. Insbesondere im frontalen, insulären, parietalen und occipitalen Kortex konnten sowohl bei den E200K-Patienten als auch bei den Patienten des sCJK-Kontrollkollektivs mehr Signalalterationen beobachtet werden. Bei allen sieben Patienten (100\%) des genetischen Kollektivs fanden sich Signalalterationen im frontalen und insulären Kortex. Weitere häufig betroffene Regionen waren der Gyrus cinguli, der parietale, temporale und occipitale Kortex sowie der Nucleus caudatus mit jeweils 71\%. Statistisch signifikante Unterschiede zwischen der E200K-Mutation und den Patienten mit sporadischer CJK fanden sich nicht. Der einzige Patient mit der V210IMutation bei dem eine DWI-Wichtung Teil des Untersuchungsprotokolls war, wies keine Hyperintensitäten auf.

Abbildung 3.9 zeigt die Ergebnisse der gCJK- und sCJK-Patienten.

\section{Abbildung 3.9 Frequenz und Verteilung von Hyperintensitäten des MM-Genotyps beider Kollektive in der DWI}

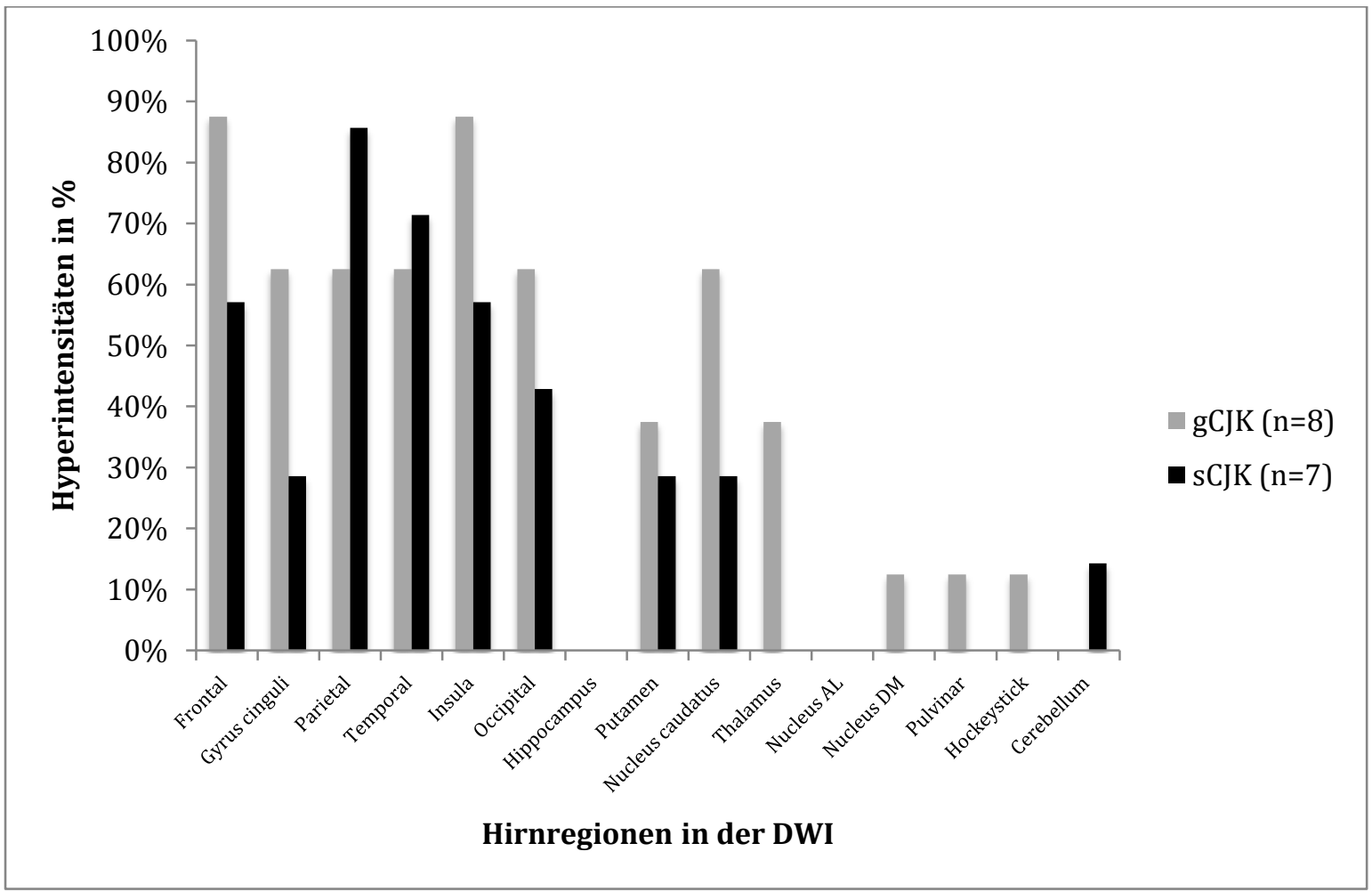




\subsubsection{Hyperintensitäten in der DWI-Wichtung: MV-Subtyp}

Für den MV-Subtyp ließen sich keine signifikanten Unterschiede zwischen den beiden Kollektiven nachweisen. Allerdings fiel auf, dass bei Patienten mit sporadischer CJK in 100\% der Fälle Hyperintensitäten im Putamen zu finden waren, während lediglich 50\% des genetischen Kollektivs in diesem Bereich Signalalterationen zeigte. Dieser Unterschied zeigte einen Trend, der jedoch keine statistische Signifikanz erreichte $(p=0,061)$. Im Vergleich zum MM-Subtyp waren kortikale Hyperintensitäten etwas seltener zu finden.

In Abbildung 3.10 sind die Ergebnisse zusammengefasst.

\section{Abbildung 3.10 Frequenz und Verteilung von Hyperintensitäten des MV-Genotyps beider Kollektive in der DWI}

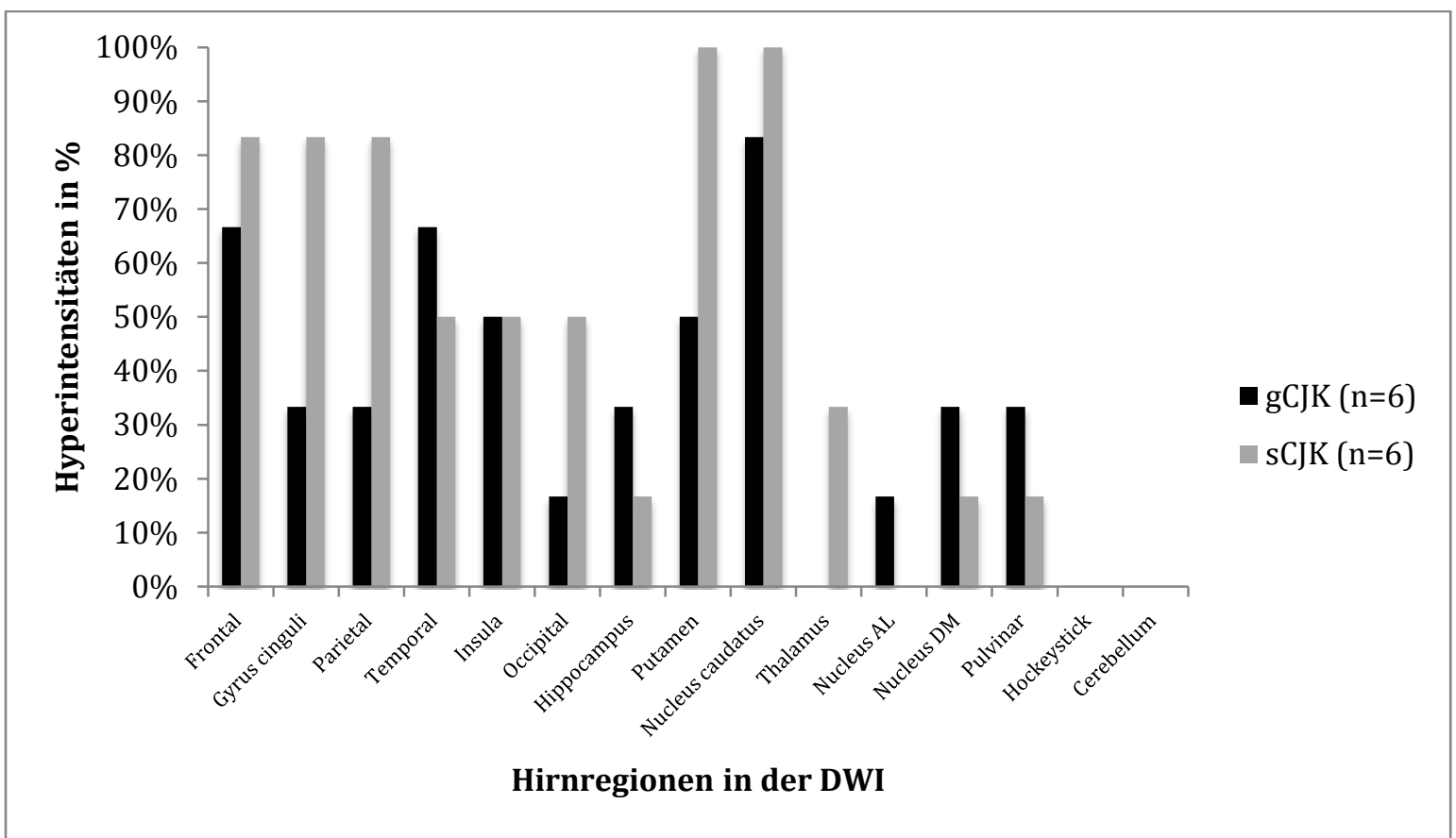

\subsubsection{Hyperintensitäten: VV-Subtyp}

Der einzige Patient mit dem VV-Genotyp aus der Gruppe der V210I-Mutation zeigte kaum Signalalterationen. Die MRT-Aufnahme wurde am Ende des 2. Krankheitsdrittels angefertigt. In der FLAIR-Wichtung fanden sich Hyperintensitäten lediglich im frontalen Kortex, während in der DWI-Wichtung Hyperintensitäten im insulären Kortex nach- 
weisbar waren. Insgesamt konnten also keine für eine CJK-typische Veränderungen gefunden werden und die etablierten MRT-Kriterien wurden nicht erfüllt.

\subsection{Ergebnisse der Zusatzdiagnostik}

\subsubsection{Liquoruntersuchung}

Die Detektion der Proteine 14-3-3 und die Bestimmung erhöhter Tau-Werte zeigten sowohl im gCJK-Kollektiv als auch im sCJK-Kontrollkollektiv eine hohe Sensitivität.

Bei insgesamt 97\% der Patienten des genetischen Kollektivs waren die Proteine 14-3-3 positiv. Betrachtete man die Gruppen getrennt nach Mutation, so fiel auf, dass in der V210I-Gruppe sogar bei allen zehn Patienten der Nachweis der 14-3-3-Proteine gelang. Die Sensitivität lag somit höher als in der E200K-Gruppe, welche im Vergleich eine Sensitivität von nur 83\%, bei insgesamt 15 Positivbefunden von 18 untersuchten Patienten, aufwies.

Im sCJK-Kontrollkollektiv erfolgte bei insgesamt 26 Patienten eine Untersuchung des Liquors auf das Vorliegen der Proteine 14-3-3. Bei allen untersuchten Patienten ließ sich im Western-Blot der Nachweis von 14-3-3 erbringen (100\%). Statistisch fand sich somit kein Unterschied zwischen den Kollektiven.

Die Sensitivität für die Bestimmung des Tau-Wertes lag im Patientenkollektiv bei 100\%. Alle Patienten $(n=29)$ hatten einen Tau-Wert oberhalb des definierten Cut-off-Wertes für CJK von 1200 pg/ml. In der E200K-Gruppe lag der Tau-Wert im Median bei 5147 $\mathrm{pg} / \mathrm{ml}$ und in der V210I-Gruppe im Median bei 5566pg/ml. Somit lag die Konzentration deutlich oberhalb der Norm. Im sCJK-Kontrollkollektiv hatten 92\% der Patienten einen pathologischen Tau-Wert oberhalb des Cut-off-Wertes. Der Median lag mit 4403 pg/ml etwas niedriger als der des Patientenkollektivs. In beiden Kollektiven fanden sich die Tau-Werte jedoch im deutlich pathologischen Bereich. Insgesamt ergaben sich jedoch bei der Betrachtung der verschiedenen Liquorparameter keine statistisch signifikanten Unterschiede zwischen den beiden Kollektiven hinsichtlich der als positiv gewerteten Befunde. 


\subsubsection{Elektroenzephalographie (EEG)}

Eine Elektroenzephalographie wurde bei 24 von 29 Patienten des gCJK-Kollektivs abgeleitet, davon bei 15 der E200K-Patienten und neun der V210I-Patienten. Im Kontrollkollektiv der sCJK-Patienten lagen ebenfalls für 24 von 29 Patienten Daten zur EEG vor. Die EEG-Untersuchung wurde im Median 2,0 Monate nach Krankheitsbeginn in der gCJKGruppe und 2,5 Monate nach Krankheitsbeginn in der sCJK-Gruppe abgeleitet. Gemessen an der gesamten Krankheitsdauer, erfolgte die EEG-Untersuchung in der gCJK-Gruppe bei 53\% der Patienten im ersten Krankheitsdrittel, bei 21\% im zweiten Krankheitsdrittel und bei 26\% im letzten Drittel der Erkrankung. Im Kontrollkollektiv der sCJKPatienten wurde die EEG tendenziell etwas später abgeleitet. 22\% der Patienten wurden im ersten, 50\% im zweiten und 28\% im letzten Drittel der Erkrankung untersucht. Die für die CJK-typischen periodischen Sharp-Wave-Komplexe (PSWC) konnten bei 54\% der Patienten mit einer Mutation im PRNP dokumentiert werden. Patienten mit der E200KMutation boten mit 60\% etwas häufiger typische Veränderungen als die Patientengruppe mit der V210I-Mutation mit nur 44\% typischer EEG-Befunde. In der Kontrollgruppe der sCJK-Patienten wiesen 33\% der Patienten typische Veränderungen im EEG auf. Es ließen sich jedoch keine statistisch signifikanten Unterschiede hinsichtlich des Nachweises periodischer Sharp-Wave-Komplexe zwischen den verschiedenen Gruppen erkennen $(\mathrm{p}=0,244)$.

Tabelle 3.5 gibt einen Überblick über die Ergebnisse der beiden Zusatzuntersuchungen in den untersuchten Patientenkollektiven.

Tabelle 3.5 Überblick über die Ergebnisse der Liquoruntersuchung und der EEG in den untersuchten Patientenkollektiven

\begin{tabular}{|ll|c|c|c|c|}
\hline & & E200K & V210I & $\mathrm{K}_{\mathrm{gCJK}}$ & $\mathrm{K}_{\mathrm{sCJK}}$ \\
\hline \hline \multirow{2}{*}{$\begin{array}{l}\text { positiv (n) } \\
\%\end{array}$} & $\begin{array}{l}15 / 18 \\
(83 \%)\end{array}$ & $\begin{array}{c}10 / 10 \\
(100 \%)\end{array}$ & $\begin{array}{c}25 / 28 \\
(89 \%)\end{array}$ & $\begin{array}{c}26 / 26 \\
(100 \%)\end{array}$ \\
\hline Tau $(\mathrm{pg} / \mathrm{ml})$ & $>1200$ & $100 \%$ & $100 \%$ & $100 \%$ & $92 \%$ \\
\hline Tau (pg/ml) & Median & 5147 & 5566 & 5362 & 4403 \\
\hline EEG & PSWC & $60 \%$ & $44 \%$ & $54 \%$ & $33 \%$ \\
\hline
\end{tabular}




\subsection{MRT-Kriterien}

Für beide Kollektive wurde die Anwendbarkeit der etablierten MRT-Kriterien für die sporadische CJK geprüft. Wie bereits oben erläutert, wird ein MRT als CJK-typisch gewertet, wenn entweder kortikale Hyperintensitäten in mindesten zwei Regionen (parietal, temporal oder occipital) oder Hyperintensitäten in den Basalganglien (Nucleus caudatus und Putamen) in der FLAIR- und/oder DWI-Wichtung zu finden sind.

\subsubsection{MRT-Kriterien nach Patientenkollektiv}

In beiden Kollektiven waren Signalalterationen häufig zu finden. Insgesamt erfüllten 76\% der Patienten des gCJK-Patientenkollektivs die etablierten MRT-Kriterien sowie 72\% des sCJK-Kontrollkollektivs.

Bei 19 von 29 Patienten des sCJK-Kollektivs konnten die MRT-Aufnahmen bereits anhand der FLAIR-Wichtung als typisch gewertet wurde. In der DWI-Wichtung wurden bei 11 von 15 Patienten die Signalalterationen als CJK-typisch gewertet. Für drei Patienten bei denen die FLAIR-Wichtung als negativ gewertet werden musste, bedeutete die DWI-Wichtung einen zusätzlichen diagnostischen Gewinn, da dort im Gegensatz zur FLAIR typische MRT-Veränderungen dokumentiert werden konnten. Drei Patienten des gCJK-Kollektivs erfüllten die MRT-Kriterien in der FLAIR-Wichtung aufgrund rein kortikaler Signalalterationen, bei zwölf Patienten waren nur der Nucleus caudatus und Putamen hyperintens und vier Patienten boten Auffälligkeiten sowohl kortikal als auch in den Basalganglien. In der DWI-Wichtung war die Verteilung wie folgt: acht Patienten hatten rein kortikale Hyperintensitäten, sechs Signalalterationen begrenzt auf den Nucleus caudatus und Putamen und drei zeigten Auffälligkeiten sowohl kortikal als auch in den Basalganglien.

Bei den Patienten des SCJK-Kontrollkollektivs zeigten sich bei 20 von 29 Patienten typische CJK-Veränderungen in der FLAIR-Wichtung. In der DWI wurden bei 11 von 13 Patienten die MRT-Kriterien für sCJK erfüllt. Bei nur einem von neun Patienten, die in der FLAIR-Wichtung die MRT-Kriterien nicht erfüllten, bedeutete die DWI einen zusätzlichen diagnostischen Gewinn bei Nachweis CJK-typischer Veränderungen.

Tabelle 3.7 gibt einen Überblick der Ergebnisse. 
Tabelle 3.6 Übersicht über die MRT-Kriterien in den untersuchten Kollektiven

\begin{tabular}{lccrrr}
\hline & & & & Kollektiv & \\
\hline MLRT-Kriterien* & & & gCJK & sCJK & Total \\
& positiv & $\mathrm{n}$ & 19 & 20 & 39 \\
& & $\%$ & $65,5 \%$ & $69 \%$ & $67 \%$ \\
& negativ & $\mathrm{n}$ & 10 & 9 & 19 \\
& & $\%$ & $34,5 \%$ & $31 \%$ & $33 \%$ \\
DWI & positiv & $\mathrm{n}$ & 11 & 11 & 22 \\
& & $\%$ & $73 \%$ & $85 \%$ & $78,5 \%$ \\
FLAIR + DWI & negativ & $\mathrm{n}$ & 4 & 2 & 6 \\
& & $\%$ & $27 \%$ & $36 \%$ & $21,5 \%$ \\
& positiv & $\mathrm{n}$ & 22 & 21 & 43 \\
& & $\%$ & $76 \%$ & $72 \%$ & $74 \%$ \\
& negativ & $\mathrm{n}$ & 7 & 8 & 15 \\
& & $\%$ & $24 \%$ & $28 \%$ & $26 \%$ \\
\hline
\end{tabular}

\subsubsection{MRT-Kriterien nach Mutation}

Betrachtete man die E200K- und V210I-Mutation getrennt voneinander, so war zu beobachten, dass in beiden Untergruppen die MRT-Kriterien etwa gleich häufig erfüllt wurden. Insgesamt erfüllten 15 von 19 Patienten (79\%) mit der E200K-Mutation und sieben von zehn Patienten (70\%) mit der V210I-Mutation die diagnostischen MRTKriterien.

Bei zwölf von 19 Patienten der E200K-Gruppe und sieben von zehn Patienten der V210I-Gruppe wurden die MRT-Aufnahmen in der FLAIR-Wichtung als CJK-typisch gewertet. In der DWI erfüllten zehn von zwölf Patienten mit der E200K-Mutation und einer von drei Patienten mit der V210I-Mutation die MRT-Kriterien. Drei der sieben Patienten aus der E200K-Mutation, bei denen keine typischen Veränderungen in der FLAIRWichtung zu erkennen waren, zeigten typische MRT-Befunde in der DWI. Diese drei Patienten hatten somit einen zusätzlichen diagnostischen Nutzen durch die DWI. 
Bei zwei E200K-Patienten und einem V210I-Patienten wurden die MRT-Kriterien in der FLAIR aufgrund von Hyperintensitäten in den definierten kortikalen Regionen erfüllt, sieben E200K-Patienten und fünf V210I-Patienten zeigten Hyperintensitäten begrenzt auf die Basalganglien und drei Patienten mit der E200K-Mutation sowie ein Patient mit der V210I-Mutation erfüllten die Kriterien sowohl anhand der kortikalen als auch der Basalganglien-Hyperintensitäten.

In der DWI-Wichtung zeigten fünf E200K-Patienten rein kortikale, zwei Patienten auf die Basalganglien begrenzte und drei Patienten in beiden Regionen Hyperintensitäten, die die MRT-Kriterien erfüllten. Von den drei Patienten aus der V210I-Gruppe bei denen Aufnahmen in der DWI vorlagen, erfüllte nur ein Patient die MRT-Kriterien anhand der DWI-Wichtung aufgrund von Hyperintensitäten im Nucleus caudatus und Putamen. Tabelle 3.8 zeigt die Ergebnisse.

Tabelle 3.7 Übersicht über die MRT-Kriterien in der Patientengruppe nach Mutation

\begin{tabular}{cccccc}
\hline & & \multicolumn{4}{c}{ Mutation } \\
\hline \multirow{2}{*}{ MRT-Kriterien } & positiv & $\mathrm{n}$ & E200K & V210I & Total \\
& & $\%$ & $79 \%$ & $70 \%$ & $76 \%$ \\
& negativ & $\mathrm{n}$ & 4 & 3 & 7 \\
& & $\%$ & $21 \%$ & $30 \%$ & $24 \%$ \\
\hline
\end{tabular}

\subsubsection{MRT-Kriterien nach Polymorphismus am Codon 129}

Da der Genotyp zusammen mit dem Prionproteintyp die Ausprägung und Verteilung von Signalalterationen in der MRT beeinflusst, wurde die Anwendbarkeit der MRT-Kriterien in Abhängigkeit vom Polymorphismus am Codon 129 geprüft.

Sowohl im gCJK-Kollektiv als auch im sCJK-Kollektiv erfüllten Patienten mit dem Genotyp MV die MRT-Kriterien etwas häufiger als MM-Patienten. Im gCJK-Kollektiv erfüllten 75\% der MM-Patienten die Kriterien (80\% der E200K und 67\% der V210I), während Patienten mit dem MV-Genotyp in 83\% der Fälle die Kriterien erfüllten (78\% der E200K und alle drei Patienten der V210I). Der Unterschied erreichte jedoch keine statistische 
Signifikanz. Der einzige VV-Patient mit einer V210I-Mutation sowie der sCJK Patient mit dem Genotyp VV erfüllten nicht die MRT-Kriterien.

Tabelle 3.6 fasst die Ergebnisse zusammen.

Tabelle 3.8 Überblick über die MRT-Kriterien nach Genotyp

\begin{tabular}{|c|c|c|c|c|c|c|c|}
\hline \multirow[b]{2}{*}{ c129 } & & & & \multirow[t]{2}{*}{ SCJK } & \multicolumn{3}{|c|}{ gCJK } \\
\hline & & & & & E200K & V210I & Gesamt \\
\hline \multirow[t]{4}{*}{$\mathbf{M M}$} & MRT-Kriterien & positiv & $\mathrm{n}$ & 10 & 8 & 4 & $\overline{12}$ \\
\hline & & & $\%$ & $62 \%$ & $80 \%$ & $67 \%$ & $75 \%$ \\
\hline & & negativ & $\mathrm{n}$ & 6 & 2 & 2 & 4 \\
\hline & & & $\%$ & $38 \%$ & $20 \%$ & $33 \%$ & $25 \%$ \\
\hline \multirow[t]{4}{*}{ MV } & MRT-Kriterien & positiv & $\mathrm{n}$ & 11 & 7 & 3 & 10 \\
\hline & & & $\%$ & $92 \%$ & $78 \%$ & $100 \%$ & $83 \%$ \\
\hline & & negativ & $\mathrm{n}$ & 1 & 2 & 0 & 2 \\
\hline & & & $\%$ & $8 \%$ & $22 \%$ & $0 \%$ & $17 \%$ \\
\hline \multirow[t]{4}{*}{ VV } & MRT-Kriterien & positiv & $\mathrm{n}$ & 0 & & 0 & 0 \\
\hline & & & $\%$ & $0 \%$ & & $0 \%$ & $0 \%$ \\
\hline & & negativ & $\mathrm{n}$ & 1 & & 1 & 1 \\
\hline & & & $\%$ & $100 \%$ & & $100 \%$ & $100 \%$ \\
\hline \multirow[t]{4}{*}{ Alle } & MRT-Kriterien & positiv & $\mathrm{n}$ & 21 & 15 & 7 & 22 \\
\hline & & & $\%$ & $72 \%$ & $79 \%$ & $70 \%$ & $76 \%$ \\
\hline & & negativ & $\mathrm{n}$ & 8 & 4 & 3 & 7 \\
\hline & & & $\%$ & $28 \%$ & $21 \%$ & $30 \%$ & $24 \%$ \\
\hline
\end{tabular}




\subsubsection{Sensitivität und Spezifität}

Da bei 22 Patienten des gCJK-Kollektivs die MRT-Untersuchung korrekterweise als positiv bewertet wurde, lag die Sensitivität somit bei 76\%.

Die Evaluation der MRT-Bilder des genetischen Kollektivs ist im Zuge der Bewertung aller Bilder für die Studie zur Etablierung der neuen MRT-Kriterien erfolgt. Teil dieser Arbeit war ein Kontrollkollektiv von 141 Patienten, die den Referenzzentren zunächst mit der Verdachtsdiagnose einer CJK gemeldet worden waren, bei denen aber schließlich eine andere Diagnose als CJK gestellt werden konnte. Zur Bestimmung der Spezifität der MRT-Kriterien für Patienten mit der E200K- und V210I-Mutation wurde daher diese Kontrollgruppe verwendet (Zerr et al. 2009).

Von den 141 eingeschlossenen nicht-CJK-Kontrollen zeigten 19 falsch positive MRTVeränderungen. Die Spezifität der MRT-Veränderungen lag somit bei 86,5\%. Bei 52 der 141 Kontrollpatienten waren im Rahmen der neurologischen Diagnostik zusätzlich eine EEG- und 14-3-3-Untersuchung erfolgt. Die Spezifität der alten klinischen Diagnosekriterien für sCJK (nur EEG und 14-3-3-Proteine gingen als Zusatzdiagnostik in die Kriterien ein) lag bei 71.2\%. Für die 24 Patienten der Studie, bei denen alle drei Untersuchungen (EEG, 14-3-3 und MRT inklusive FLAIR und DWI) durchgeführt worden waren, lag die Spezifität bei 70,8\%.

\subsection{Vergleich der E200K-Patienten aus Argentinien und Deutschland}

Acht Patienten aus der Gruppe der Patienten mit der E200K-Mutation stammten aus Argentinien, die übrigen elf aus Deutschland. In der Literatur werden für Patienten mit der E200K-Mutation verschiedener Länder oder Cluster diskrete Unterschiede im Phänotyp nachgesagt (z.B. Penetranz der Mutation). Diesen Differenzen könnten z.B. die unterschiedlichen Ursprungsmutationen zugrunde liegen (Lee et al. 1999). Um mögliche Unterschiede der Signalalterationen der argentinischen im Vergleich zu deutschen Patienten zu untersuchen, wurden beide Gruppen miteinander verglichen. Es fanden sich weder in der FLAIR-Wichtung noch in der DWI-Wichtung signifikante Unterschiede hinsichtlich der Häufigkeit und Verteilung von hyperintensen Signalalterationen.

Die FLAIR-Wichtung ließ in beiden Gruppen am häufigsten Hyperintensitäten im frontalen Kortex (75\% der argentinischen und 55\% der deutschen Patienten), Putamen (50\% der argentinischen und 55\% der deutschen Patienten) und Nucleus caudatus (63\% der 
argentinischen und 64\% der deutschen Patienten) erkennen. Bei wenigen Patienten aus Deutschland konnten Signalalterationen im Thalamus dokumentiert werden (18\%). Unter den argentinischen E200K-Patienten hingegen wies dort keiner Hyperintensitäten auf.

In der DWI waren, wie zu erwarten, häufiger kortikale Hyperintensitäten zu finden. Sowohl in der argentinischen als auch in der deutschen Subgruppe waren die am häufigsten betroffenen Regionen der frontale Kortex (100\% und 80\%), der insuläre Kortex (100\% und 60\%), der Nucleus caudatus (71\% und $80 \%)$ sowie der temporale $(70 \%$ und $60 \%$ ) und parietale Kortex (57\% und 60). Insgesamt erfüllten sieben der acht E200KPatienten aus Argentinien (88\%) und acht der elf Patienten aus Deutschland (73\%) die definierten MRT-Kriterien.

Abbildung 3.11 und 3.12 zeigen die Ergebnisse jeweils für FLAIR und DWI.

\section{Abbildung 3.11 Frequenz und Verteilung von Hyperintensitäten in der FLAIR bei der E200K-Mutation aufgeschlüsselt nach Land}

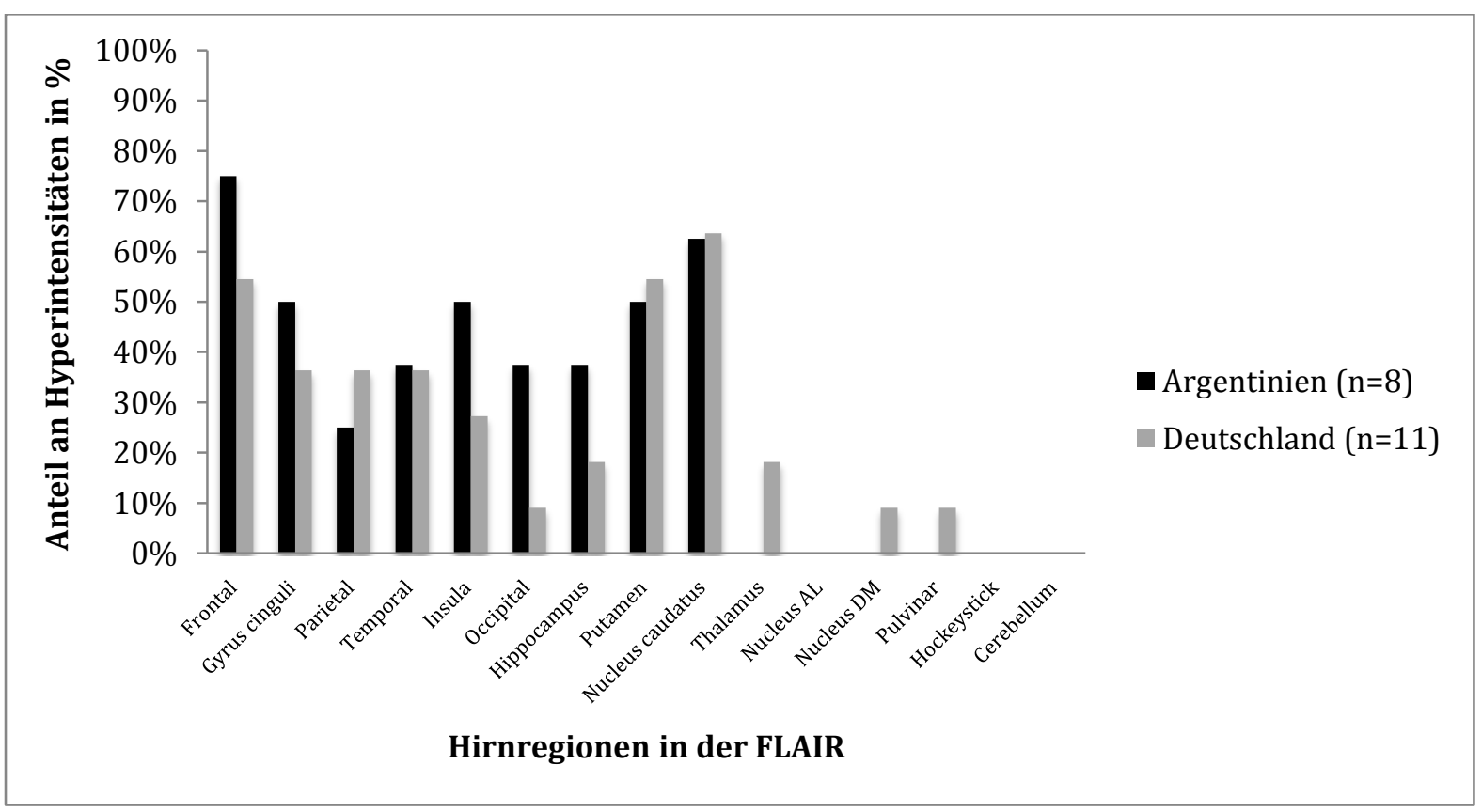




\section{Abbildung 3.12 Frequenz und Verteilung von Hyperintensitäten in der DWI bei der E200K-Mutation aufgeschlüsselt nach Land}

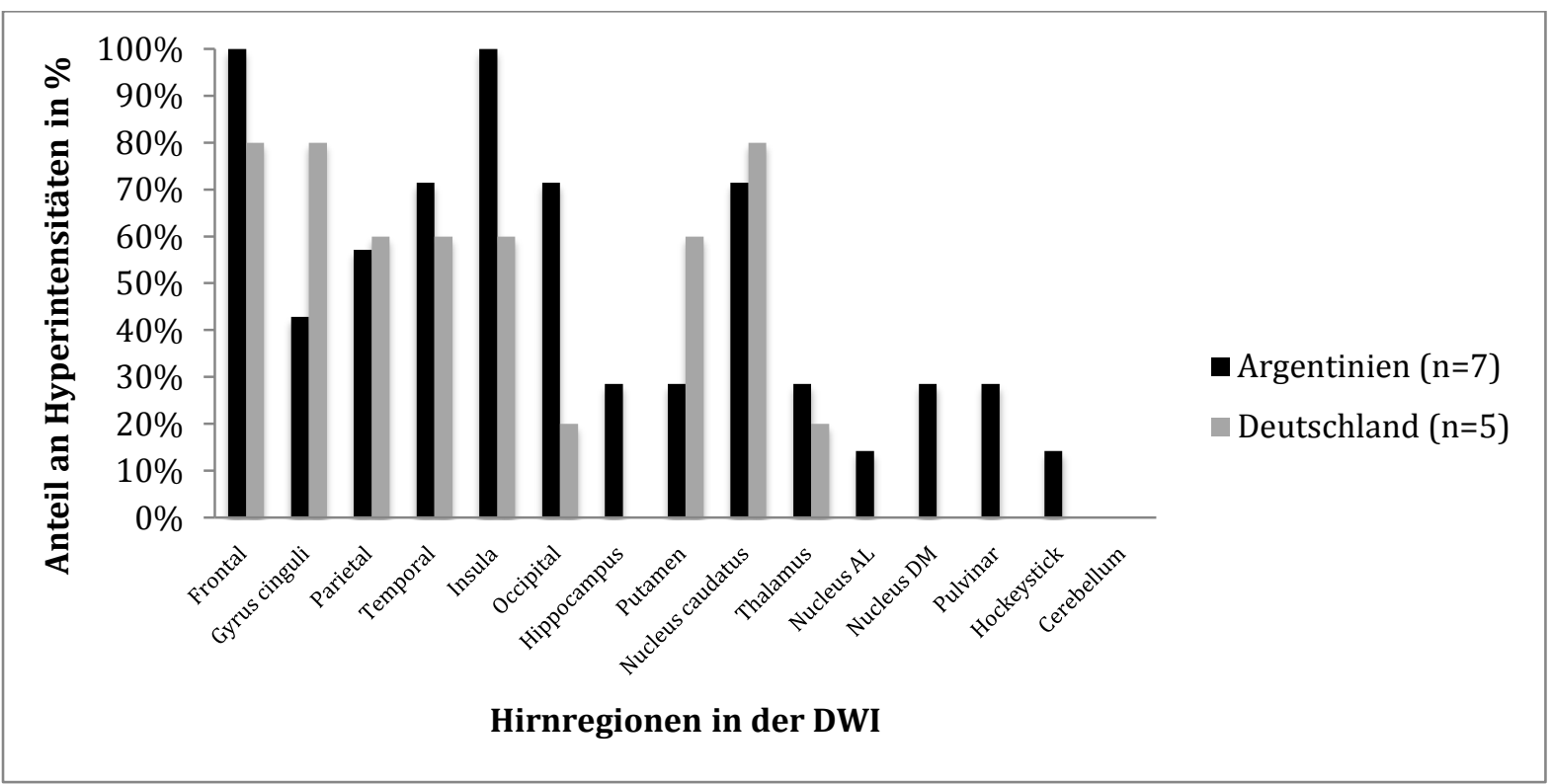

\subsection{Vergleich der beiden Rater und Inter-Rater-Übereinstimmung}

Die Übereinstimmung der Urteile oder auch Inter-Rater-Reliabilität zwischen den beiden Neuroradiologen, welche die Evaluation der MRT-Aufnahmen des gCJK-Kollektivs vorgenommen hatten, war für beide Wichtungen (FLAIR und DWI) gut. In der FLAIR fanden sich gute Übereinstimmungen für den occipitalen Kortex, den Nucleus caudatus, Putamen und Thalamus $(\mathrm{p}<0,001)$. Darüber hinaus zeigten sich gute Übereinstimmungen für den frontalen und temporalen Kortex, den Hippokampus und Gyrus cinguli.

In der DWI-Wichtung ließen sich ähnliche Ergebnisse nachweisen, die besten Übereinstimmungen fanden sich hier jedoch in der Bewertung des Hippocampus, Nucleus caudatus und Thalamus.

Beide Neuroradiologen werteten in der FLAIR-Wichtung 19 MRT-Aufnahmen als CJKtypisch laut den definierten Kriterien. In der DWI-Wichtung erfüllten laut Rater 1 elf Patienten die MRT-Kriterien, Rater 2 fand typische Veränderungen bei insgesamt zwölf Patienten. 


\section{Diskussion}

10-15\% der humanen TSE sind genetisch bedingt und daher sowohl erblich als auch potentiell infektiös. Die definitive Diagnose beruht nach wie vor auf dem Nachweis einer Mutation im Prion-Protein-Gen. Einige genetische Prionerkrankungen weisen einen besonderen Phänotyp auf, wie z.B. das GSS, andere Mutationen hingegen, wie z.B. die E200K- oder V210I-Mutationen, ähneln sowohl im klinischen Erscheinungsbild als auch in den erhobenen Befunden der Zusatzdiagnostik (EEG und Bestimmung der Proteine 14-3-3) sehr der sporadischen CJK. Dies macht eine Identifizierung der Fälle anhand des Phänotyps der Erkrankung fast unmöglich. Die Diagnose einer genetischen Prionerkrankung erfolgt also in der Regel nur bei positiver Familienanamnese und somit begründetem Verdacht oder als Zufallsbefund, wenn eine Sequenzierung des PRNP erfolgt. In der vorliegenden Arbeit sollte untersucht werden, ob die Befunde der kraniellen Kernspintomographie bei Patienten mit der E200K- oder V210I-Mutation ebenfalls denen von SCJK ähneln. Insbesondere sollte dabei auf mögliche Unterschiede im Verteilungsmuster der Signalalterationen in der FLAIR und/oder DWI geachtet werden. Darüber hinaus sollte geprüft werden, ob die erst kürzlich definierten und in die Diagnosekriterien aufgenommenen MRT-Kriterien für sCJK auch Patienten mit der E200K- und V210I-Mutation erfasst werden. Im Folgenden werden zunächst die eigenen Ergebnisse diskutiert und anschließend mit denen der Literatur verglichen.

\subsection{Die untersuchten Patientenkollektive}

In der vorliegenden Arbeit wurden im Rahmen einer großen multizentrischen Studie Patienten mit einer Mutation im PRNP hinsichtlich MRT-Alterationen in der FLAIRund/oder DWI-Wichtung untersucht und mit einer Kontrollgruppe, bestehend aus Patienten mit einer sporadischen $\mathrm{CJK}$, verglichen. In die Patientengruppe eingeschlossen wurden Patienten mit den häufigsten Mutationen einer genetischen CJK, der E200K- und V210I-Mutation, um eine ausreichend große Fallzahl evaluieren zu können. Außerdem ähneln diese beiden Mutationen in ihrem Phänotyp der sporadischen CJK und erlauben 
daher bei negativer Familienanamnese eine Diagnose in der Regel nur durch eine genetische Testung (de Pedro-Cuesta et al. 2006).

Primäres Einschlusskriterium für die Patienten des genetischen Kollektivs war neben dem Nachweis einer Mutation im PRNP das Vorhandensein von MRT-Aufnahmen mit FLAIR und/oder DWI. Die demographischen Daten des selektierten Patientenkollektivs ähnelten den Angaben aus der Literatur. Unter den E200K-Patienten fanden sich tendenziell mehr weibliche Patienten mit einem Geschlechterverhältnis von 1,37. Im V210IKollektiv von 10 Patienten fanden sich jeweils fünf Frauen und Männer. In einer großen internationalen Studie der EURO-CJK-Gruppe wurde das jeweilige Geschlechterverhältnis für die E200K-Patienten und V210I-Patienten mit 1,59 und 1,62 angegeben (Kovács et al. 2005).

Da die Mutation im PRNP in den meisten Fällen an Methionin gekoppelt ist, verschiebt sich die Verteilung des Polymorphismus am Codon 129 gegenüber der sporadischen CJK zugunsten von Methionin (Kovács et al. 2005). Die meisten Patienten mit gCJK haben daher den Genotyp MM oder MV am Codon 129. Dies ließ sich auch in unserem Patientenkollektiv bestätigen, da keiner der E200K-Patienten und nur ein einziger V210IPatient homozygot für Valin war. Eine Übersicht der Verteilung des Polymorphismus am Codon 129 im untersuchten Patientenkollektiv und sCJK-Patienten einer publizierten Studie gibt Abbildung 4.1. 
Abbildung 4.1 Verteilung des Genotyps am Codon 129 im gCJK-Kollektiv dieser Arbeit und bei sCJK anhand publizierter Daten aus der Studie von Heinemann et al. 2007

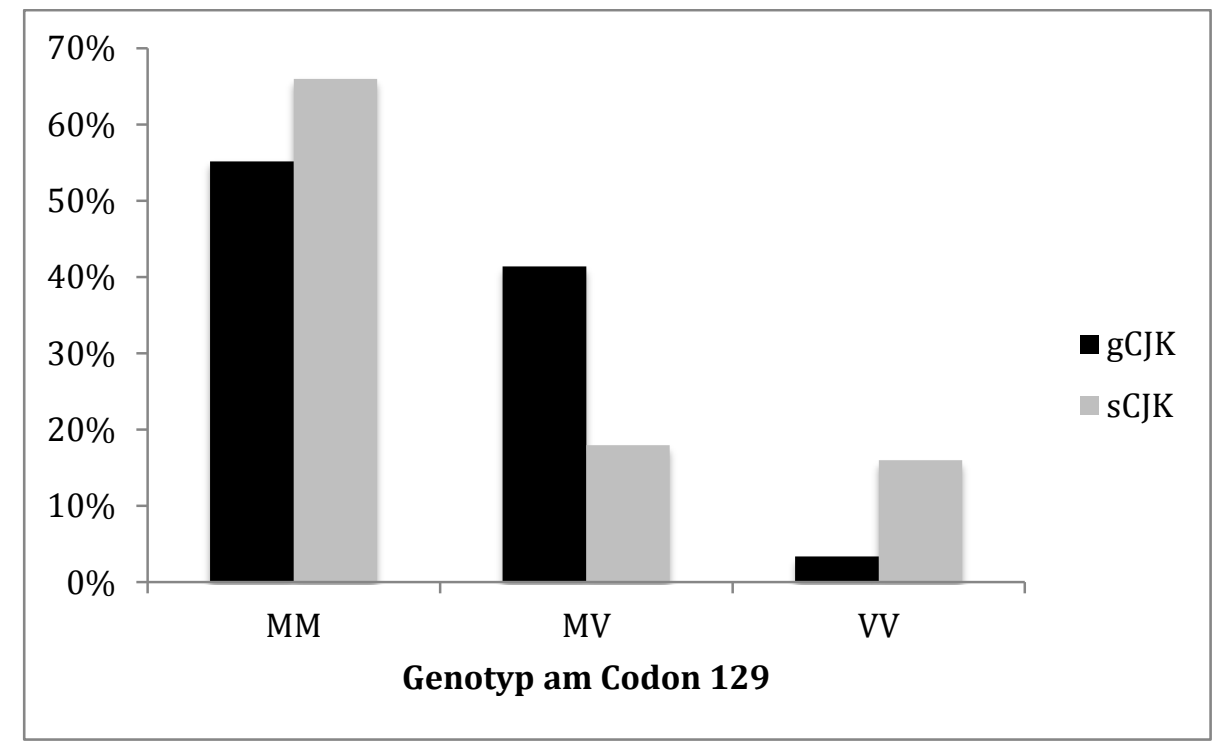

Das Alter bei Erkrankung lag bei den E200K-Patienten unseres Kollektivs im Median bei 61 Jahren, bei den V210I-Patienten bei 60 Jahren. Wie in der Literatur bereits beschrieben, wiesen somit beide Patientengruppen einen etwas früheren Krankheitsbeginn auf als Patienten mit sporadischer CJK (Heinemann et al. 2007).

Die mediane Krankheitsdauer der E200K-Patienten lag bei 6 Monaten und entspricht den Angaben der Literatur (Nozaki et al. 2010; Meiner et al. 2011). Bei den Patienten mit der V210I-Mutation hingegen war die mediane Überlebenszeit mit 5 Monaten etwas länger als in den wenigen publizierten Daten der Literatur beschrieben (Mastrianni et al. 2001; Kovács et al. 2005).

In Tabelle 4.1 ist eine Übersicht über die Verteilung der demographischen Daten des Patientenkollektivs dieser Arbeit und denen der Literatur dargestellt. 
Tabelle 4.1 Geschlechterverhältnis, Alter bei Erkrankung, Krankheitsdauer und Polymorphismus am Codon 129 der E200K- und V210I-Mutation des untersuchten Kollektivs dieser Studie im Vergleich mit Literaturdaten

\begin{tabular}{|c|c|c|c|c|c|c|c|c|c|}
\hline & $\begin{array}{c}\text { Eigene } \\
\text { Ergebnisse* }\end{array}$ & $\begin{array}{c}\text { Kovács et al. } \\
2005^{*}\end{array}$ & $\begin{array}{c}\text { Ladogana et al. } \\
2005^{*}\end{array}$ & $\begin{array}{c}\text { Mitrova und } \\
\text { Belay } 2002\end{array}$ & $\begin{array}{l}\text { Heinemann et } \\
\text { al. } 2007^{*}\end{array}$ & $\begin{array}{c}\text { Nozaki et al. } \\
2010\end{array}$ & $\begin{array}{c}\text { Meiner et al. } \\
2011\end{array}$ & $\begin{array}{c}\text { Cohen et al. } \\
2012\end{array}$ & $\begin{array}{c}\text { Mastrianni et } \\
\text { al. } 2001\end{array}$ \\
\hline $\mathbf{E 2 0 0 K}(\mathrm{n})$ & 19 & 175 & 42 & 95 & 21 & 37 & 70 & 43 & \\
\hline $\mathrm{w}: \mathrm{m}$ & 1,37 & 1,59 & & & 0,5 & 0,7 & 0,93 & 0,7 & \\
\hline Alter (J.) & 61 & 60,4 & & & 61,5 & 58,5 & 60 & 58,7 & \\
\hline Dauer (M.) & 6 (Median) & 5.0 (Median) & & $\begin{array}{c}\mathrm{MM}=3,7 \\
\mathrm{MV}=7,8\end{array}$ & 6,5 & 3,9 & 8,9 & 3,9 & \\
\hline \multicolumn{10}{|l|}{ c129 (\%) } \\
\hline MM & 53 & 78,3 & 79 & 78,6 & & 92 & & & \\
\hline MV & 47 & 19,9 & 18 & 21,4 & & & & & \\
\hline VV & 0 & 1,8 & 3 & & & & & & \\
\hline V210I (n) & 10 & 69 & 54 & & 15 & & & & 4 \\
\hline $\mathrm{w}: \mathrm{m}$ & 1 & 1,62 & & & 0,9 & & & & 0,33 \\
\hline Alter (J.) & 60 & 59,3 & & & 61,5 & & & & 52 \\
\hline Dauer (M.) & 5 (Median) & 4,0 (Median) & & & 3,6 & & & & 5,5 \\
\hline \multicolumn{10}{|l|}{ c129 (\%) } \\
\hline MM & 60 & 73,1 & 73 & & & & & & 100 \\
\hline MV & 30 & 26,9 & 27 & & & & & & 0 \\
\hline VV & 10 & 0 & 0 & & & & & & 0 \\
\hline
\end{tabular}

*überlappende Datensätze 
Da sowohl der Krankheitsverlauf als auch die Ergebnisse der apparativen Diagnostik verschiedenen Einflussfaktoren unterliegen, wurde das Kontrollkollektiv der sCJKPatienten hinsichtlich des Zeitpunktes des MRT-Untersuchung im Krankheitsverlauf, des Geschlechts, des Alters bei Symptombeginn und des Polymorphismus am Codon 129 angeglichen. In den meisten Fällen war der PrP-Typ aufgrund fehlender Informationen nicht bekannt, so dass dieser Faktor bei der Auswahl des Kontrollkollektivs nicht berücksichtigt werden konnte. Dies stellt eine potentielle Fehlerquelle in der Beurteilung der Daten dar, die sich jedoch dadurch relativiert, dass die Subtypen MM2 und VV1 sehr selten auftreten (Meissner et al. 2005; Krasnianski et al. 2006).

\subsection{Magnetresonanztomographie (MRT)}

Die Datenlage zu MRT-Veränderungen bei genetischer CJK ist insbesondere aufgrund der Seltenheit der Erkrankung und fehlender größerer Studien dünn. Die meisten Erkenntnisse beruhen auf Fallbeispielen, kleineren Fallserien oder epidemiologischen Studien, in denen Patienten mit genetischer und sporadischer CJK in einem Kollektiv vereint untersucht wurden. Im Folgenden werden die Ergebnisse der MRT-Auswertung des gCJK- und sCJK-Kollektivs dieser Arbeit miteinander verglichen. Darüber hinaus erfolgt ein Vergleich mit den Daten früherer Arbeiten aus der Literatur.

\subsubsection{MRT-Datensatz}

Die MRT-Bilder diese Studie wurden im Rahmen der Routinediagnostik an verschiedenen Kliniken und verschiedenen Geräten durchgeführt. Dadurch unterlagen auch die Studienprotokolle der Auswahl der jeweiligen Kliniken. Im gCJK-und sCJK-Kollektiv war bei allen Patienten die FLAIR-Wichtung Bestandteil des Untersuchungsprotokolls. Die DWI wurde hingegen nur bei 15 Patienten des gCJK-Kollektivs und 13 Patienten des sCJK-Kontrollkollektivs durchgeführt. Dies ist dadurch erklärt, dass auf der einen Seite, zum Zeitpunkt der Durchführung des MRT, die CJK nicht immer eine Verdachtsdiagnose war, auf der anderen Seite in einigen Kliniken die DWI nicht Routine in der Demenzdiagnostik ist. Da die DWI als sensitivste Wichtung des MRT in der Diagnose der CJK gilt, 
stellt die geringere Anzahl an DWI-Bildern in der vorliegenden Arbeit einen Nachteil dar. Die Qualität der durchgeführten Bilder, welche in Schulnoten von 1 (exzellent) bis 4 (ausreichend) bewertet wurden, war in beiden Gruppen vergleichbar. Im Kollektiv der gCJK-Patienten wurden 42\% der Fälle als „exzellent“ oder „gut“ bewertet, im Kontrollkollektiv waren es 49\% der MRT-Bilder. Da die MRT-Bilder im Rahmen der Routinediagnostik angefertigt wurden, erfolgte die Untersuchung in verschiedenen Krankenhäusern in Argentinien und Deutschland und somit an verschiedenen Scannern unterschiedlicher Hersteller. Dies könnte einen möglichen Einfluss auf die Untersuchungsergebnisse haben - sowohl innerhalb des jeweiligen Landes, als auch zwischen den Ländern. Der Zeitpunkt der MRT-Untersuchung nach Beginn erster klinischer Symptome war in beiden Kollektiven vergleichbar. Die Patienten mit genetischer CJK erhielten im Median 2,7 Monate nach Auftreten erster Symptome eine MRT. Im Kontrollkollektiv wurde die Untersuchung bei einem Median von 3,1 etwas später durchgeführt. Wurde der Untersuchungszeitpunkt in Relation zur gesamten Krankheitsdauer gesetzt, war festzustellen, dass 31\% der Patienten im ersten Drittel der Erkrankung, 41\% im zweiten Drittel und 28\% im letzten Drittel untersucht worden waren. Signalalterationen können sich über den Zeitraum der Erkrankung ändern und an Intensität zunehmen (Murata et al. 2002; Russmann et al. 2005). Die Patienten des Kontrollkollektivs waren daher auch bezüglich des Zeitpunktes der MRT-Untersuchung dem Patientenkollektiv angepasst. In Untersuchungen an asymptomatischen Trägern der E200K-Mutation, konnten jedoch bereits vor Auftreten erster klinischer Symptome Änderungen im Signalverhalten der MRT dokumentiert werden (Lee et al. 2009). Somit bleibt zu klären in wie weit der Zeitpunkt der MRT-Untersuchung die Sensitivität beeinflusst, man muss jedoch annehmen, dass die genannten Veränderungen bei E200K schon sehr früh zu erwarten sind.

\subsubsection{Einfluss der MRT-Wichtung}

In der vorliegenden Arbeit wurden für die Auswertung der MRT-Untersuchungen lediglich die sensitivsten Wichtungen FLAIR und DWI berücksichtigt. Für diese beiden Wichtungen ist in der Literatur die Überlegenheit gegenüber anderen Wichtungen, wie T2 und PD, in der Detektion von Signalalterationen gut belegt (Kallenberg et al. 2006; Zerr et al. 2009; Vitali et al. 2011). Sowohl im gCJK- als auch im sCJK-Kontrollkollektiv konnten Hyperintensitäten im Bereich des Nucleus caudatus und Putamen etwa gleich häufig in der FLAIR und DWI beobachtet werden. Hyperintensitäten im Bereich des Cerebel- 
lums konnten bei keinem der Patienten des gCJK-Kollektivs nachgewiesen werden, jedoch bei 17\% des sCJK-Kollektivs (p=0,052). In Anbetracht der kleinen Fallzahl, ist dieses Ergebnis durchaus als Trend zu betrachten. Pathologische Signalalterationen im Bereich des Kortex hingegen ließen sich in beiden Kollektiven häufiger in der DWI nachweisen. Diese Ergebnisse korrelieren gut mit den Daten der Literatur. Die Überlegenheit der DWI gegenüber anderen Wichtungen hinsichtlich der Sensitivität ist hinlänglich bekannt. In mehreren Studien wurde eine höhere Sensitivität der DWI für den Nachweis kortikaler Hyperintensitäten beschrieben (Shiga et al. 2004; Young et al. 2005; Kallenberg et al. 2006; Vitali et al. 2011). Längere Zeit lag der Fokus bei der Suche nach CJK-typischen Veränderungen allein auf den Basalganglien. Erst später, insbesondere nach Einführung der DWI, fiel auf, dass auch kortikale Regionen sehr häufig in der MRT von CJK-Patienten zu finden sind. Mittlerweile sind Hyperintensitäten im parietalen, temporalen und/oder occipitalen Kortex Teil der definierten Diagnosekriterien. Die höherer Sensitivität der DWI kann also insbesondere durch die bessere Detektion kortikaler Signalalterationen erklärt werden. Ein weiterer Vorteil der DWI gegenüber anderen Wichtungen, ist die geringere Anfälligkeit gegenüber Artefakten beispielsweise durch Bewegung des Patienten während der Untersuchung.

Die MRT-Aufnahmen der Patienten dieser Arbeit wurden in verschiedenen Krankenhäusern angefertigt und nicht anhand eines einheitlichen Studienprotokolls erstellt. Somit war die DWI nicht immer Bestandteil der Routinediagnostik zur Demenzabklärung. Während FLAIR-Aufnahmen für alle eingeschlossenen Patienten vorlagen, lag bei nur 15 Patienten des genetischen Kollektivs und 13 Patienten des sCJK-Kontrollkollektivs eine zusätzliche DWI-Wichtung vor. Dies stellt eine Einschränkung in der Beurteilung der Sensitivität dar. Bei drei Patienten konnten Hyperintensitäten in der DWI gesichert werden, welche in der FLAIR nicht ersichtlich waren. Es ist möglich, dass die Sensitivität der MRT-Veränderungen in beiden Kollektiven höher gewesen wäre, wenn mehr Patienten eine Untersuchung mit DWI erhalten hätten. Insbesondere, wenn man beachtet, dass bei einem Drittel der Patienten mit sCJK rein kortikale Hyperintensitäten zu finden sind (Meissner et al. 2008). 


\subsubsection{Einfluss der Mutation}

In dem untersuchten Patientenkollektiv dieser Arbeit schien die Mutation im PRNP keinen wesentlichen Einfluss auf die Häufigkeit oder das Verteilungsmuster von Hyperintensitäten im cMRT zu haben. Es konnten keine signifikanten Unterschiede zwischen der E200K-, der V210I-Gruppe und dem sCJK-Kontrollkollektiv festgestellt werden. Es ist bekannt, dass die in dieser Arbeit untersuchten Mutationen des PRNP dem häufigsten Subtyp der sCJK ähneln. Andere Mutationen im PRNP hingegen unterscheiden sich hinsichtlich ihres Phänotyps deutlich von der sporadischen CJK. Auch die diagnostischen Tests inklusive der cMRT weisen andere Sensitivitäten auf. Bei Patienten mit FFI finden sich häufig gar keine Signalalterationen in der Kernspintomographie, sondern oftmals nur eine generelle Hirnatrophie (Krasnianski et al. 2008a). Im Folgenden werden die Ergebnisse für die E200K- und V210I-Mutation im Einzelnen diskutiert.

\subsubsection{MRT-Veränderungen bei der E200K-Mutation}

Bei mehr als der Hälfte aller Patienten mit der E200K-Mutation konnten Signalalterationen in den MRT-Untersuchungen nachgewiesen werden. Betroffen waren insbesondere die Regionen der Basalganglien (Nucleus caudatus und Putamen), der frontale Kortex gefolgt von weiteren kortikalen Regionen (temporal, insulär, occipital und parietal). Dabei konnten in der sensitiveren DWI häufiger Veränderungen nachgewiesen werden als in der FLAIR-Wichtung. Insgesamt ließen sich keine Unterschiede in der Verteilung oder Häufigkeit von MRT-Alterationen im Vergleich zum sCJK-Kontrollkollektiv feststellen. Eine Differenzierung zwischen Patienten mit der E200K-Mutation und Patienten mit sporadischer CJK anhand des MRT ist somit nicht möglich.

In einer gemeinschaftlichen Studie des EUROCJD-Netzwerkes an einem größeren Patientenkollektiv mit genetischer CJK, wurden pathologische MRT-Veränderungen bei 50\% der E200K-Patienten beschrieben (Kovács et al. 2005). Prospektive Beobachtungsstudien im Rahmen der epidemiologischen Arbeit der Referenzzentren in Deutschland und Japan konnten bei respektive 62,5\% und 81\% der Patienten Hyperintensitäten im Bereich der Basalganglien nachweisen (Heinemann et al. 2007; Nozaki et al. 2010). Spezifische Angaben zum Vorliegen oder Verteilungsmuster kortikaler Signalalterationen oder eine genaue Definition der „pathologischen“ MRT-Befunde erfolgten jedoch nicht. 
Die wenigen prospektiven Studien zur Untersuchung von MRT-Veränderungen bei genetischer CJK, gelangten zu ähnlichen Ergebnissen wie die vorliegende Studie. In einer verblindeten und kontrollierten Studie an 15 Patienten mit der E200K-Mutation und 22 gesunden Kontrollen, wiesen 13 von 15 Patienten (87\%) pathologische Signalalterationen auf (Fulbright et al. 2008). Der Nachweis von Hyperintensitäten in der FLAIR im Bereich des Putamens oder Nucleus caudatus erreichte eine Sensitivität von $87 \%$ und eine Spezifität von 91\%. Im Patientenkollektiv dieser Arbeit fanden sich hingegen bei 63\% in der FLAIR und 75\% in der DWI Hyperintensitäten im Bereich des Putamens oder Nucleus caudatus. Betrachtet man jedoch die Ergebnisse der Signalalterationen in kortikalen Regionen, so konnten diese, auch unter Ausschluss artefaktanfälliger Regionen wie der frontale Kortex oder Gyrus cinguli, im vorliegenden Kollektiv dieser Arbeit häufiger nachgewiesen werden als in der Studie von Fulbright (37\% vs. 245). Mögliche Erklärungen für diese Unterschiede sind Einflussfaktoren wie der Zeitpunkt der Untersuchung oder die Qualität der MRT-Bilder. Übereinstimmend mit den Ergebnissen dieser Arbeit werden in der Literatur keine Hyperintensitäten bei E200K-Patienten im Bereich des Zerebellums beschrieben.

Die Auswertung der MRT-Aufnahmen erfolgte rein deskriptiv ohne die Verwendung quantitativer Methoden. Neuere Studien beschreiben den frühen Nachweis von Diffusionseinschränkungen im Bereich thalamo-striataler Netzwerke und des Putamens mittels Voxel- oder Computer-basierter Berechnungen (Lee et al. 2009; Seror et al. 2010).

\subsubsection{MRT-Veränderungen bei der V210I-Mutation}

Die Ergebnisse der MRT-Alteration in der FLAIR-Wichtung von Patienten mit der V210IMutation unterschieden sich nicht von denen der E200K-Gruppe oder dem Kontrollkollektiv. Etwas häufiger als bei der E200K-Mutation ließen sich im V210I-Kollektiv Hyperintesitäten im Bereich der Basalganglien nachweisen. Das Ergebnis war jedoch nicht statistisch signifikant. Es muss kritisch angemerkt werden, dass die Ergebnisse der MRT-Veränderungen in der DWI-Wichtung aufgrund zu niedriger Fallzahlen nicht statistisch verglichen werden. Somit ist eine Auswertung der sensitivsten Wichtung nicht möglich und es kann keine sichere Aussage zur Sensitivität der DWI bei V210I-Patienten getroffen werden. 
In der Literatur finden sich aufgrund der geringen Fallzahlen nur sehr wenige Daten zu MRT-Veränderungen bei der V210I-Mutation. Einzelne Fallbeispiele beschreiben Hyperintensitäten im Bereich der Basalganglien und verschiedener kortikaler Regionen (Shyu et al. 1996; Huang et al. 2001; Nitrini et al. 2001). In den Daten aus größeren Kollektiven in der Kollaborationsstudie zu genetischen Prionerkrankungen des EUROCJD-Netzwerks fanden die Autoren lediglich bei $15 \%$ der 46 Patienten pathologische MRTVeränderungen (Kovács et al. 2005). Eine genauere Beschreibung oder Definition der Signalalterationen erfolgte jedoch nicht. Etwas häufiger, bei 45\% der Patienten mit einer V210I-Mutation, konnten Hyperintensitäten im Bereich der Basalganglien in einer prospektiven Studie des Referenzzentrums für Prionerkrankungen beobachtet werden, wobei sich die Datensätze zum Teil überlappen (Heinemann et al. 2007). Im Vergleich zu den einzigen beiden Studien, waren MRT-Veränderungen im gCJK-Kollektiv dieser Arbeit häufiger zu finden. Bisher existieren keine kontrollierten, prospektiven Studien zu MRT-Veränderungen bei V210I-Patienten. Ein genauer Vergleich der Daten ist somit nicht möglich, da weder eine genaue Beschreibung der Patientenkollektive noch der MRT-Daten vorliegt.

Tabelle 4.2 gibt einen Überblick über die Daten zu MRT-Befunden bei E200K- und V210I-Patienten aus der Literatur. Die Datenlage zur MRT-Veränderungen bei der E200K- und V210I-Mutation ist insgesamt sehr dünn. Viele der beschriebenen Veränderungen stammen aus Fallberichten oder Fallserien. In den meisten Fällen hat keine standardisierte Auswertung der MRT-Bilder stattgefunden. Es wurden lediglich, wie in der EUROCJD-Studie, Befunde aus den Patientenakten statistisch erhoben. Eine erneute Evaluation der MRT-Aufnahmen durch einen erfahrenen Neuroradiologen fand nicht statt. Den meisten Beschreibungen in der Literatur kann kein genaues Verteilungsmuster der Läsionen entnommen werden. Auch liegen in den meisten Fällen keinerlei Informationen zu den beurteilten Wichtungen vor. Bei vielen älteren Studien kann angenommen werden, dass die DWI-Wichtung nicht durchgeführt oder berücksichtigt wurde. 
Tabelle 4.2 Literaturübersicht zu MRT-Veränderungen bei der E200K- und V210I Mutation zum Zeitpunkt der Datenerhebung dieser Arbeit

\begin{tabular}{|c|c|c|c|c|c|c|c|c|c|}
\hline & Autor & Studienart & Fallzahl & $\begin{array}{c}\text { MRT- } \\
\text { Wichtung }\end{array}$ & Ergebnisse & & salganglien & & tex \\
\hline & (Furukawa et al. 1996) & Fallbericht & 1 & Nicht genannt & Atrophie & - & & - & \\
\hline & (Tsuboi et al. 2005) & Fallbericht & 1 & DWI & & + & Nucleus caudatus, Putamen & + & Insula, Gyrus cinguli \\
\hline & (Kovács et al. 2005) & Studie & 175; 66 MRT & Nicht genannt & $\begin{array}{l}\text { MRT "positiv“ bei } 50 \% \\
\text { der Patienten }\end{array}$ & & & & \\
\hline & (Fulbright et al. 2006) & Fallbericht & 4 & FLAIR/DWI & & + & Putamen, Thalamus & & \\
\hline & (Rene et al. 2007) & Fallbericht & 1 & Nicht genannt & & + & Nucleus caudatus, Putamen & & \\
\hline & (Farbu et al. 2007) & Fallbericht & 2 & DWI & & + & & - & \\
\hline & (Heinemann et al. 2007) & Studie & 21 & FLAIR/DWI & & + & Hyperintensitäten bei $63 \%$ & & \\
\hline & (Fulbright et al. 2008) & Studie & $\begin{array}{l}15 \text { Patienten } \\
22 \text { Kontrollen }\end{array}$ & FLAIR/DWI & $\begin{array}{l}87 \% \text { der Patienten } \\
\text { zeigten ein abnormes } \\
\text { MRT }\end{array}$ & + & $\begin{array}{l}\text { FLAIR Nucleus caudatus und Puta- } \\
\text { men: Sensitivität } 87 \% \text { und Spezifität } \\
91 \% \\
\text { DWI Nucleus caudatus: Sensitivität } \\
73 \% \text { und Spezifität } 100 \% \text {. }\end{array}$ & + & $\begin{array}{l}\text { Gyrus cinguli, frontal und } \\
\text { occipital }\end{array}$ \\
\hline E200K & (Ghoshal et al. 2009) & Fallbericht & 4 & $\begin{array}{l}\text { DWI nur bei } \\
\text { einem Teil der } \\
\text { Patienten }\end{array}$ & & + & $\begin{array}{l}\text { 3/4 Nucleus caudatus, Putamen, } \\
\text { Thalamus }\end{array}$ & + & $50 \%$ Frontal und parietal \\
\hline & (Choi et al. 2009) & Fallbericht & 1 & FLAIR/DWI & & + & Nucleus caudatus & + & $\begin{array}{l}\text { Frontal, temporal, parie- } \\
\text { tal }\end{array}$ \\
\hline & (Mancuso et al. 2009) & Fallbericht & 1 & FLAIR/DWI & & + & Nucleus caudatus und Pallidum & & Frontal, Gyrus cinguli \\
\hline & (Lee et al. 2009) & Studie & $\begin{array}{l}14 \text { Patienten, } \\
20 \text { Mutationsträger } \\
20 \text { Kontrollen }\end{array}$ & DWI & & + & thalamo-striatale & & \\
\hline & (Nozaki et al. 2010) & Studie & 37 & FLAIR/DWI & $\begin{array}{l}\text { Hyperintensitäten bei } \\
89 \%\end{array}$ & + & & & \\
\hline & (Seror et al. 2010) & Studie & $\begin{array}{l}12 \text { E200K } \\
20 \text { Kontrollen }\end{array}$ & DWI & & + & $\begin{array}{l}\text { Diffusionseinschränkung im Putamen } \\
\text { in der Voxel-basierten Analyse }\end{array}$ & & \\
\hline & (Masullo et al. 2010) & Fallbericht & 1 & FLAIR/DWI & & + & $\begin{array}{l}\text { Nucleus caudatus, Putamen, Pulvinar, } \\
\text { Thalamus }\end{array}$ & + & Gesamter Kortex \\
\hline & (Cohen et al. 2011) & Studie & 31 & DWI & & + & Thalamus & + & Frontal \\
\hline & (Shyu et al. 1996) & Fallbericht & 1 & Nicht genannt & Atrophie & + & $\begin{array}{l}\text { Nucleus caudatus, Putamen, Tha- } \\
\text { lamus }\end{array}$ & & \\
\hline & (Huang et al. 2001) & Fallbericht & 1 & DWI & & + & & & \\
\hline V210I & (Mastrianni et al. 2001) & Fallbericht & 4 & Nicht genannt & $\begin{array}{l}\text { Keine Hyperintensitä- } \\
\text { ten, aber kotikale Hy- } \\
\text { poperfusion }\end{array}$ & - & & - & \\
\hline & (Nitrini et al. 2001) & Fallbericht & 2 & DWI & & + & Striatum & + & Insula, frontal, parietal \\
\hline & (Kovács et al. 2005) & Studie & 67; 46 MRT & Nicht genannt & 15\% positives MRT & & & & \\
\hline & (Heinemann et al. 2007) & Studie & 15 & FLAIR/DWI & & + & Hyperintensitäten bei $45 \%$ & & \\
\hline
\end{tabular}




\subsubsection{Einfluss des Subtyps anhand des Polymorphismus am Codon 129}

Neben dem klinischen Phänotyp und Krankheitsverlauf haben der Polymorphismus am Codon 129 und der PrP-Typ mit den daraus resultierenden Subtypen Einfluss auf die Sensitivität verschiedener diagnostischer Tests bei der sporadischen CJK (Parchi et al. 1999b; Collins et al. 2006). Die Patienten wurden daher in Subgruppenanalysen nach dem Genotyp am Codon 129 stratifiziert. Informationen über den jeweiligen PrP-Typ lagen nur für einige Patienten vor. Eine Berücksichtigung des genauen Subtyps in der Analyse der MRT-Aufnahmen war somit aufgrund der sehr niedrigen Fallzahlen nicht möglich.

In der vorliegenden Arbeit wiesen Patienten mit dem Genotyp MV am Codon 129 am häufigsten Hyperintensitäten im MRT auf. In dieser Patientengruppe wurden daher auch die MRT-Kriterien am häufigsten erfüllt. Bei insgesamt 83\% der MV-Patienten des genetischen Patientenkollektivs wurde das MRT als CJK-typisch gewertet. Im sCJKKontrollkollektiv fanden sich bei Patienten, die heterozygot am Codon 129 waren, mit 93\% sogar tendenziell noch häufiger MRT-Alterationen. Ein Einfluss auf das Verteilungsmuster von Hyperintensitäten im MRT durch den Polymorphismus am Codon 129 ist in der Literatur gut beschrieben. Der häufige MV1-Subtyp weist in der Regel kortikale Hyperintensitäten auf (Meissner et al. 2009). Der sehr seltene MV2-Subtyp, hingegen, unterscheidet sich von anderen Subtypen insbesondere durch thalamische Signalalterationen im MRT (Krasnianski et al. 2006; Meissner et al. 2009). Thalamische Signalalterationen fanden sich in beiden Kollektiven dieser Arbeit sehr selten. Aufgrund der fehlenden Informationen bezüglich des PrP-Typs war eine genauere Klassifizierung des Kollektivs leider nicht möglich.

Patienten des genetischen Kollektivs, die homozygot für Methionin (MM) am Codon 129 waren, zeigten in 75\% der Fälle ein CJK-typisches MRT. In der FLAIR ließen sich Hyperintensitäten am häufigsten im Bereich der Basalganglien nachweisen, gefolgt von Veränderungen im frontalen Kortex und Gyrus cinguli. Anders verhielt es sich in der DWI, wo sich Signalalterationen im Kortex häufiger als in den Basalganglien fanden. Letztere Erkenntnis deckt sich mit Daten aus der Literatur, in der für den MM-Subtyp häufiger Hyperintensitäten im Kortex als im Putamen und Nucleus caudatus beschrieben werden (Heinemann et al. 2007; Meissner et al. 2008). 
Da lediglich ein Patient des genetischen Kollektivs den Genotyp VV aufwies, ist eine Beurteilung und Interpretation der MRT-Ergebnisse für diesen Subtyp in der vorliegenden Arbeit nicht möglich. Der einzige eingeschlossene VV-Patient zeigte keine typischen MRT-Veränderungen. Die MRT-Aufnahme wurde am Ende des 2. Krankheitsdrittels angefertigt und die Kotrolle entsprechend gematched, so dass eigentlich anzunehmen sein sollte, dass Veränderungen bereits sichtbar sind. Für den VV1-Subtyp sind überwiegend kortikale Hyperintensitäten beschrieben, während der VV2-Subtyp charakteristischerweise die deutlichsten MRT-Veränderungen im Thalamus und den Basalganglien aufweist (Meissner et al. 2009).

Die mangelnde Fallzahl von VV-Patienten stellt eine Einschränkung in der Interpretation und Analyse der Daten dar. Auch in den wenigen prospektiven Studien zu MRTBefunden bei genetischer CJK wurde keine genaue Analyse nach Subtyp durchgeführt. Aufgrund der Seltenheit der Erkrankung ist die Datenlage sehr begrenzt. Größere Studien mit Informationen über neuropathologische Befunde sind notwendig, um eine genaue Auswertung der MRT-Veränderungen für die Mutationen E200K und V210I anhand der Subtypen vornehmen zu können.

\subsubsection{Einfluss des Ursprungslandes}

Weltweit werden verschiedene Cluster von Patienten mit genetischer CJK beobachtet, wie z.B. in Israel und der Slowakei. Betrachtet man verschiedene phänotypische Merkmale, lassen sich in der Literatur Unterschiede in den Patientengruppen verschiedener Länder feststellen. Ursächlich für diese Unterschiede sind möglicherweise unterschiedliche Ursprungsmutationen. In der Literatur werden mindestens vier verschiedene Ursprungsmutationen beschrieben (Lee et al. 1999). Um mögliche Unterschiede in der Ausprägung von MRT-Alterationen zu untersuchen, wurden die Patienten aus Argentinien mit denen aus Deutschland verglichen.

Die Patienten mit Nachweis der E200K-Mutation aus Deutschland und Argentinien unterschieden sich weder in ihren demographischen Daten noch hinsichtlich der MRTVeränderungen. Ein Vergleich der V210I-Patienten war nicht möglich, da die Mutation im Kollektiv argentinischer Patienten nicht zu finden war. 88\% der E200K-Patienten aus Argentinien und 73\% der E200K-Patienten aus Deutschland hatten „CJK-typische“Veränderungen im MRT und erfüllten die definierten Kriterien. Sowohl in der FLAIR- 
Wichtung als auch in der DWI waren häufig Hyperintensitäten im Bereich der Basalganglien und des Kortex zu finden. Vorangegangene Studien an slowakischen und japanischen E200K-Patienten konnten bei 50\% und 62,5\% der Fälle pathologische MRTVeränderungen nachweisen (Kovács et al. 2005; Nozaki et al. 2010). Im Vergleich zeigten sich in den beiden Gruppen dieser Studie etwas häufiger Signalalterationen. Fulbright et al. konnten hingegen in einem Kollektiv amerikanischer Patienten mit 87\% häufiger Signalalterationen beobachten (Fulbright et al. 2008).

\subsection{Diagnostische Zusatzuntersuchungen}

\subsubsection{Liquoruntersuchung}

Lange Zeit waren die Bestimmung der Proteine 14-3-3 und der Nachweis periodischer Sharp-Wave-Komplexe (PSWC) im EEG die beiden einzigen Zusatzuntersuchungen, die in den klinischen Diagnosekriterien der sCJK Berücksichtigung fanden. Die Sensitivität für den Nachweis der 14-3-3-Proteine im Liquor bei Patienten mit einer sporadischen CJK wird in der Literatur mit 44-64\% angegeben (Steinhoff et al. 2004; Collins et al. 2006; Zerr et al. 2009).

Bei genetischen Prionerkrankungen, wie z.B. der FFI, kann die Sensitivität der 14-3-3Proteine jedoch deutlich geringer sein (Kovács et al. 2005). Bei den beiden Mutationen E200K und V210I, welche in ihrem Phänotyp dem häufigsten MM1-Subtyp der sCJK ähneln, lassen sich die Proteine 14-3-3 jedoch laut Angaben der Literaturdaten häufig nachweisen. Die Sensitivität bei Patienten mit der E200K-Mutation liegt in den meisten Studien bei ca. 90\% (Kovács et al. 2005; Heinemann et al. 2007; Nozaki et al. 2010; Schelzke et al. 2012). Für V210I-Patienten wird die Sensitivität sogar mit $97 \%$ bis 100\% beschrieben (Mastrianni et al. 2001; Kovács et al. 2005; Heinemann et al. 2007; Schelzke et al. 2012). Der Vergleich mit den erhobenen Daten dieser Arbeit zeigt eine gute Übereinstimmung mit den Ergebnissen der publizierten Studien. Die Proteine 14-3-3 konnten bei insgesamt 89\% der gCJK-Patienten nachgewiesen werden. Die Sensitivität bei der E200K-Mutation war mit 83\%, wie in der Literatur beschrieben, geringer als die der V210I-Patienten, bei denen eine Sensitivität von 100\% dokumentiert werden konnte.

Im Kontrollkollektiv wurden bei allen 29 Patienten mit sporadischer CJK 14-3-3Proteine im Liquor nachgewiesen. Die Sensitivität der Proteine 14-3-3 bei der sporadischen CJK wird in der Literatur mit 88 bis 96\% angegeben (Zerr et al. 2000; Collins et al. 
2006; Zanusso et al. 2011). Dass die Sensitivität im vorliegenden Kollektiv bei 100\% liegt, könnte durch die kleine Fallzahl bedingt sein.

Abbildung 4.2 gibt einen Überblick über die Sensitivität der 14-3-3-Proteine in der vorliegenden Arbeit im Vergleich mit Angaben aus der Literatur.

Abbildung 4.2 Sensitivität der 14-3-3-Proteine im Liquor bei Patienten mit der E200K- und V210I-Mutation der eigenen Daten im Vergleich mit Literaturdaten

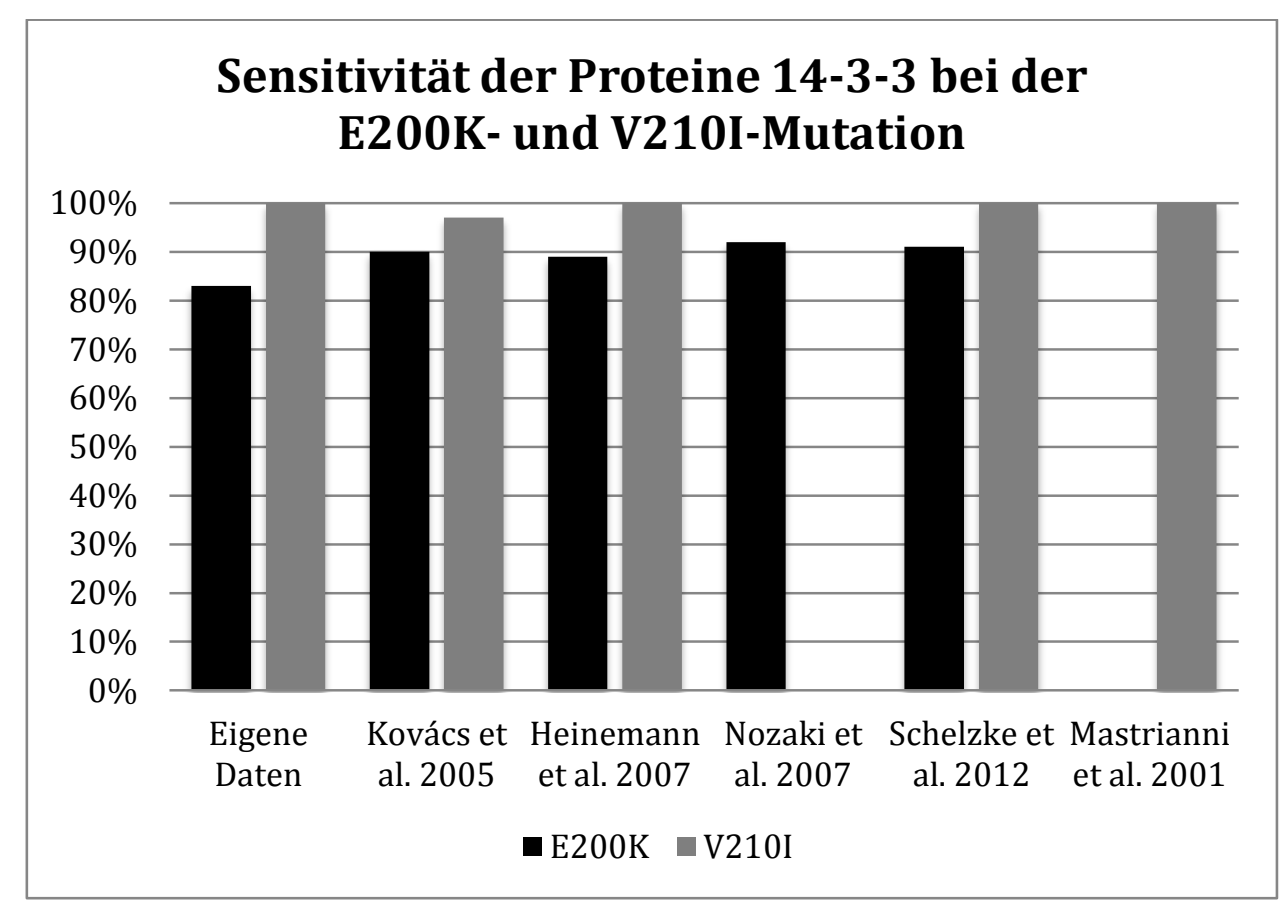

Seit einiger Zeit wird das Tau-Protein im Liquor als möglicherweise noch sensitiverer Parameter in der Diagnostik der CJK betrachtet. Es stellt einen sensitiven Marker für neurodegenerative Prozesse dar und ist daher bei Patienten mit CJK aufgrund des raschen und massiven Zelluntergangs in der Mehrzahl der Fälle mit stark erhöhten Werten nachweisbar. Die Sensitivität und Spezifität des Tau-Wertes für die sCJK wird mit 9194\% und 88-90\% angegeben (Otto et al. 2002; Coulthart et al. 2011).

Alle untersuchten 29 Patienten des genetischen Kollektivs hatten einen Tau-Wert oberhalb des Cut-off Wertes von 1200pg/ml. In der Literatur finden sich kaum publizierte Daten hinsichtlich der Sensitivität der Tau-Wert Bestimmung im Liquor von gCJKPatienten. Eine jüngere Studie an 46 Patienten mit der E200K-Mutation ergab, dass bei 
$72 \%$ der Patienten ein Tau-Wert über dem festgelegten Cut-off von 1000pg/ml nachgewiesen werden konnte (Meiner et al. 2011). Es wurden jedoch keine Angaben darüber gemacht zu welchem Zeitpunkt der Erkrankung die Liquoruntersuchung durchgeführt worden war.

\subsubsection{Elektroenzephalographie (EEG)}

Im Vergleich aller Zusatzuntersuchungen ergibt sich, dass die diagnostische Sensitivität für PSWC im EEG von CJK-Patienten am geringsten ist. Auch im Patientenkollektiv dieser Arbeit konnten lediglich bei 60\% der E200K-Patienten und 44\% der V210I-Patienten typische Veränderungen in Form von periodischen Sharp-Wave-Komplexen gefunden werden. Im Kontrollkollektiv, bestehend aus Patienten mit einer sporadischen CJK ,wurden nur bei einem guten Drittel (33\%) der Patienten PWSC im EEG diagnostiziert. Zusammengefasst war somit die Sensitivität der EEG-Untersuchung in der vorliegenden Arbeit im gCJK-Kollektiv höher als im sCJK-Kollektiv. Ein möglicher Einflussfaktor ist der Zeitpunkt der Untersuchung. Die Wahrscheinlichkeit CJK-typische PSWC im EEG von Patienten zu dokumentieren, steigt mit zunehmender Krankheitsdauer(Steinhoff et al. 2004; Wieser et al. 2004). In den vorliegenden Kollektiven wurden die sCJK-Patienten zwar im Mittel etwas später untersucht als die gCJK-Patienten, jedoch erfolgte in beiden Kollektiven nur in etwa bei einem Viertel der Patienten die Untersuchung im letzten Drittel der Erkrankung. Da die Sensitivität mit 33\% deutlich unterhalb der in der Literatur berichteten Sensitivität des EEG bei sCJK-Patienten liegt, ist die geringe Fallzahl ein weiterer möglicher Erklärungsfaktor.

Die Datenlage in der Literatur ist uneinheitlich, was unter anderem durch die unterschiedlichen Fallzahlen und unterschiedlichen Zeitpunkte der Untersuchungen erklärt sein könnte. In der größten Studie der EUROCJD-Gruppe mit 175 E200K-Patienten und 69 V210I-Patienten konnten bei etwa 68\% der E200K-Patienten und etwa 78\% der V210I-Patienten typische Veränderungen in Form von PSWC dokumentiert werden. Heinemann et al. fanden PSCW in 73\% der EEG von E200K-Patienten und in 53\% der V210I-Mutation. Die Daten der beiden größten Studien, deren Kollektive sich jedoch teilweise überlappen, ähneln den Ergebnissen unserer Untersuchung, obgleich in unserem Kollektiv V210I-Patienten etwas seltener PWSC im EEG zeigten (Kovács et al. 2005; Heinemann et al. 2007). In der weiteren Literatur finden sich teils widersprüchliche Da- 
ten. In einem japanischen Kollektiv von E200K-Patienten ließen sich bei 92\% typische PSWC nachweisen, während in einem argentinischen Kollektiv nur 46\% und bei israelischen E200K-Patienten nur 38\% ein CJK-typisches EEG aufwiesen (Nozaki et al. 2010; Begué et al. 2011; Appel et al. 2012). Die Ergebnisse weiterer kleinerer Studien zu EEGVeränderungen bei Patienten mit gCJK sind in Abbildung 4.3 aufgeführt.

Abbildung 4.3 Sensitivität der PSWC im EEG von Patienten mit der E200K- und V210I-Mutation der eigenen Daten im Vergleich mit Literaturdaten

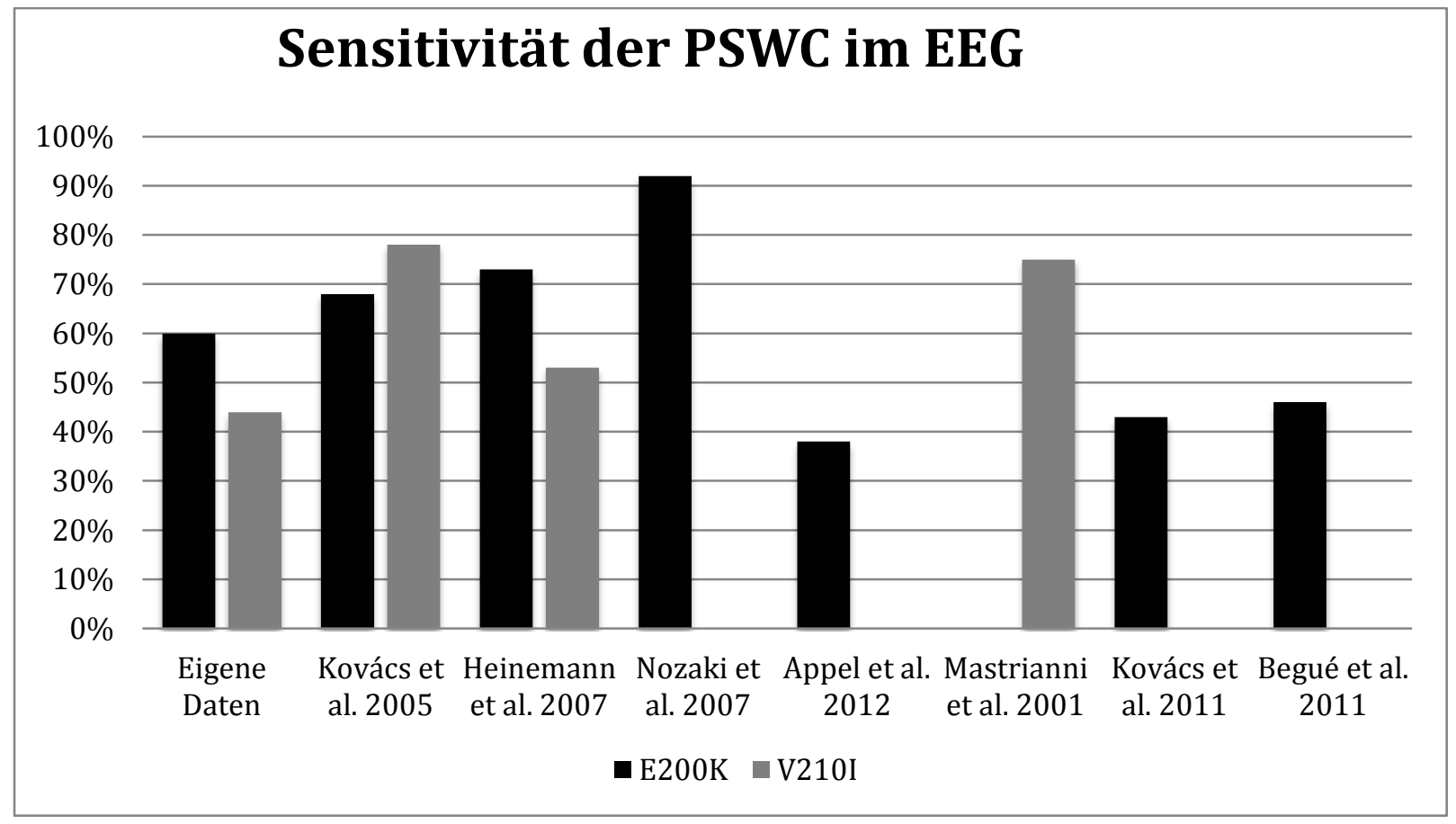

\subsection{Anwendbarkeit der MRT-Kriterien}

Die Definition bestimmter MRT-Kriterien für die sCJK sowie die Berücksichtigung in den klinischen Diagnosekriterien haben zu einer höheren diagnostischen Sicherheit geführt (Zerr et al. 2009). Eine wesentliche Fragestellung dieser Arbeit war, ob sich die MRTKriterien der sCJK auch auf das genetische Kollektiv der E200K- und V210I-Mutation anwenden lassen. 


\subsubsection{Sensitivität}

Es konnte gezeigt werden, dass die Sensitivität mit 76\% im genetischen Kollektiv sogar etwas höher war als im Kontrollkollektiv (72\%). Unterschiede zwischen den zwei Mutationen fanden sich nicht. Die MRT unterstützt somit bei der E200K- und V210I-Mutation genauso gut die Diagnose einer CJK wie bei Fällen ohne Nachweis einer Mutation im PRNP. In der Originalarbeit von Zerr et al. waren die MRT-Aufnahmen von 436 Patienten mit der Verdachtsdiagnose oder einer gesicherten CJK mit denen von 141 Kontrollpatienten zunächst hinsichtlich des Verteilungsmusters hyperintenser Signalalterationen untersucht worden. Nachdem die Kombination von MRT-Veränderungen mit der höchsten Sensitivität und Spezifität identifiziert worden war (Nucleus caudatus und $\mathrm{Pu}$ tamen ODER zwei definierte kortikale Regionen), konnte basierend darauf bei 83\% der Patienten ein CJK-typisches MRT beschrieben werden. Die Sensitivität der MRT liegt sowohl im Patienten- als auch im sCJK-Kontrollkollektiv etwas unter der von Zerr et al. Dies ist möglicherweise zum einen durch die kleinere Fallzahl, zum anderen durch die geringere Anzahl von MRT-Aufnahmen in der DWI erklärt. Insgesamt ist die Sensitivität jedoch immer noch relativ hoch. Da sich die Kollektive nicht von einander unterscheiden, ist eine Differenz in der Sensitivität bei höherer Fallzahl unwahrscheinlich.

Der Polymorphismus am Codon 129 hat ebenso wie bei der SCJK einen Einfluss auf die MRT-Befunde. So erfüllten Patienten mit dem MV-Subtyp häufiger die MRT-Kriterien als Patienten mit dem MM-Subtyp. In der vorangegangenen Arbeit von Zerr et al. hingegen, erfüllten Patienten, die homozygot für Methionin waren, häufiger die MRT-Kriterien (Zerr et al. 2009). Sowohl in der vorliegenden Arbeit, als auch in der veröffentlichten Studie war die Zahl des MV-Subtyps jedoch vergleichsweise gering, so dass dies den Unterschied möglicherweise erklärt. Für die sporadische CJK konnte gezeigt werden, dass die Ergänzung der diagnostischen Kriterien um die MRT-Untersuchung die Diagnose seltener Subtypen wie z.B. des MV2-Subtyps erleichtert (Zerr et al. 2009). Insgesamt konnte die Sensitivität der diagnostischen Kriterien für die sCJK durch Berücksichtigung der MRT auf $98 \%$ verbessert werden.

Auch wenn die MRT-Bildgebung die Sensitivität der klinischen Diagnosekriterien für die E200K- und V210I-Mutation verbessert, so konnten die Ergebnisse dieser Studie zeigen, dass eine Unterscheidung zwischen genetischer CJK und sporadischer CJK anhand der MRT nicht möglich scheint. Eine genetische Testung zur Identifizierung dieser Fälle, insbesondere vor dem Hinblick hygienischer Aspekte, ist daher weiterhin unabdingbar. 


\subsubsection{Spezifität}

Die Spezifität wurde aus 141 Kontrollpatienten, die nicht an einer CJK erkrankt waren, mit 86,5\% berechnet. Eine Reihe anderer neurologischer und internistischer Erkrankungen können Hyperintensitäten in der MRT hervorrufen. So sind auch bei Patienten während oder nach einem Status epilepticus non-convulsivus insbesondere kortikale Signalalterationen zu finden. Weitere Erkrankungen bei denen sich Hyperintensitäten im Bereich der Basalganglien oder des Kortex beobachten lassen sind entzündliche ZNSErkrankungen, zerebrale Lymphome, steroid-responsive Enzephalopathien oder der Thiaminmangel (Zerr et al. 2009; Schmidt et al. 2010). Eine sorgfältige Ausschlussdiagnostik anderer möglicherweise behandelbarer Erkrankungen ist daher unabdingbar. Die weitere Zusatzdiagnostik, wie laborchemische und liquoranalytische Untersuchungen, kann helfen falsch positive, fehlleitende Befunde der MRT zu relativieren. Bei vorliegen falsch positiver Signalalterationen in der MRT und nicht wegweisenden Zusatzuntersuchungen, kann die Diagnose jedoch weiterhin eine große Herausforderung darstellen. Eine molekulargenetische Untersuchung ermöglicht zumindest den Nachweis oder Ausschluss einer genetischen Prionerkrankung. In Anbetracht des autosomal-dominanten Erbgangs und fehlender therapeutischer Möglichkeiten ergeben sich jedoch auch ethische Bedenken. Eine molekulargenetische Untersuchung sollte daher nur nach sorgfältiger Aufklärung des Patienten und dessen Familie erfolgen.

\subsection{Inter-Rater-Bewertung}

Die Beurteilung der MRT-Aufnahmen erfolgte hinsichtlich des Vorliegens hyperintenser Signalalterationen im Vergleich zum normalen, isointensen Hirngewebe. Die Bewertung stellt somit ein semiquantitatives Verfahren dar und obliegt zum großen Teil dem Auge des Betrachters. Beide Neuroradiologen, die im Rahmen dieser Arbeit die Auswertungen der MRT-Aufnahmen vorgenommen haben sind sehr erfahren auf dem Gebiet der CJK. Die Übereinstimmung beider Untersucher in der Beurteilung der MRT-Aufnahmen war sehr gut. In der FLAIR fanden sich gute Übereinstimmungen für den occipitalen Kortex, den Nucleus caudatus, Putamen und Thalamus $(\mathrm{p}<0,001)$. Darüber hinaus zeigten sich gute Übereinstimmungen für den frontalen und temporalen Kortex, den Hippokampus 
und Gyrus cinguli. In der DWI-Wichtung ließen sich ähnliche Ergebnisse nachweisen, die besten Übereinstimmungen fanden sich hier jedoch in der Bewertung des Hippocampus, Nucleus caudatus und Thalamus.

Beide Neuroradiologen werteten in der FLAIR-Wichtung 19 MRT-Aufnahmen als CJKtypisch laut den definierten Kriterien. In der DWI-Wichtung erfüllten laut Rater 1 elf Patienten die MRT-Kriterien, Rater 2 fand typische Veränderungen bei insgesamt zwölf Patienten.

Bereits frühere Arbeiten konnten zeigen, dass generell die Übereinstimmung zwischen verschiedenen beurteilenden Neuroradiologen sehr gut ist. Vitali et al. führten eine Studie an 90 Patienten mit rapid-progressiver Demenz oder einer Prionerkrankung durch. Ziel war es die Sensitivität zur erfassen mit der die DWI eine andere Form von rasch progredienter Demenz (z.B. Demenz vom Alzheimertyp) von einer CJK unterscheiden kann. Zwei verschiedene Neuroradiologen, die beide verblindet gegenüber den klinischen Informationen waren, untersuchten die MRT-Aufnahmen hinsichtlich des Vorliegens hyperintenser Signalalerationen. Die Sensitivität und Spezifität des einen Untersuchers lag bei $94 \%$ und 100\%, die des anderen bei 92\% und 72\%. Nach gemeinsamer Durchsicht der Bilder konnte eine Sensitivität von 96\% und Spezifität von 93\% erreicht werden (Vitali et al. 2011). Eine weitere Studie konnte eine gute Übereinstimmung für die Bewertung von MRT-Aufnahmen des MM1- und MV2-Subtyps dokumentieren (Krasnianski et al. 2008b). 


\section{Zusammenfassung}

Prionerkrankungen gehören zu einer Gruppe neurodegenerativer Erkrankungen, die sporadisch, genetisch oder infektiös bedingt sein können. Allen gemeinsam ist die potentielle Übertragbarkeit des pathologischen Prionproteins ( $\mathrm{PrPsc}^{\mathrm{sc}}$ ). Die Diagnose kann nur durch eine neuropathologische Untersuchung von Hirngewebe gesichert werden. Es existieren jedoch Diagnosekriterien, die anhand der klinischen Symptomatik und verschiedener diagnostischer Tests eine hohe Diagnosesicherheit erlauben. Seit 2009 ist auch die cMRT-Untersuchung als Zusatzdiagnostik Bestandteil der diagnostischen Kriterien der SCJK. Hyperintensitäten in mindestens zwei kortikalen Regionen (temporalparietal-occipital) und/oder im Nucleus caudatus und Putamen, sichtbar in der FLAIR und/oder DWI, werden als CJK-typisch gewertet. Für die genetische CJK, welche etwa 10-15\% aller Prionerkrankungen ausmacht, gelten andere Diagnosekriterien als für die sCJK. Einige Mutationen im PRNP, wie z.B. die E200K- und V210I-Mutation, bewirken einen klinischen Phänotyp, welcher dem der häufigsten Subtypen der sCJK sehr ähnelt. In der vorliegenden Arbeit wurden 35 Patienten mit genetischer CJK hinsichtlich der Veränderungen in der MRT untersucht. Nach Ausschluss jener Patienten, deren MRTBilder eine zu schlechte Qualität aufwiesen, blieben 19 Patienten mit der E200KMutation und 10 Patienten mit der V210I-Mutation eingeschlossen. Dem Patientenkollektiv wurde ein Kontrollkollektiv von $\mathrm{SCJK}$ zugewiesen, welches hinsichtlich wichtiger Einflussfaktoren (PRNP-Genotyp, Zeitpunkt der MRT-Untersuchung, Alter und Geschlecht,) gepaart angepasst war. Die MRT-Aufnahmen wurden von zwei geschulten Neuroradiologen anhand eines standardisierten Protokolls hinsichtlich des Vorliegens von Signalalterationen bewertet. Zum Zeitpunkt der Auswertung waren die Bewerter im Hinblick auf klinische Informationen und das Ergebnis der Genotypisierung verblindet. Die Frequenz und das Verteilungsmuster von Hyperintensitäten in der FLAIR und DWI wiesen keine signifikanten Unterschiede zwischen der Patienten- und Kontrollgruppe auf. Insgesamt konnten Signalalterationen im Bereich des Kortex und der Basalganglien in beiden Kollektiven häufig beobachtet werden. Die für die sCJK definierten MRTKriterien waren auch auf das E200K- und V210I-Kollektiv anwendbar. Die Sensitivität 
der MRT-Kriterien im Patientenkollektiv betrug 76\% gegenüber 72\% im Kontrollkollektiv.

Eine Unterscheidung der E200K- und V210I-Patienten gegenüber Patienten mit sporadischer CJK war nicht möglich. Eine genetische Testung zur Identifizierung genetischer CJK Fälle ist daher unabdingbar. 


\section{Auszüge dieser Arbeit wurden in folgenden Publikationen veröffentlicht:}

Zerr I, Kallenberg K, Summers DM, Romero C, Taratuto A, Heinemann U, Breithaupt M, Varges D, Meissner B, Ladogana A et al. (2009): Updated clinical diagnostic criteria for sporadic Creutzfeldt-Jakob disease. Brain 132, 2659-2668

Breithaupt M, Romero C, Kallenberg K, Begué C, Sanchez-Juan P, Eigenbrod S, Kretzschmar H, Schelzke G, Meichtry E, Taratuto A et al. (2013): Magnetic resonance imaging in E200K and V210I mutations of the prion protein gene. Alzheimer Dis Assoc Disord 27, 87-90 


\section{Literaturverzeichnis}

Alperovitch A, Zerr I, Pocchiari M, Mitrova E, de Pedro Cuesta J, Hegyi I, Collins S, Kretzschmar H, van Duijn C, Will RG (1999): Codon 129 prion protein genotype and sporadic Creutzfeldt-Jakob disease. Lancet 353, 1673-1674

Appel SA, Chapman J, Prohovnik I, Hoffman C, Cohen OS, Blatt I (2012): The EEG in E200K familial CJD: relation to MRI patterns. J Neurol 259, 491-496

Begué C, Martinetto H, Schultz M, Rojas E, Romero C, D'Giano C, Sevlever G, Somoza M, Taratuto AL (2011): Creutzfeldt-Jakob disease surveillance in Argentina, 1997-2008. Neuroepidemiology $\underline{37}, 193-202$

Brandel JP, Heath CA, Head MW, Levavasseur E, Knight R, Laplanche JL, Langeveld JP, Ironside JW, Hauw JJ, Mackenzie J et al. (2009): Variant Creutzfeldt-Jakob disease in France and the United Kingdom: Evidence for the same agent strain. Ann Neurol $\underline{65}$, 249-256

Brown DR, Qin K, Herms JW, Madlung A, Manson J, Strome R, Fraser PE, Kruck T, von Bohlen A, Schulz-Schaeffer W et al. (1997): The cellular prion protein binds copper in vivo. Nature $\underline{390}, 684-687$

Brown P, Preece M, Brandel JP, Sato T, McShane L, Zerr I, Fletcher A, Will RG, Pocchiari M, Cashman NR et al. (2000): Iatrogenic Creutzfeldt-Jakob disease at the millennium. Neurology $\underline{55}$, 1075-1081

Bruce ME, Will RG, Ironside JW, McConnell I, Drummond D, Suttie A, McCardle L, Chree A, Hope J, Birkett C et al. (1997): Transmissions to mice indicate that 'new variant' CJD is caused by the BSE agent. Nature $\underline{389}$, 498-501

Budka H, Aguzzi A, Brown P, Brucher JM, Bugiani O, Gullotta F, Haltia M, Hauw JJ, Ironside JW, Jellinger $\mathrm{K}$ et al. (1995): Neuropathological diagnostic criteria for Creutzfeldt-Jakob disease (CJD) and other human spongiform encephalopathies (prion diseases). Brain Pathol $\underline{5}$, 459-466

Castellani RJ, Colucci M, Xie Z, Zou W, Li C, Parchi P, Capellari S, Pastore M, Rahbar MH, Chen SG et al. (2004): Sensitivity of 14-3-3 protein test varies in subtypes of sporadic Creutzfeldt-Jakob disease. Neurology $\underline{63}, 436-442$

Chapman J, Ben-Israel J, Goldhammer Y, Korczyn AD (1994): The risk of developing Creutzfeldt-Jakob disease in subjects with the PRNP gene codon 200 point mutation. Neurology $\underline{44}$, 1683-1686

Choi BY, Kim SY, Seo SY, An SS, Kim S, Park SE, Lee SH, Choi YJ, Kim SJ, Kim CK, et al. (2009): Mutations at codons 178, 200-129, and 232 contributed to the inherited prion diseases in Korean patients. BMC Infect Dis $\underline{9}, 132$ 
Cohen OS, Chapman J, Lee H, Nitsan Z, Appel S, Hoffman C, Rosenmann H, Korczyn AD, Prohovnik I (2011): Pruritus in familial Creutzfeldt-Jakob disease: a common symptom associated with central nervous system pathology. J Neurol 258, 89-95

Collins SJ, Sanchez-Juan P, Masters CL, Klug GM, van Duijn C, Poleggi A, Pocchiari M, Almonti S, Cuadrado-Corrales N, de Pedro-Cuesta J et al. (2006): Determinants of diagnostic investigation sensitivities across the clinical spectrum of sporadic Creutzfeldt-Jakob disease. Brain $\underline{129}$ 2278-2287

Coulthart MB, Jansen GH, Olsen E, Godal DL, Connolly T, Choi BC, Wang Z, Cashman NR (2011): Diagnostic accuracy of cerebrospinal fluid protein markers for sporadic Creutzfeldt-Jakob disease in Canada: a 6-year prospective study. BMC Neurol $\underline{11}, 133$

Creutzfeldt H (1920): Über eine eigenartige herdförmige Erkrankung des Zentralnervensystems. Z Ges Neurol Psychiatr $\underline{57}$, 1-18

Cuillé J, Chelle P (1939): Experimental transmission of trembling to the goat. CR Seances Acad. Sci. 208, 1058-1060

D'Alessandro M, Petraroli R, Ladogana A, Pocchiari M (1998): High incidence of Creutzfeldt-Jakob disease in rural Calabria, Italy. Lancet $\underline{352}$ 1989-1990

de Pedro-Cuesta J, Glatzel M, Almazan J, Stoeck K, Mellina V, Puopolo M, Pocchiari M, Zerr I, Kretszchmar HA, Brandel JP et al. (2006): Human transmissible spongiform encephalopathies in eleven countries: diagnostic pattern across time, 1993-2002. BMC Public Health $\underline{6} 278$

Duffy P, Wolf J, Collins G, DeVoe AG, Streeten B, Cowen D (1974): Letter: Possible person-to-person transmission of Creutzfeldt-Jakob disease. N Engl J Med 290, 692-693

Farbu E, Tysnes OB, Mork S, Krossnes BK, Bindoff LA (2007): Two Norwegian sisters with late onset Creutzfeldt-Jakob disease caused by the E200K mutation. J Neurol 254 , 262-263

Finkenstaedt M, Szudra A, Zerr I, Poser S, Hise JH, Stoebner JM, Weber T (1996): MR imaging of Creutzfeldt-Jakob disease. Radiology 199, 793-798

Fulbright RK, Kingsley PB, Guo X, Hoffmann C, Kahana E, Chapman JC, Prohovnik I (2006): The imaging appearance of Creutzfeldt-Jakob disease caused by the E200K mutation. Magn Reson Imaging 24, 1121-1129

Fulbright RK, Hoffmann C, Lee H, Pozamantir A, Chapman J, Prohovnik I (2008): MR imaging of familial Creutzfeldt-Jakob disease: a blinded and controlled study. AJNR Am J Neuroradiol 29, 1638-1643

Furukawa H, Kitamoto T, Hashiguchi H, Tateishi J (1996): A Japanese case of CreutzfeldtJakob disease with a point mutation in the prion protein gene at codon 210. J Neurol Sci $\underline{141}, 120-122$ 
Gajdusek DC, Zigas V (1957): Degenerative disease of the central nervous system in New Guinea; the endemic occurrence of kuru in the native population. N Engl J Med 257, 974978

Gajdusek DC, Gibbs CJ, Alpers M (1966): Experimental transmission of a Kuru-like syndrome to chimpanzees. Nature 209, 794-796

Gertz HJ, Henkes H, Cervos-Navarro J (1988): Creutzfeldt-Jakob disease: correlation of MRI and neuropathologic findings. Neurology $\underline{38}, 1481-1482$

Geschwind MD, Potter CA, Sattavat M, Garcia PA, Rosen HJ, Miller BL, DeArmond SJ (2009): Correlating DWI MRI with pathologic and other features of Jakob-Creutzfeldt disease. Alzheimer Dis Assoc Disord 23, 82-87

Ghoshal N, Cali I, Perrin RJ, Josephson SA, Sun N, Gambetti P, Morris JC (2009): Codistribution of amyloid beta plaques and spongiform degeneration in familial Creutzfeldt-Jakob disease with the E200K-129M haplotype. Arch Neurol 66, 1240-1246

Goldfarb LG, Mitrova E, Brown P, Toh BK, Gajdusek DC (1990): Mutation in codon 200 of scrapie amyloid protein gene in two clusters of Creutzfeldt-Jakob disease in Slovakia. Lancet $\underline{36}$, 514-515

Heath CA, Cooper SA, Murray K, Lowman A, Henry C, MacLeod MA, Stewart GE, Zeidler M, MacKenzie JM, Ironside JW et al. (2010): Validation of diagnostic criteria for variant Creutzfeldt-Jakob disease. Ann Neurol $\underline{67}$, 761-770

Heinemann U, Krasnianski A, Meissner B, Varges D, Kallenberg K, Schulz-Schaeffer WJ, Steinhoff BJ, Grasbon-Frodl EM, Kretzschmar HA, Zerr I (2007): Creutzfeldt-Jakob disease in Germany: a prospective 12-year surveillance. Brain 130, 1350-1359

Hewitt PE, Llewelyn CA, Mackenzie J, Will RG (2006): Creutzfeldt-Jakob disease and blood transfusion: results of the UK Transfusion Medicine Epidemiological Review study. Vox Sang 91, 221-230

Hu W, Rosenberg RN, Stuve O (2007): Prion proteins: a biological role beyond prion diseases. Acta Neurol Scand $\underline{116}, 75-82$

Huang N, Marie SK, Kok F, Nitrini R (2001): Familial Creutzfeldt-Jakob disease associated with a point mutation at codon 210 of the prion protein gene. Arq Neuropsiquiatr $\underline{59}, 932-935$

Jakob A (1921): Über eigenartige Erkrankung des Zentralnervensystems mit bemerkenswerten anatomischen Befunden (spastische PseudoskleroseEncephalomyelopathie mit disseminierten Degenerationsherden). Z Ges Neurol Psychiatr 64, 147-228

Kallenberg K, Schulz-Schaeffer WJ, Jastrow U, Poser S, Meissner B, Tschampa HJ, Zerr I, Knauth M (2006): Creutzfeldt-Jakob disease: comparative analysis of MR imaging sequences. AJNR Am J Neuroradiol 27, 1459-1462 
Kovács GG, Puopolo M, Ladogana A, Pocchiari M, Budka H, van Duijn C, Collins SJ, Boyd A, Giulivi A, Coulthart M et al. (2005): Genetic prion disease: the EUROCJD experience. Hum Genet 118, 166-174

Kramer ML, Kratzin HD, Schmidt B, Romer A, Windl O, Liemann S, Hornemann S, Kretzschmar H (2001): Prion protein binds copper within the physiological concentration range. J Biol Chem $\underline{276}, 16711-16719$

Krasnianski A, Meissner B, Schulz-Schaeffer W, Kallenberg K, Bartl M, Heinemann U, Varges D, Kretzschmar HA, Zerr I (2006): Clinical features and diagnosis of the MM2 cortical subtype of sporadic Creutzfeldt-Jakob disease. Arch Neurol 63, 876-880

Krasnianski A, Bartl M, Sanchez Juan PJ, Heinemann U, Meissner B, Varges D, SchulzeSturm U, Kretzschmar HA, Schulz-Schaeffer WJ, Zerr I (2008a): Fatal familial insomnia: Clinical features and early identification. Ann Neurol $\underline{63}, 658-661$

Krasnianski A, Kallenberg K, Collie DA, Meissner B, Schulz-Schaeffer WJ, Heinemann U, Varges D, Summers DM, Kretzschmar HA, Talbot T et al. (2008b): MRI in the classical MM1 and the atypical MV2 subtypes of sporadic CJD: an inter-observer agreement study. Eur J Neurol 15, 762-771

Kretzschmar HA, Feiden W (2002): [Human prion diseases]. Pathologe 23, 241-251

Kretzschmar HA, Ironside JW, DeArmond SJ, Tateishi J (1996): Diagnostic criteria for sporadic Creutzfeldt-Jakob disease. Arch Neurol $\underline{53}$ 913-920

Ladogana A, Puopolo M, Croes EA, Budka H, Jarius C, Collins S, Klug GM, Sutcliffe T, Giulivi A, Alperovitch A et al. (2005): Mortality from Creutzfeldt-Jakob disease and related disorders in Europe, Australia, and Canada. Neurology 64, 1586-1591

Lee H, Rosenmann H, Chapman J, Kingsley PB, Hoffmann C, Cohen OS, Kahana E, Korczyn AD, Prohovnik I (2009): Thalamo-striatal diffusion reductions precede disease onset in prion mutation carriers. Brain $\underline{132}$, 2680-2687

Lee HS, Sambuughin N, Cervenakova L, Chapman J, Pocchiari M, Litvak S, Qi HY, Budka H, del Ser T, Furukawa H et al. (1999): Ancestral origins and worldwide distribution of the PRNP 200K mutation causing familial Creutzfeldt-Jakob disease. Am J Hum Genet $\underline{64}$, 1063-1070

Llewelyn CA, Hewitt PE, Knight RS, Amar K, Cousens S, Mackenzie J, Will RG (2004): Possible transmission of variant Creutzfeldt-Jakob disease by blood transfusion. Lancet $\underline{363}, 417-421$

Mackay GA, Knight RS, Ironside JW (2011): The molecular epidemiology of variant CJD. Int J Mol Epidemiol Genet 2, 217-227

Mancuso M, Siciliano G, Capellari S, Orsucci D, Moretti P, Di Fede G, Suardi S, Strammiello R, Parchi P, Tagliavini F et al. (2009): Creutzfeldt-Jakob disease with E200K PRNP mutation: a case report and revision of the literature. Neurol Sci $\underline{30}$, 417-420 
Manners DN, Parchi P, Tonon C, Capellari S, Strammiello R, Testa C, Tani G, Malucelli E, Spagnolo C, Cortelli P et al. (2009): Pathologic correlates of diffusion MRI changes in Creutzfeldt-Jakob disease. Neurology $\underline{72}$, 1425-1431

Mastrianni JA, Capellari S, Telling GC, Han D, Bosque P, Prusiner SB, DeArmond SJ (2001): Inherited prion disease caused by the V210I mutation: transmission to transgenic mice. Neurology $\underline{57}, 2198-2205$

Masullo C, Bizzarro A, Guglielmi V, Iannaccone E, Minicuci G, Vita MG, Capellari S, Parchi P, Servidei S (2010): An atypical phenotype of CJD associated with the E200K mutation in the prion protein gene. Neurol Sci $\underline{31}, 837-839$

Meiner Z, Gabizon R, Prusiner SB (1997): Familial Creutzfeldt-Jakob disease. Codon 200 prion disease in Libyan Jews. Medicine (Baltimore) 76, 227-237

Meiner Z, Kahana E, Baitcher F, Korczyn AD, Chapman J, Cohen OS, Milo R, Aharon-Perez J, Abramsky O, Gabizon R et al. (2011): Tau and 14-3-3 of genetic and sporadic Creutzfeldt-Jakob disease patients in Israel. J Neurol 258, 255-262

Meissner B, Kortner K, Bartl M, Jastrow U, Mollenhauer B, Schroter A, Finkenstaedt M, Windl O, Poser S, Kretzschmar HA et al. (2004): Sporadic Creutzfeldt-Jakob disease: magnetic resonance imaging and clinical findings. Neurology $\underline{63}, 450-456$

Meissner B, Westner IM, Kallenberg K, Krasnianski A, Bartl M, Varges D, Bosenberg C, Kretzschmar HA, Knauth M, Schulz-Schaeffer WJ et al. (2005): Sporadic CreutzfeldtJakob disease: clinical and diagnostic characteristics of the rare VV1 type. Neurology $\underline{65}$, 1544-1550

Meissner B, Kallenberg K, Sanchez-Juan P, Krasnianski A, Heinemann U, Varges D, Knauth M, Zerr I (2008): Isolated cortical signal increase on MR imaging as a frequent lesion pattern in sporadic Creutzfeldt-Jakob disease. AJNR Am J Neuroradiol 29, 15191524

Meissner B, Kallenberg K, Sanchez-Juan P, Collie D, Summers DM, Almonti S, Collins SJ, Smith P, Cras P, Jansen GH et al. (2009): MRI lesion profiles in sporadic CreutzfeldtJakob disease. Neurology $\underline{72}$, 1994-2001

Milton WJ, Atlas SW, Lavi E, Mollman JE (1991): Magnetic resonance imaging of Creutzfeldt-Jacob disease. Ann Neurol 29, 438-440

Mitrova E, Belay G (2002): Creutzfeldt-Jakob disease with E200K mutation in Slovakia: characterization and development. Acta Virol $\underline{46}$, 31-39

Mouillet-Richard S, Schneider B, Pradines E, Pietri M, Ermonval M, Grassi J, Richards JG, Mutel V, Launay JM, Kellermann O (2007): Cellular prion protein signaling in serotonergic neuronal cells. Ann N Y Acad Sci 1096, 106-119

Murata T, Shiga Y, Higano S, Takahashi S, Mugikura S (2002): Conspicuity and evolution of lesions in Creutzfeldt-Jakob disease at diffusion-weighted imaging. AJNR Am J Neuroradiol 23, 1164-1172 
Nitrini R, Mendonca RA, Huang N, LeBlanc A, Livramento JA, Marie SK (2001): Diffusionweighted MRI in two cases of familial Creutzfeldt--Jakob disease. J Neurol Sci 184, 163167

Nozaki I, Hamaguchi T, Sanjo N, Noguchi-Shinohara M, Sakai K, Nakamura Y, Sato T, Kitamoto T, Mizusawa H, Moriwaka F et al. (2010): Prospective 10-year surveillance of human prion diseases in Japan. Brain $\underline{133}$, 3043-3057

Otto M, Wiltfang J, Tumani H, Zerr I, Lantsch M, Kornhuber J, Weber T, Kretzschmar HA, Poser S (1997): Elevated levels of tau-protein in cerebrospinal fluid of patients with Creutzfeldt-Jakob disease. Neurosci Lett 225, 210-212

Otto M, Wiltfang J, Cepek L, Neumann M, Mollenhauer B, Steinacker P, Ciesielczyk B, Schulz-Schaeffer W, Kretzschmar HA, Poser S (2002): Tau protein and 14-3-3 protein in the differential diagnosis of Creutzfeldt-Jakob disease. Neurology $\underline{58}, 192-197$

Palmer MS, Collinge J (1993): Mutations and polymorphisms in the prion protein gene. Hum Mutat $\underline{2}, 168-173$

Pan KM, Baldwin M, Nguyen J, Gasset M, Serban A, Groth D, Mehlhorn I, Huang Z, Fletterick RJ, Cohen FE et al. (1993): Conversion of alpha-helices into beta-sheets features in the formation of the scrapie prion proteins. Proc Natl Acad Sci U S A 90, 10962-10966

Parchi P, Castellani R, Capellari S, Ghetti B, Young K, Chen SG, Farlow M, Dickson DW, Sima AA, Trojanowski JQ et al. (1996): Molecular basis of phenotypic variability in sporadic Creutzfeldt-Jakob disease. Ann Neurol $\underline{39}$ 767-778

Parchi P, Capellari S, Chen SG, Petersen RB, Gambetti P, Kopp N, Brown P, Kitamoto T, Tateishi J, Giese A et al. (1997): Typing prion isoforms. Nature $\underline{386}$, 232-234

Parchi P, Capellari S, Chin S, Schwarz HB, Schecter NP, Butts JD, Hudkins P, Burns DK, Powers JM, Gambetti P (1999a): A subtype of sporadic prion disease mimicking fatal familial insomnia. Neurology $\underline{52}, 1757-1763$

Parchi P, Giese A, Capellari S, Brown P, Schulz-Schaeffer W, Windl O, Zerr I, Budka H, Kopp N, Piccardo P et al. (1999b): Classification of sporadic Creutzfeldt-Jakob disease based on molecular and phenotypic analysis of 300 subjects. Ann Neurol 46, 224-233

Prusiner SB (1982): Novel proteinaceous infectious particles cause scrapie. Science $\underline{216}$, 136-144

Prusiner SB (2001): Shattuck lecture--neurodegenerative diseases and prions. N Engl J Med $\underline{344}, 1516-1526$

Puoti G, Bizzi A, Forloni G, Safar JG, Tagliavini F, Gambetti P (2012): Sporadic human prion diseases: molecular insights and diagnosis. Lancet Neurol 11, 618-628 
Rene R, Campdelacreu J, Ferrer I, Escrig A, Povedano M, Gascon-Bayarri J, Moral E (2007): Familial Creutzfeldt-Jakob disease with E200K mutation presenting with neurosensorial hypoacusis. J Neurol Neurosurg Psychiatry 78, 103-104

Rother J, Schwartz A, Harle M, Wentz KU, Berlit P, Hennerici M (1992): Magnetic resonance imaging follow-up in Creutzfeldt-Jakob disease. J Neurol 239, 404-406

Russmann H, Vingerhoets F, Miklossy J, Maeder P, Glatzel M, Aguzzi A, Bogousslavsky J (2005): Sporadic Creutzfeldt-Jakob disease: a comparison of pathological findings and diffusion weighted imaging. J Neurol 252, 338-342

Schelzke G, Kretzschmar HA, Zerr I (2012): Clinical aspects of common genetic Creutzfeldt-Jakob disease. Eur J Epidemiol 27, 147-149

Schmidt C, Plickert S, Summers D, Zerr I (2010): Pulvinar sign in Wernicke's encephalopathy. CNS Spectr $\underline{15}$, 215-218

Schroter A, Zerr I, Henkel K, Tschampa HJ, Finkenstaedt M, Poser S (2000): Magnetic resonance imaging in the clinical diagnosis of Creutzfeldt-Jakob disease. Arch Neurol $\underline{57}$ $1751-1757$

Seror I, Lee H, Cohen OS, Hoffmann C, Prohovnik I (2010): Putaminal volume and diffusion in early familial Creutzfeldt-Jakob disease. J Neurol Sci $\underline{288}, 129-134$

Shiga Y, Miyazawa K, Sato S, Fukushima R, Shibuya S, Sato Y, Konno H, Doh-ura K, Mugikura S, Tamura H et al. (2004): Diffusion-weighted MRI abnormalities as an early diagnostic marker for Creutzfeldt-Jakob disease. Neurology $\underline{63}$, 443-449

Shyu WC, Hsu YD, Kao MC, Tsao WL (1996): Panencephalitic Creutzfeldt-Jakob disease in a Chinese family. Unusual presentation with PrP codon 210 mutation and identification by PCR-SSCP. J Neurol Sci $\underline{143}$, 176-180

Steinhoff BJ, Zerr I, Glatting M, Schulz-Schaeffer W, Poser S, Kretzschmar HA (2004): Diagnostic value of periodic complexes in Creutzfeldt-Jakob disease. Ann Neurol $\underline{56}$, 702-708

Steinhoff BJ, Racker S, Herrendorf G, Poser S, Grosche S, Zerr I, Kretzschmar H, Weber T (1996): Accuracy and reliability of periodic sharp wave complexes in Creutzfeldt-Jakob disease. Arch Neurol 53, 162-166

Tschampa HJ, Kallenberg K, Urbach H, Meissner B, Nicolay C, Kretzschmar HA, Knauth M, Zerr I (2005): MRI in the diagnosis of sporadic Creutzfeldt-Jakob disease: a study on inter-observer agreement. Brain 128, 2026-2033

Tsuboi Y, Baba Y, Doh-ura K, Imamura A, Fujioka S, Yamada T (2005): Diffusionweighted MRI in familial Creutzfeldt-Jakob disease with the codon 200 mutation in the prion protein gene. J Neurol Sci 232, 45-49 
Vitali P, Maccagnano E, Caverzasi E, Henry RG, Haman A, Torres-Chae C, Johnson DY, Miller BL, Geschwind MD (2011): Diffusion-weighted MRI hyperintensity patterns differentiate CJD from other rapid dementias. Neurology $\underline{76}$, 1711-1719

WHO $=$ World Health Organisation (1998): Human transmissible spongiform encephalopathies. Wkly Epidemiol Rec 47, 361-365

Wieser HG, Schwarz U, Blattler T, Bernoulli C, Sitzler M, Stoeck K, Glatzel M (2004): Serial EEG findings in sporadic and iatrogenic Creutzfeldt-Jakob disease. Clin Neurophysiol 115, 2467-2478

Will RG (2003): Acquired prion disease: iatrogenic CJD, variant CJD, kuru. Br Med Bull 66, 255-265

Will RG, Ironside JW, Zeidler M, Cousens SN, Estibeiro K, Alperovitch A, Poser S, Pocchiari M, Hofman A, Smith PG (1996): A new variant of Creutzfeldt-Jakob disease in the UK. Lancet 347, 921-925

Windl O, Giese A, Schulz-Schaeffer W, Zerr I, Skworc K, Arendt S, Oberdieck C, Bodemer M, Poser S, Kretzschmar HA (1999): Molecular genetics of human prion diseases in Germany. Hum Genet 105, 244-252

Young GS, Geschwind MD, Fischbein NJ, Martindale JL, Henry RG, Liu S, Lu Y, Wong S, Liu $\mathrm{H}$, Miller BL et al. (2005): Diffusion-weighted and fluid-attenuated inversion recovery imaging in Creutzfeldt-Jakob disease: high sensitivity and specificity for diagnosis. AJNR Am J Neuroradiol 26, 1551-1562

Zanusso G, Fiorini M, Ferrari S, Gajofatto A, Cagnin A, Galassi A, Richelli S, Monaco S (2011): Cerebrospinal fluid markers in sporadic creutzfeldt-jakob disease. Int J Mol Sci $12,6281-6292$

Zerr I, Pocchiari M, Collins S, Brandel JP, de Pedro Cuesta J, Knight RS, Bernheimer H, Cardone F, Delasnerie-Laupretre N, Cuadrado Corrales N et al. (2000): Analysis of EEG and CSF 14-3-3 proteins as aids to the diagnosis of Creutzfeldt-Jakob disease. Neurology $\underline{55}, 811-815$

Zerr I, Kallenberg K, Summers DM, Romero C, Taratuto A, Heinemann U, Breithaupt M, Varges D, Meissner B, Ladogana A et al. (2009): Updated clinical diagnostic criteria for sporadic Creutzfeldt-Jakob disease. Brain 132, 2659-2668 


\section{Danksagung}

Ich danke allen voran meiner Doktormutter und der Leiterin des Nationalen Referenzzentrums für Prionerkrankungen Frau Prof. Dr. med. Inga Zerr für die Vergabe des Themas, die Anregungen, die Unterstützung und enge Zusammenarbeit bei der Erstellung meiner Doktorarbeit.

Mein besonderer Dank gilt außerdem den Neuroradiologen Kai Kallenberg und Carlos Romero für die hervorragende Unterstützung und fachmännische Beurteilung der neuroradiologischen Bilder sowie den Mitgliedern des Nationalen Referenzzentrums für Prionerkrankungen in Argentinien für die Bereitstellung der notwendigen Daten.

Darüber hinaus bedanke ich mich bei allen Kollegen und Mitgliedern der Prionforschungsgruppe für und ihre Hilfsbereitschaft und die anregende Atmosphäre in der Arbeitsgruppe. 


\section{Lebenslauf}

Ich wurde am 7. Mai 1982 als erstes Kind von Martin Breithaupt und Barbara Breithaupt in Kappeln geboren. Ich besuchte die Grundschule in Süderbrarup und anschließend das Klaus-Harms Gymnasium in Kappeln. 1998 zog meine Familie aus beruflichen Gründen nach Virginia Beach in die USA. Dort besuchte ich die Frank W. Cox High School und beendete 2000 die Schule mit der Allgemeinen Hochschulreife.

Noch im selben Jahr kehrte ich nach Deutschland zurück und begann im Oktober 2000 zunächst ein Vorsemester Medizin am Rheinischen Bildungszentrum in Köln. Zum Sommersemester 2001 immatrikulierte ich mich dann an der Georg-August Universität in Göttingen für den Studiengang Humanmedizin.

Die ärztliche Vorprüfung legte ich im März 2003 in Göttingen ab und absolvierte dann den weiteren klinischen Studienabschnitt in Göttingen. Im August 2006 begann ich das Praktische Jahr in der Abteilung Neurologie im Universitätsklinikum Göttingen. Anschließend absolvierte ich den chirurgischen Teil des Praktischen Jahres im Hospital Civil Viejo in Guadalajara, Mexiko. Für den internistischen und letzten Teil meines Praktischen Jahres kehrte ich dann an die Universitätsklinik Göttingen zurück.

Im Dezember 2007 absolvierte ich erfolgreich den Zweiten Abschnitt der Ärztlichen Prüfung. Seit April 2008 bin ich als Assistenzärztin in der Abteilung Neurologie der Universitätsmedizin Göttingen beschäftigt. 